\title{
Il periodo sismico della Sicilia occidentale iniziato il 14 Gennaio 1968
}

\author{
On the seismic phenomena which started in West Sicily \\ on January 14th 1968
}

M. De Panfilis - L. Marcelli

Ricevuto il 15 Giugno 1968

Riassunto. - Viene esposta dapprima una breve relazione sull attività svolta dall'Istituto Nazionale di Geofisica in occasione dei terremoti che hamno violentemente colpito numerosi paesi della Sicilia occidentale, a partire dal 14 gennaio 1968: l'Osservatorio sismico di Roma ha seguito con continuità l'intero sviluppo della lunga arisi sismica, documentando il fenomeno con rilevamenti strumentali e di calcolo. Qualche giorno dopo l'inizio, l'I.N.G. ha provveduto alla installazione di tre stazioni sismiche intomo alla zona epicentrale (riattando la stazione di Palermo dissestata dalle prime violente scosse e impiantandone altre due, una a Trapani, l'altra ad Agrigento) onde poter seguire l'andamento del periodo sismico anche nelle sue minime manifestazioni.

Vengono esposti i risultati delle osservazioni eseguite per i terremoti più forti (rilevamento dei tempi di registrazione, magnitudo e intensità all'epicentro) e viene presentato un grafico indicativo della frequenza con la quale si sono manifestati i sismi, giorno per giomo, fino al 10 giugno 1968.

Nella fig. 5 sono state disegnate le posizioni di alcuni epicentri calcolati dall'Istituto Nazionale di Geofisica (I.N.G.), dal Bureau Central International de Séismologie (B.C.I.S.) e dal United States Coast and Geodetic Survey (U.S.C.G.S.). I a carta degli epicentri è confrontabile con la carta geologica della zona.

Un notevole rilievo viene dato. all'aspetto macrosismico del fenomeno. Dopo una sintetica rassegna degli effetti più importanti dovuti alle scosse più forti (rassegna resa difficoltosissima dall'incalyare pauroso degli eventi), vengono esposti i risultati ottenuti da studi e calcoli effettuati sulla base dei danni accertati ufficialmente dai competenti Uffici del Genio Civile.

Nella impossibilità di costruire la rete delle "isosiste", è stata disegnata la carta delle "isoblabe" (fig. 6) che riassume gli effetti globali 
dell'intero periodo. Segue una accurata e dettagliata analisi dei risultati conseguiti.

In una terza parte vengono ampiamente riassunti i precedenti sismici delle località colpite, con particolare riferimento alla Vallata del Belice ed al Palermitano.

Summar. - The memoir begins with a brief report on the activity carried out by the Istituto Nazionale di Ceofisica on the occasion of the earthquakes, which violently hit mumerous villages in West Sicily as from January 14th 1968: the full development of the seismologieal crisis was unceasingly followed by the seismological Observatory in Rome, which documented the phenomenon with instrumental surveys and calculations. A few days after the first shocks, the I.X.f. provided for the installation of three seismological stations around the meizoseismal area (the station in Palermo which had been damaged by the first violent shocks was rearranged and two more were installed, one at Trapani and the other at $A$ grigento) for the purpose of following the course of the long series of aftershocks even in their slightest manifestations.

The menoir contains the results of observations carried out in respect of the more severe shocks (survey of registration times, magnitude and epicentral intensity) and grives a graph indicating the recurring frequency of the earthquakes, day by day, up to June loth 1968.

Figure 5) shows the position of some epicentres calculated by the Istituto Nazionale di Geofisica (I.N.G.), the Bureau Central International de Seismologie (B.C.I.S.) and by the Cnited States Coast and Geodetic Survey (I.S.C.G.S.). The epicentre map may be compared with the tectonic map) of the area.

The macroseismic feature of the phenomenon is duly emphasised. After a concise survey of the most important effects caused by the shocks of greatest intensity (a survey rendered most difficult by the frightening rapid succession of events) the memoir sets forth the results obtained by means of studies and calculations based on the damages officially ascertained by the (ienio (ivile Offices.

As it was impossible to draw a chart of isoseismical lines, a chart of lines of even damage (isoblabe) has been drawn (Fig. 6) and it summarizes the global effects of the whole series of shocks with respect to buildings. It is followed by an accurate and detailed analysis of results achieved.

Finally the seismic precedents of the localities affected are resumed, with particular reference to the Belice Valley and Palermo area. 


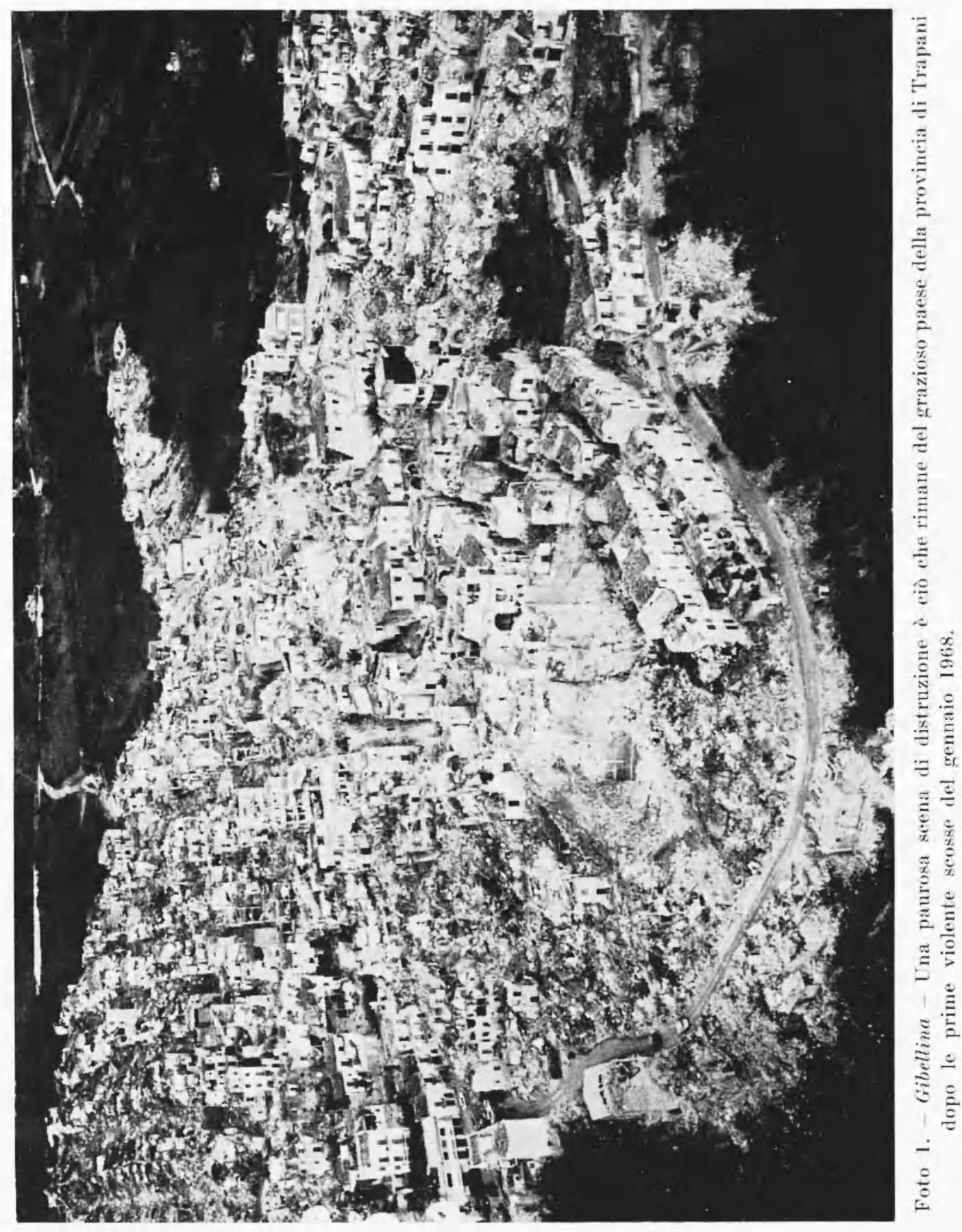


INTRODUZIONE.

Quid enim cuiquam satis tutum vi-
deri potest, si mundus ipse concuti.
tur et partes eius solidissimae labant? L. Anvaeus Seneca

Domenica 14 Gennaio 1968: una domenica, fino al primo pomeriggio, trascorsa in Sicilia come tante altre, anzi animata, in alcuni paesi, da una vivace ed insolita attività. Nel "Giornale di Sicilia " di quel 14 Gennaio poteva leggersi infatti questa notizia: " 85 mila Siciliani oggi alle urne ". "Nuovo turno elettorale in Sicilia dopo quello del 10 Dicembre che vide impegnati 15 comuni. Ia nuova tornata interessa 19 comuni di 7 province. Le operazioni di voto hanno inizio alle ore 8 e si protrarranno fino alle 22. Riprenderanno lunedi mattina per concludersi alle 14 ". Poi, di seguito, l'elenco dei centri dove in quella giornata e nella successiva si sarebbero svolte le votazioni per il rinnovo delle Amministrazioni comunali. Fra essi, Gibellina, un paese della provincia di Trapani, con circa 6400 abitanti, adagiato, ad una quota di 400 metri, sopra una collina digradante verso la vallata del Fiume Belice.

Ton erano passate molte ore dall'inizio della consultazione elettorale, quando una serie di violentissime scosse telluriche si abbatteva sul popoloso centro portando la distruzione e la morte là dove fino a poco prima ferveva una vita serena ed operosa.

Altri paesi della Valle del Belice venivano tragicamente colpiti e travolti nella catastrofe sismica:

Salaparuta, in provincia di Trapani, paese di origine araba, a 340 metri sul mare, con circa 2900 abitanti, distante un paio di chilometri da Gibellina;

Poggioreale, pure in provincia di Trapani, paese con una popolazione di circa 2700 abitanti, situato a 406 metri sul mare sopra il versante meridionale del Monte Castellazzo;

Montevago, paese della provincia di Agrigento, con una popolazione di 3000 abitanti, costruito a quota 360 metri sopra un vasto altipiano dominante la Valle del Belice.

La prima scossa di terremoto, poi la seconda, poi la terza, la quarta, la quinta e via di seguito hanno cancellato in quei paesi ogni caratteristica ed ogni singolarità, uguagliandoli tutti in un unico agghiac- 
ciante aspetto di desolazione totale: spenta la vita e gli abitati trasformati in enormi distese di macerie.

\section{1. - Generalitì e considerazioni varie.}

Fin dal primo insorgere della violenta crisi sismica che, a partire dal 14 Gennaio 1968, ha sconvolto molte località della Sicilia Occidentale, l'Istituto Nazionale di Geofisica, mediante la stazione sismica di Roma, ha potuto seguire con continuità l'evolversi del fenomeno.

La distanza di detta stazione dalla zona epicentrale (circa $450 \mathrm{~km}$ ) ha reso possibile una ininterrotta documentazione dei terribili eventi che si sono susseguiti con tragica impressionante rapidità. Non troppo vicina all'epicentro (il che avrebbe compromesso la regolarità delle registrazioni come è accaduto per alcune stazioni più prossime), né troppo lontana (il che ha dato la possibilità di registrare tutte le scosse superiori al IV grado della scala Mercalli), essa è stata continuamente in grado di rilevare - e comunicare ufficialmente - dati precisi sul numero delle scosse, le ore in cui avvenivano, la loro magnitudo e di conseguenza la loro intensità all'epicentro, ristabilendo cosi un certo ordine ed un certo ridimensionamento delle notizie che pervenivano dalle zone disastrate, accavallandosi confuse e caotiche, alterate sovente da una comprensibile dilagante psicosi collettiva.

Presi immediati contatti con le stazioni periferiche della rete italiana, sono stati organizzati scambi continui di dati in modo da tener meglio sotto controllo lo sviluppo dei fenomeni sismici.

I'ininterrotto susseguirsi delle convulsioni telluriche che, sia pure in proporzioni molto più modeste sono continuate per mesi (e che anche al momento in cui scriviamo non possono dirsi estinte del tutto) ha impedito sulle prime di concentrare l'attenzione scientifica sul fenomeno cosi da poterne trarre tutti quegli elementi essenziali (quali ad esempio le coordinate ipocentrali e la natura della scossa all'origine) che sono frutto di lunghi e laboriosi studi.

Nonostante questa impossibilità materiale, è risultato tuttavia evidente, dopo i primi scambi di notizie con altri Osservatorî, che le scosse non provenivano tutte da un unico fuoco ipocentrale, ma da più focolari che entravano via via in azione, investendo, nel loro complesso, una vasta area epicentrale. Questa prima supposizione risultò poi infatti confermata dai dati forniti dai Centri internazionali di elaborazione. Circa la profondità ipocentrale, elemento importantissimo 


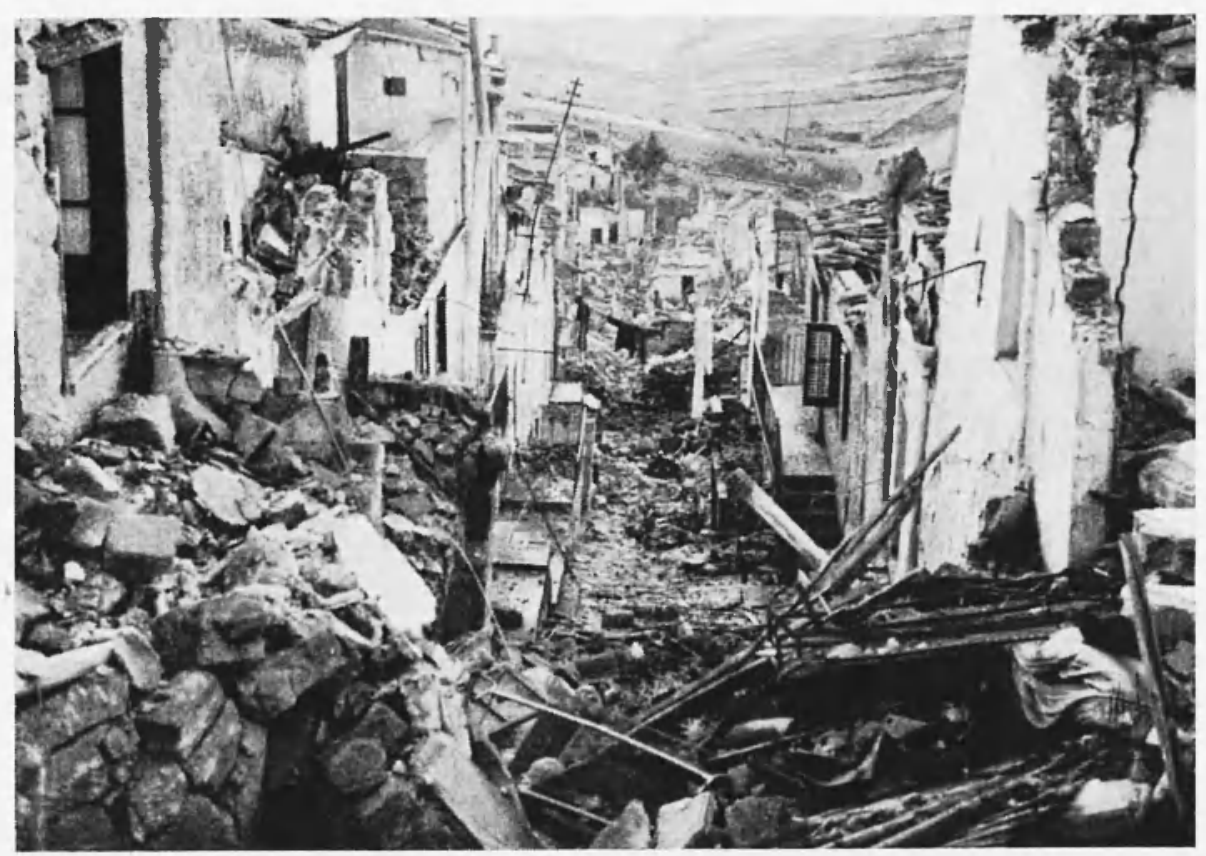

Foto 2. - Gibellina - Una strada del paese dopo il terremoto.

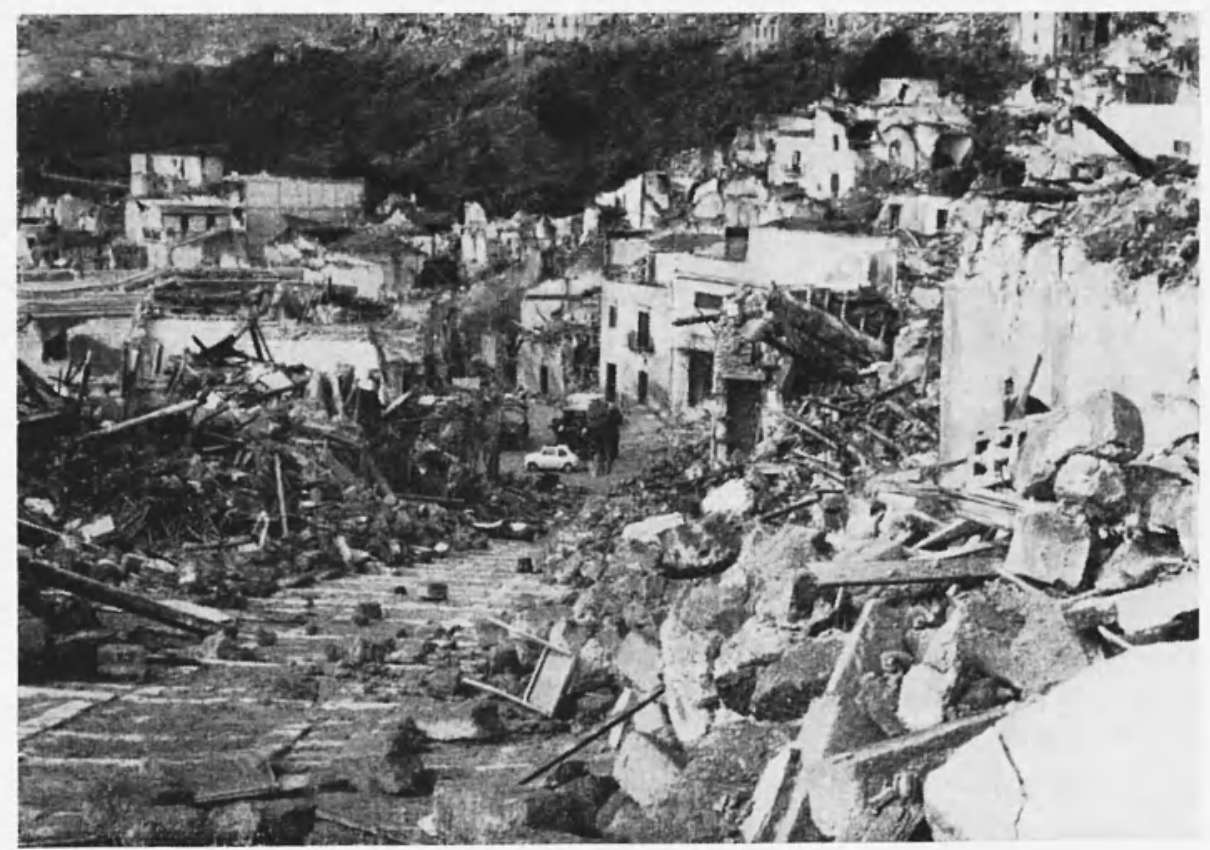

Foto 3. - Un'altra strada di Gibellina dopo il terremoto. 
che tuttavia scaturisce anch'esso da studi complessi e prolungati, si è supposto fin dall'inizio che si trattasse di un fenomeno piuttosto superficiale, contenuto entro i limiti dello spessore della crosta terrestre, per quanto la Sicilia, nella parte che si estende ad oriente della zona attualmente interessata, sia stata teatro, per l'addietro, di fenomeni sismici piuttosto profondi. Anche questa ipotesi è stata suffragata dalle notizie elaborate dai Centri internazionali che danno, per le profondità, valori oscillanti fra i 2 e i $33 \mathrm{~km}$.

Però se in linea di massima concordiamo nell'ammettere la "piccola profondità", siamo tuttavia dell'idea che l'indagine meriti di essere approfondita e perfezionata.

Un esame accurato di tutti i sismogrammi che sono stati immediatamente richiesti a molti Osservatori renderà possibile la elaborazione analitica dei dati sperimentali. Solo allora saremo in grado di conoscere con sufficiente attendibilità gli elementi base del fenomeno sismico.

E ovvio che un tale studio, condotto su basi scientifiche, richiederà un lungo periodo di tempo e, se si vorranno cogliere tutti gli aspetti geofisici del fenomeno, impegnerà un gran numero di ricercatori in tutti i settori della geofisica.

\section{2. - INSTALLAZIONI STRUMENTALI LOCALI.}

Prima delle tragiche giomate del Gennaio 1968 l'Istituto Nazionale di Geofisica disponeva in Sicilia di due stazioni sismiche che, come tante altre installate in varie parti del territorio nazionale, servono ad apportare il loro contributo al normale rilevamento dell'attività sismica. Le due stazioni siciliane, l'una a Palermo, l'altra a Messina, erano dotate di sismografi tipo Wiechert, particolarmente adatti per gli studi sulla sismicità regionale. Per la violenza delle prime scosse, gli strumenti della stazione di Palermo (distante dagli epicentri circa $50 \mathrm{~km}$ ) sono stati posti fuori funzionamento e per qualche giorno (purtroppo proprio durante le giornate più convulse) non hanno più potuto registrare. Questo inconveniente tuttavia non ha tolto quasi nulla alla documentaeione del fenomeno perché tante altre stazioni meno vicine - prima fra tutte quella dell'Università di Messina dotata di ottima strumentazione - hamo seguito l'andamento senza troppi disturbi. 
Naturalmente l'I.N.G. ha provveduto nel più breve tempo possibile alla rimessa a punto dei sismografi di Palermo e, immediatamente dopo, ha installato altre due stazioni, una a Trapani e l'altra ad Agrigento, trasferendovi, data l'emergenza del momento, le attrezzature di Rocca di Papa (Roma) e di Messina I.N.G.

Ise tre stazioni di Palermo, Trapani e Agrigento, cosi attrezzate, costituiscono ancora una interessante e indispensabile rete di rilevamento atta a sorvegliare l'evoluzione del fenomeno sismico nella fase successiva a quella parossistica.

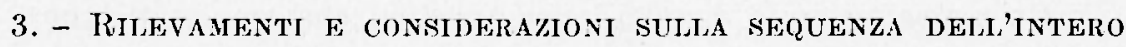 PERIODO SISMICO: HREQUEX\%, MAGXITLDO, INTENSITA.}

L'attuale periodo sismico si è aperto il 14 Gennaio 1968 con la prima scossa delle $13^{\mathrm{n}} 29^{\mathrm{m}}$ (tempo italiano), per la quale l'Osservatorio sismico di Roma ha calcolato una magnitudo 4,7 pari ad una intensità epicentrale compresa tra i gradi VI $1 / 2$ e VI $3 / 4$ della Scala Mercalli.

A questo primo terremoto ha fatto seguito, con impressionante frequenza, una serie di numerosissime altre scosse.

Della maggior parte dei terremoti registrati sono state calcolate le magnitudo (e da esse dedotte le intensità all'epicentro).

Un lungo elenco è stato compilato in base ai dati rilevati presso le stazioni sismiche di Roma, Messina, Palermo, Trapani e Agrigento. Fino al 25 Gennaio si sono potuti utilizzare solo i sismogrammi di Roma e Messina; dopo tale data la documentazione si è arricchita di tutti i dati minori forniti dalla rete sismica locale.

Le scosse più violente si addensano, anche per la frequenza, intorno alle prime 52 ore raggiungendo la punta massima della intensità con il sisma delle $03^{\text {h }} 02^{m}$ della notte del 15 Gennaio, di magnitudo 6, pari al grado IX della scala Mercalli nella zona epicentrale.

Dopo l'altro massimo del giorno 16 Gennaio (ore $17^{\mathrm{h}} 43^{\mathrm{m}}$ ), di grado VIII $3 / 4$ Mercalli, le scosse vanno diminuendo di intensità e di numero, ma improvvisamente il giorno 25 , alle $10^{\mathrm{h}} 58^{\mathrm{m}}$, a dieci giorni di distanza dai movimenti più intensi, una nuova violenta scossa di magnitudo 5,70 (corrispondente all'VIII 1/2 Mercalli) semina nuovi lutti e nuove rovine.

Il grafico della Fig. 1 illustra chiaramente l'andamento delle frequenze: è stato disegnato tenendo presente soltanto il numero delle 
Tabella 1 - Frequenza delle scosse dal giorno d'inizio del periodo sismico (14 Gennaio 1968)

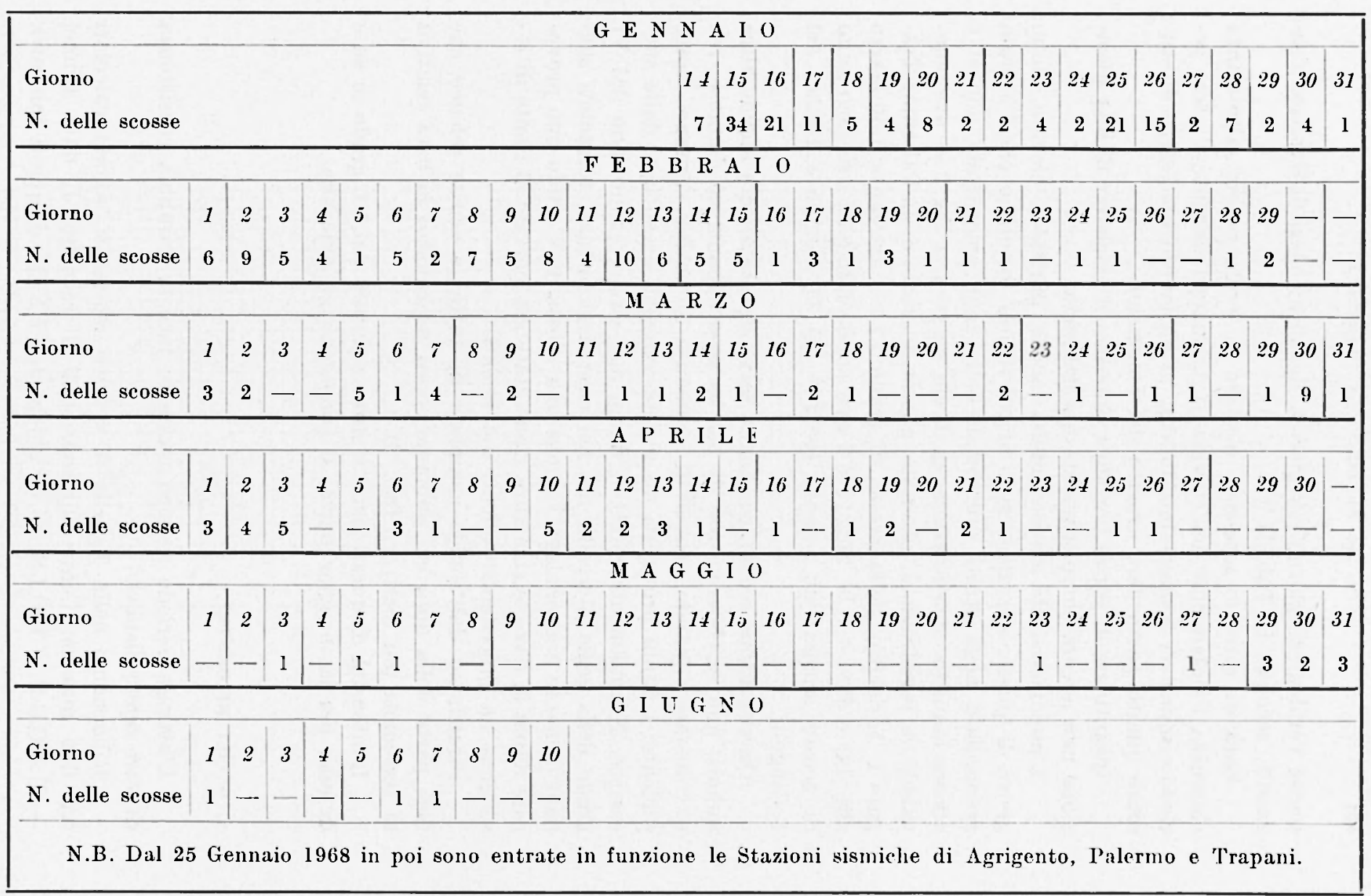


scosse verificatesi, giomo per giomo, durante i mesi di Gennaio e seguenti, secondo la Tabella 1.

Sarà di estremo interesse mettere in evidenza con altrettanta chiarezza l'andamento dell'energia sprigionatasi durante l'intero periodo sismico: (i proponiamo, infatti, in un lavoro successivo di studiare questo particolare aspetto del fenomeno.

Intanto già di per sé il grafico dimostra il persistere di una situazione non ancora completamente normalizzata.

L'impenuarsi di alcune punte, anche piuttosto elevate, dopo giorni di quiete, e il ripetersi di questi ritorni denotano che l'energia accumulata negli strati subcrostali della zona epicentrale non si è ancora esaurita. $\Lambda$ testimonianza di ciò valgano la Fig. 2 - ove compaiono le registrazioni, ottenute presso le stazioni di Palermo, Trapani e Agrigento, della scossa di grado VI $1 / 2$ avvenuta il 30 Marzo alle $14^{\mathrm{h}}$ e $38^{\mathrm{m}}$ - e le Figg. 3 e $f$ ove sono riprodotti i sismogrammi di scosse ancora più recenti $\left(00^{\mathrm{h}} 20^{\mathrm{m}}\right.$ del 31 Maggio e $16^{\mathrm{h}} 29^{\mathrm{m}}$ del 1 Giugno).

Queste ultime scosse, eui hanno fatto seguito ancora alcune altre minori, non sarebbero state di per sè preoccupanti né dannose, ma ovviamente, quando scosse di moderata intensità seguono scosse violente, i danni provocati da queste vengono accentuati dalle successive. Normalmente infatti i danni agli edifici cominciano dal VI grado della scala Mercalli, ma nel caso degli attuali terremoti siciliani (come in casi analoghi) anche una scossa di $\mathrm{V}$ grado può provocare danni là dove le strutture siano state già portate al limite di resistenza da precedenti violenti movimenti.

Stralciamo dall'elenco completo di tutte le scosse (elenco che far̀̀ parte della nota cui abbiamo sopra accennato) la lista relativa ai terremoti più forti (v. Tab. 2).

L'intensità di questi sismi è stata valutata dal VI grado in su e di essi, per la maggior parte, si conoscono gli epicentri.

\section{4. - Gil epicen'tri.}

L'attuale periodo sismico mette in luce la indubbia coesistenza di vari centri sismici.

Riportiamo nella Tabella 3 ventitrè epicentri, alcuni calcolati dai due massimi Centri internazionali di raccolta di dati sismici - U.S.C.G.S. e B.C.I.S. - ed alcuni dall'I.N.G.: di questi epicentri, 


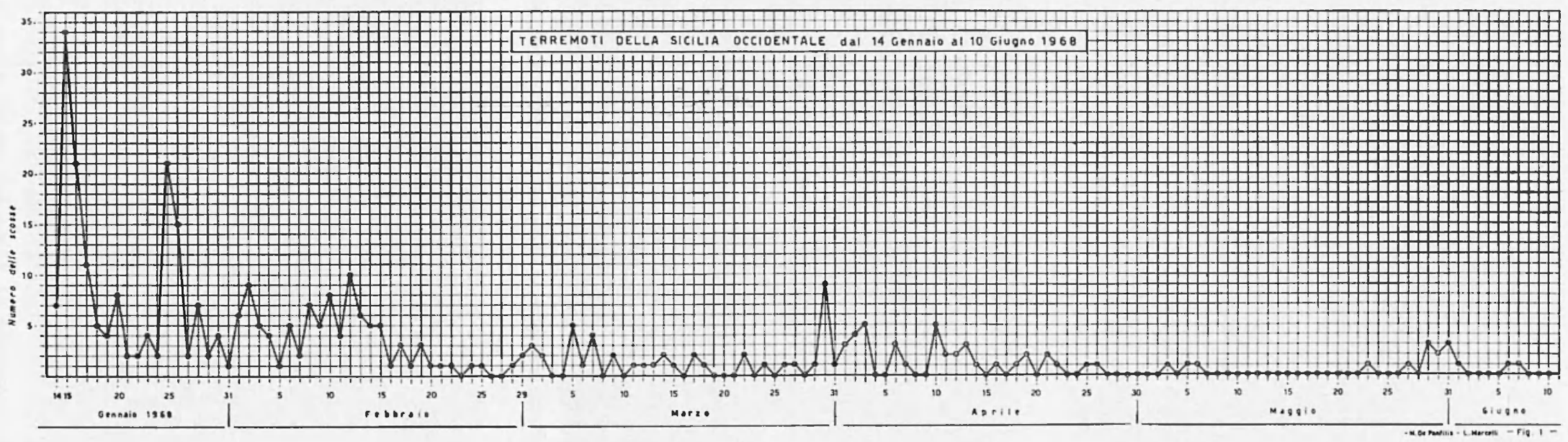

Fir. 1 - Grafico delle frequenze. 


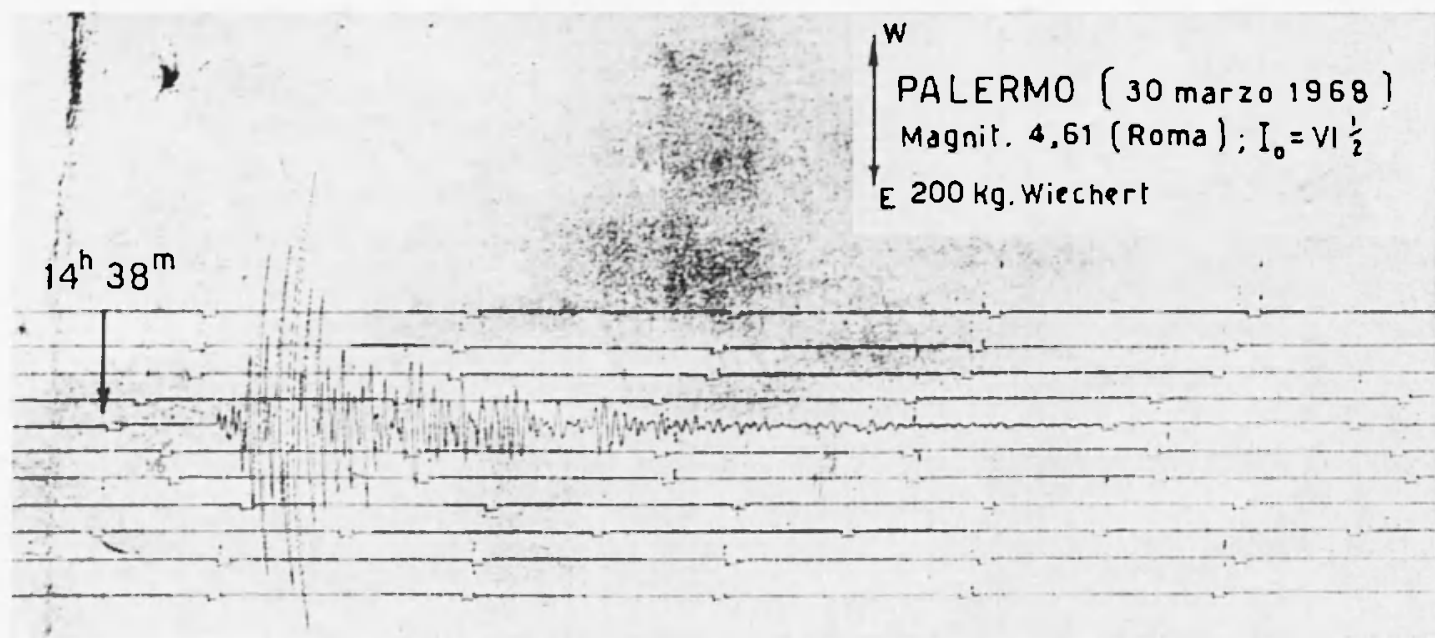

Fig. 2 a - Registrazione di Palermo del 30 marzo 1968

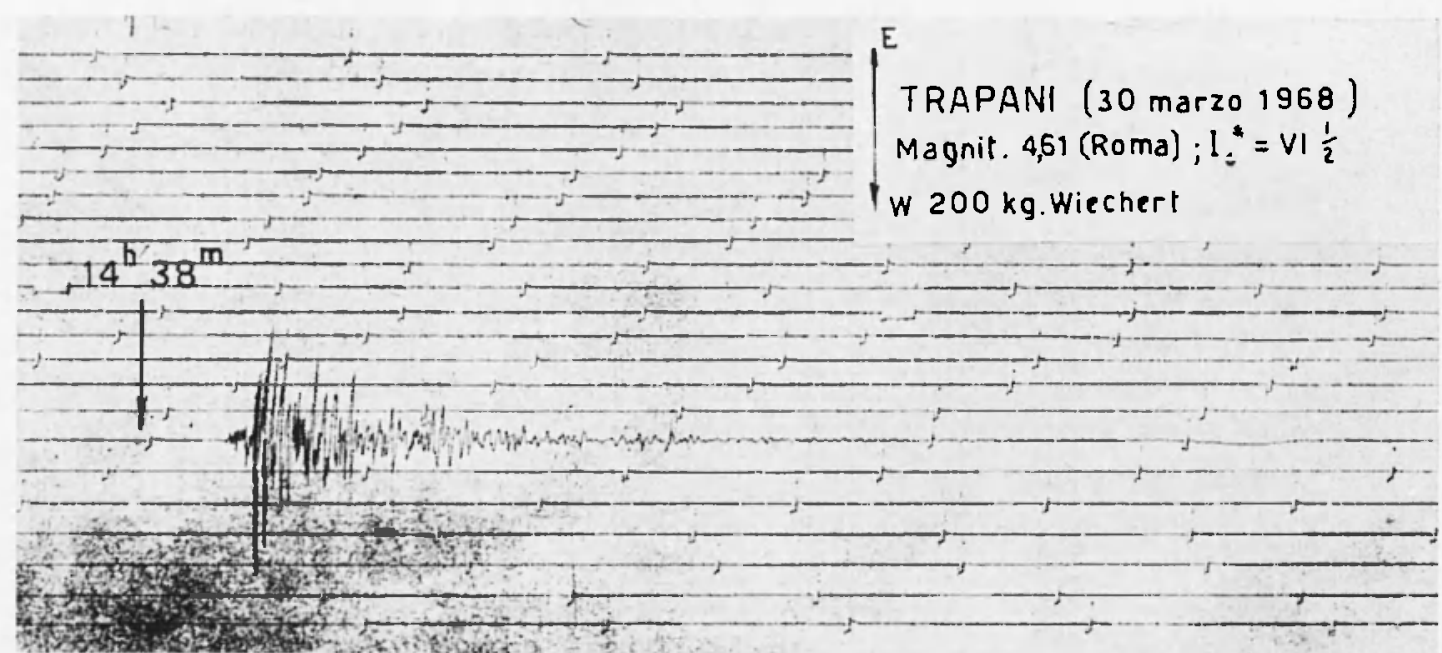

Fig. 2 b - Registrazione di Trapani del 30 marzo 1968

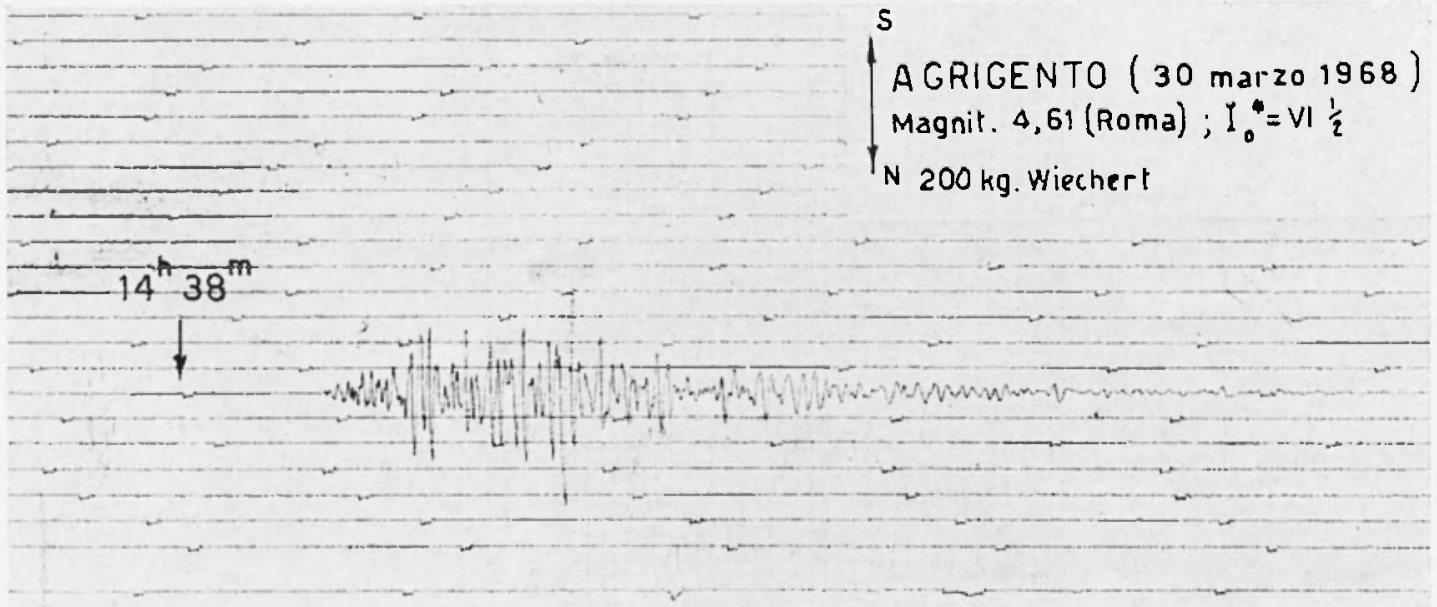

Fig. 2 c - Registrazione di Agrigento del 30 marzo 1968 , 


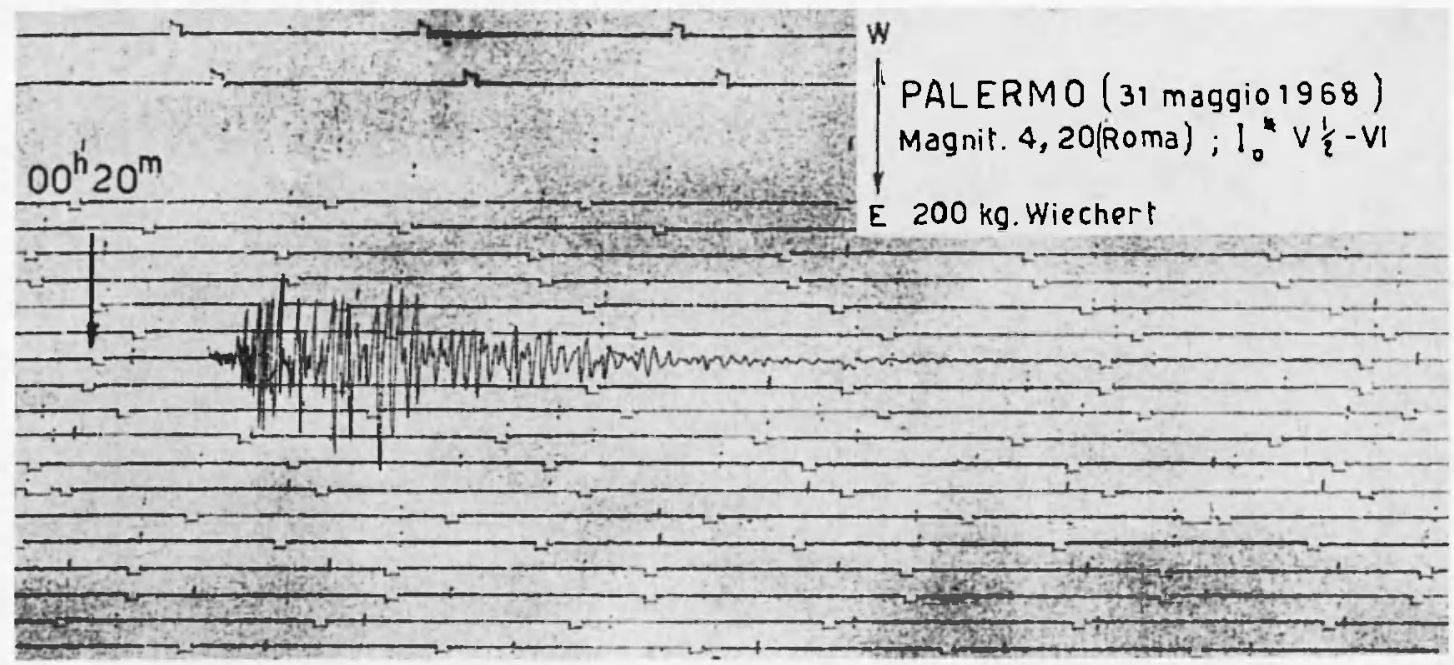

Fig. 3 a - Registrazione di Palermo del 31 maggio 1968
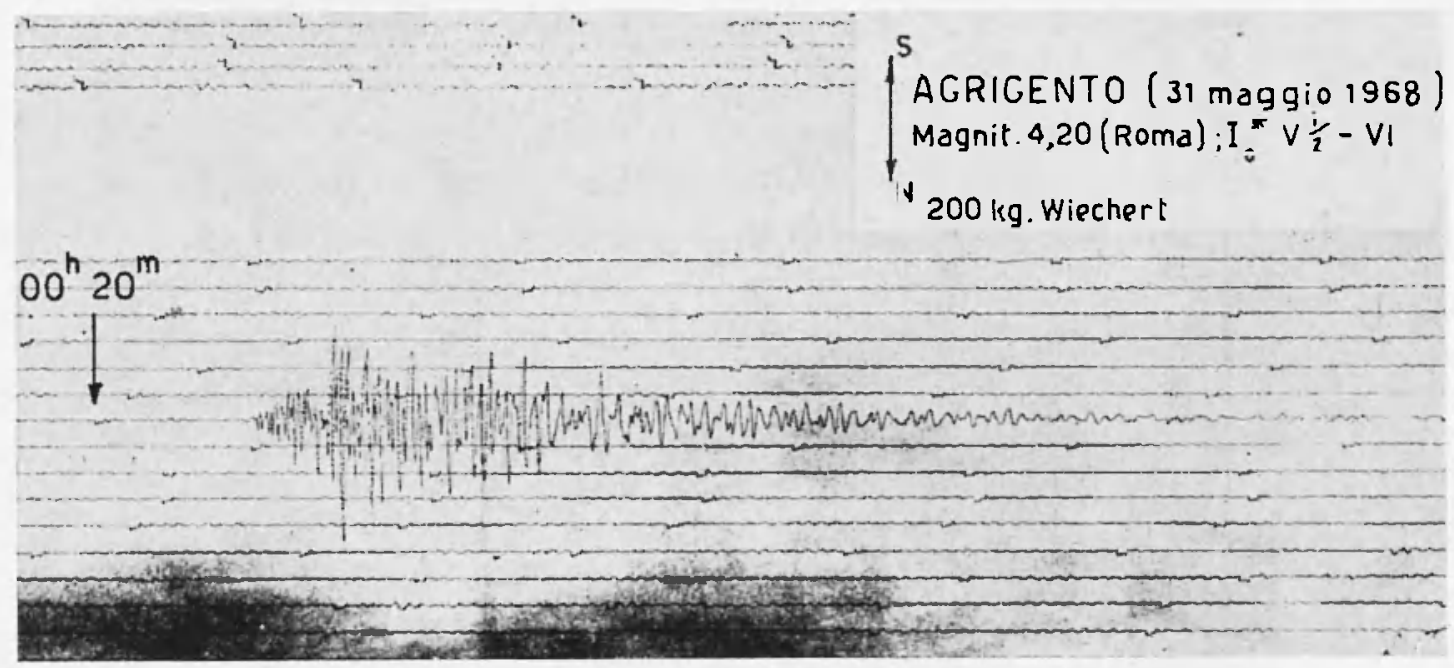

Fig. 3 b - Registrazione di Agrigento del 31 maggio 1968

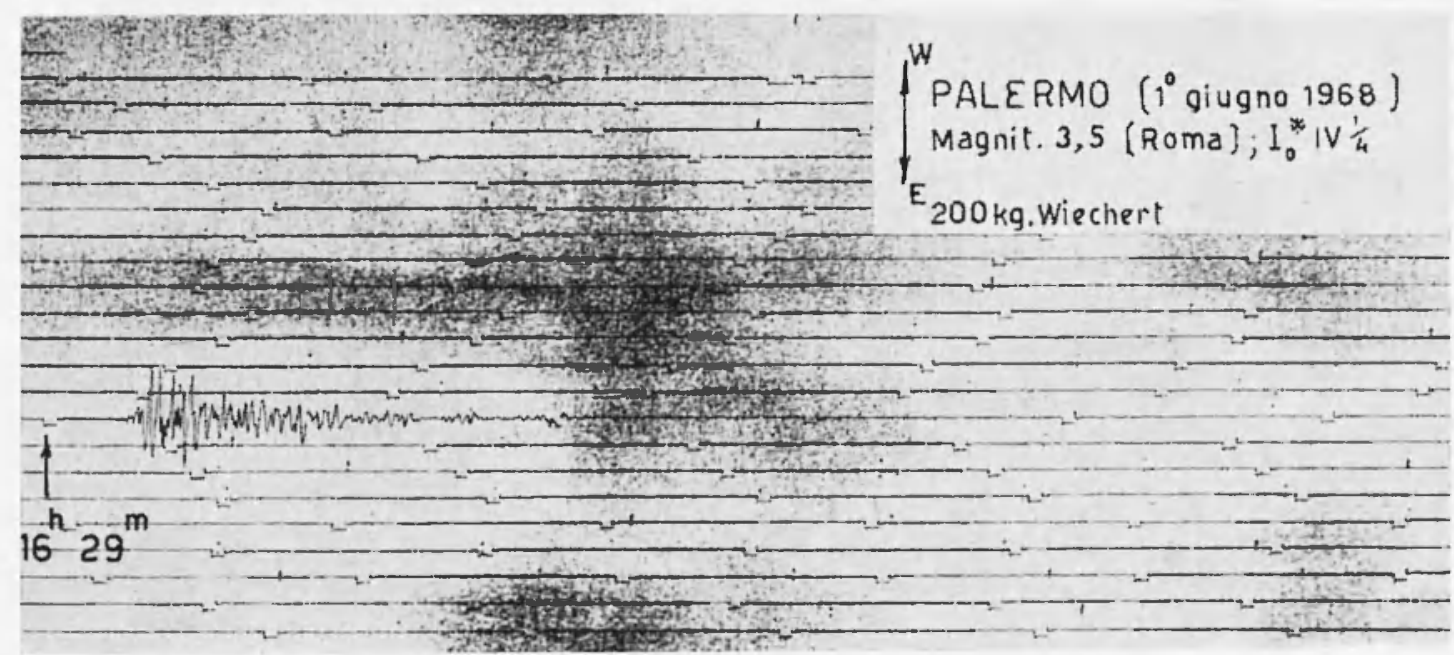

Fig. 4 - Registrazione di Palermo del l giugno 1968. 
Tabella 2 - Sicilia OCCIDExtale

Flexco deI TERREMOTI di GRADO VI E SUPERIORE AL VI

(dal 14 Gennaio al 10 Giugno 1968)

\begin{tabular}{|c|c|c|c|c|c|c|c|}
\hline N. & Data & di $r$ & $\begin{array}{l}\text { Ten } \\
\text { gist }\end{array}$ & $\begin{array}{l}\text { po } \\
\text { azione }\end{array}$ & & udo & $I^{*}{ }_{a}$ \\
\hline I & 14.1 .68 & $\begin{array}{c}4 \\
13\end{array}$ & $\begin{array}{l}\mathrm{m} \\
29\end{array}$ & $\begin{array}{c}\mathrm{s} \\
29.5\end{array}$ & 4,70 & Roma & $V I \quad 1 / 2-3 / 4$ \\
\hline 2 & & 14 & 16 & 47,5 & 4,77 & $"$ & VII - \\
\hline 3 & & 16 & 49 & 32,8 & 4,94 & $"$ & VII $1 / 4$ \\
\hline 4 & I5. 1.68 & 02 & 34 & 03,2 & 5,76 & $"$ & VIII $3 / 4$ \\
\hline 5 & & 03 & 02 & 09,2 & 6,00 & $"$ & IX \\
\hline 6 & & 03 & 10 & 36,4 & 4,30 & Messina & VI \\
\hline 7 & & 04 & 19 & 41 & 5,04 & Roma & VII $1 / 2$ \\
\hline 8 & & 11 & 56 & 12 & 4,36 & $"$ & $\mathrm{VI}+$ \\
\hline 9 & & 14 & 43 & 41 & 4,38 & ” & $\mathrm{VI}+$ \\
\hline 10 & & 16 & 01 & 23 & 4,44 & $"$ & $\mathrm{VI} \quad 1 / 4$ \\
\hline 11 & & 16 & 39 & 12 & 4,32 & $"$ & $\mathrm{VI}$ \\
\hline 12 & & 18 & 33 & 21 & 4,31 & $"$ & $\mathrm{VI}+$ \\
\hline 13 & & 19 & 24 & 22 & 4,66 & $"$ & VI $3 / 4$ \\
\hline 14 & & 23 & 21 & 06 & 4,34 & $"$ & VI \\
\hline 15 & 16.1 .68 & 14 & 12 & 00,5 & 4,33 & $"$ & $\mathrm{VI}+$ \\
\hline 16 & & 17 & 43 & 47,4 & 5,77 & $"$ & VIII $3 / 4$ \\
\hline 17 & 25.1 .68 & 10 & 57 & 58 & 5,70 & $"$ & VIII $1 / 2+$ \\
\hline 18 & & 15 & 36 & 47 & 4,70 & $"$ & VI $1 / 2-3 / 4$ \\
\hline 19 & 12.2 .68 & 17 & 27 & 04 & 4,60 & $"$ & VI $1 / 2$ \\
\hline 20 & 30.3 .68 & 14 & 39 & 34 & 4,61 & $"$ & $\mathrm{VI} \quad 1 / 2$ \\
\hline 21 & 1.4 .68 & 17 & 16 & 20 & 4,30 & $"$ & VI \\
\hline 22 & 31.5 .68 & 00 & 21 & 41 & 4,20 & ") & VI ca \\
\hline
\end{tabular}

quindici si riferiscono alle scosse più forti dell'intero periodo; gli altri sono stati scelti tra le scosse minori.

E praticamente impossibile calcolare gli epicentri di tutte le scosse (oltre 300) dell'intero periodo sismico; però già la ubicazione di questi soli punti mette in luce una vasta area interessata al fenomeno. 


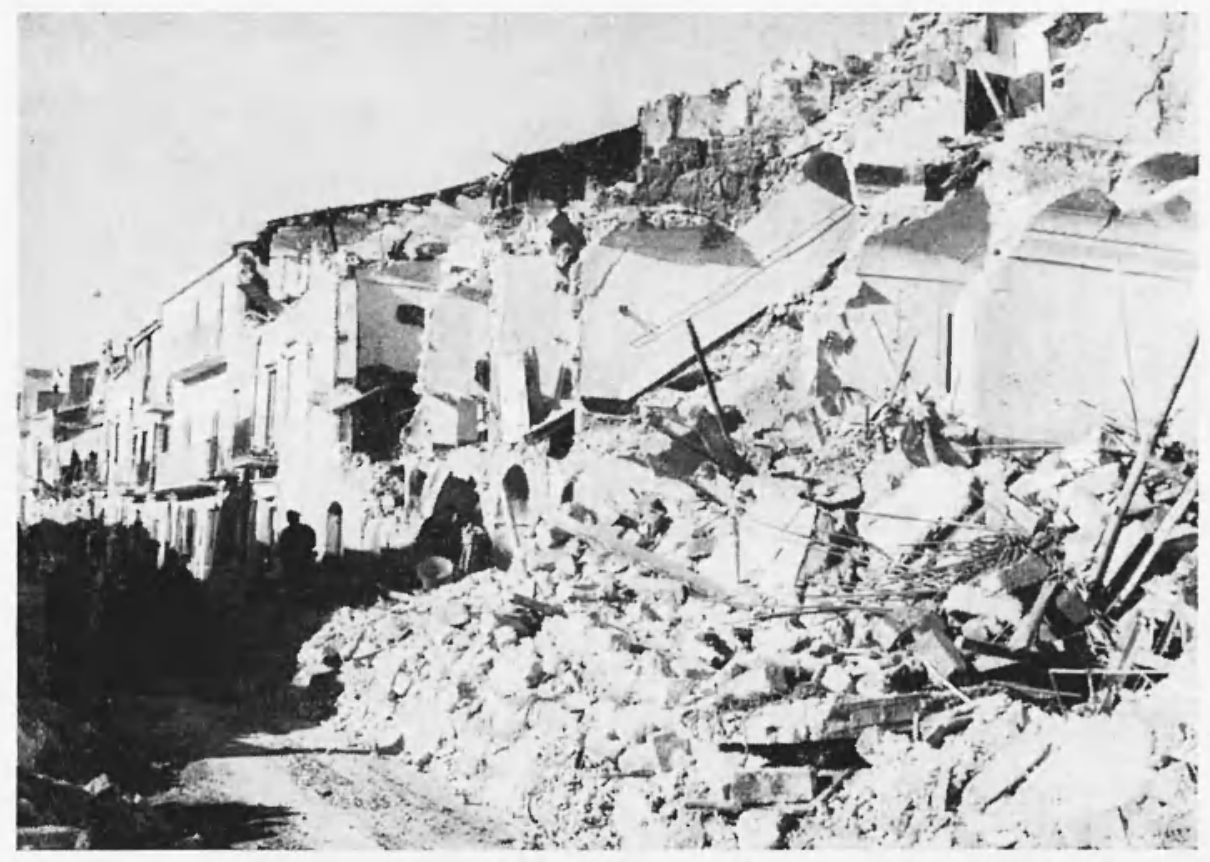

Foto 4 - Gibellina - Rffetti del terremoto su edifici in muratura.

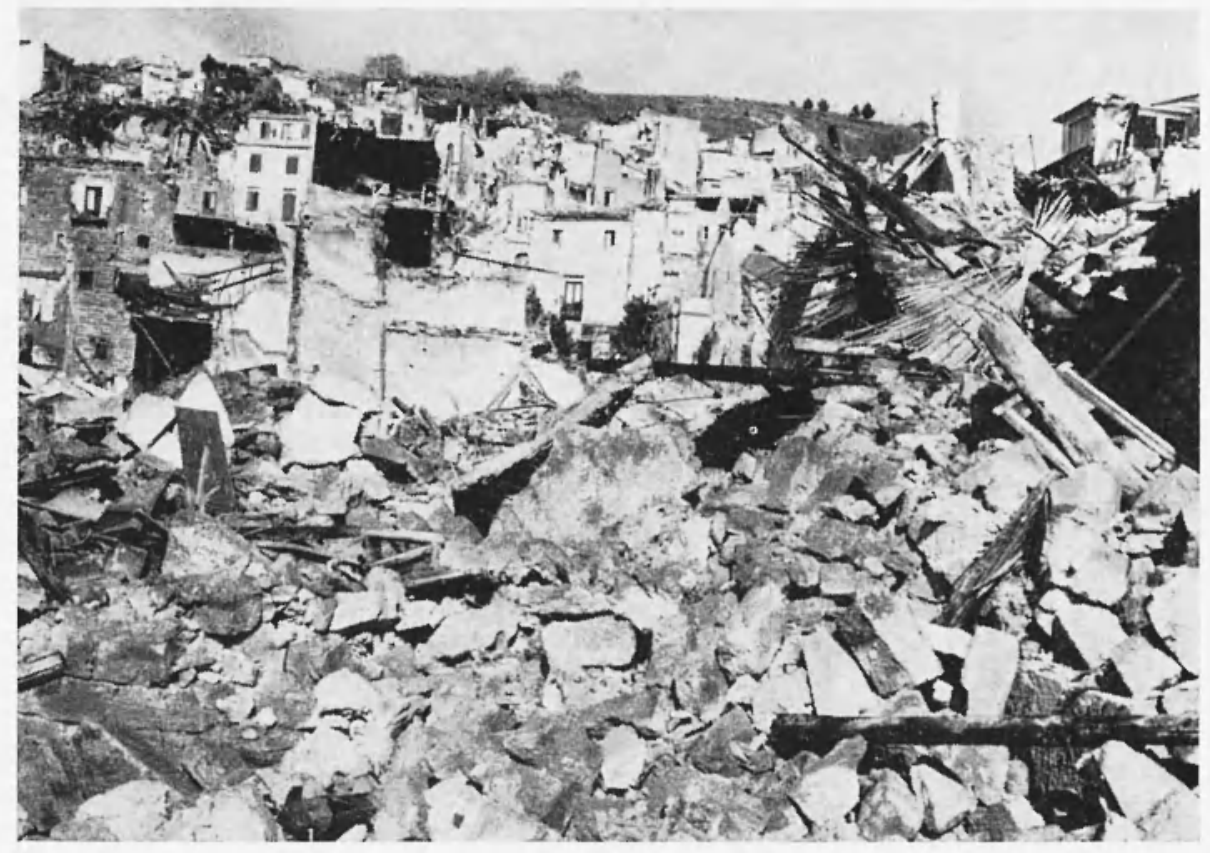

Foto 5. - Gibellina - Case in muratura ridotte ad informi ammassi di travi. detriti e blocchi di tufo. 
Tabella 3 - Epicestri di alcuni terreyoti della Valle del belice (Periodo sismico iniziato il 14 gennaio 1968)

\begin{tabular}{|c|c|c|c|c|c|}
\hline $\mathrm{N}$. & $\begin{array}{c}\text { Data e } \\
\text { tempo origine }\end{array}$ & $p$ & $\lambda$ & Magnit. & $I^{*}$ 。 \\
\hline $1^{*}$ & $\begin{array}{l}14 \text { genn. } 1968 \\
\text { II }=13^{\mathrm{n}} 28^{\mathrm{m}} 23^{\mathrm{s}}\end{array}$ & $37^{\circ}, 9 \mathrm{~N}$ & $13^{\circ}, 0 \mathrm{E}$ & 4,70 & YI $1 / 2-3 / 4$ \\
\hline $2^{*}$ & $\begin{array}{l}14 \text { gen } 11 . \\
I I \stackrel{=}{=} 14^{\mathrm{n}} 15^{\mathrm{m}} 46^{\mathrm{s}}\end{array}$ & $37^{\circ}, 7 \mathrm{~N}$ & $13^{\circ}, 1 \mathrm{E}$ & 4,77 & VII - \\
\hline $3^{*}$ & $\begin{array}{l}14 \text { genn. } \\
I 1 \stackrel{=}{=} 16^{\mathrm{h}} 48^{\mathrm{m}} 31^{\mathrm{s}}\end{array}$ & $37^{\circ}, 7 \mathrm{~N}$ & $13^{\circ}, 2 \mathrm{E}$ & 4,94 & VII $1 / 4$ \\
\hline $4^{*}$ & $\begin{array}{l}15 \text { genn. } \\
11 \stackrel{0}{=} 02^{\mathrm{h}} 33^{\mathrm{m}} 02^{\mathrm{s}}\end{array}$ & $37^{\circ}, 8 \mathrm{~N}$ & $13^{\circ}, 2 \mathrm{E}$ & 5,76 & VIII $3 / 4$ \\
\hline $5^{*}$ & $\begin{array}{l}15 \text { gremn. } \\
\text { II }=03^{\text {hol }} 01^{m} 06^{s}\end{array}$ & $37^{\circ}, 7 \mathrm{~N}$ & $13^{\circ}, 1 \mathrm{E}$ & 6,00 & $I X$ \\
\hline $6^{*}$ & $\begin{array}{l}15 \text { genm. } \\
I I \stackrel{=}{=} 04^{\mathrm{h}} 18^{\mathrm{m}} 40^{\mathrm{s}}\end{array}$ & $37^{\circ}, 8 \mathrm{~N}$ & $13^{\circ}, 2 \mathrm{E}$ & 5,04 & VII $1 / 2$ \\
\hline $7 * *$ & $\begin{array}{l}15 \text { genul. } \\
I I=19^{\mathrm{ln}} 22^{\mathrm{m}} 50^{\mathrm{s}}, 1\end{array}$ & $37^{\circ}, 7 \mathrm{~N}$ & $13^{\circ}, 1 \mathrm{E}$ & 4,66 & VI $3 / 4$ \\
\hline $8 * *$ & $\begin{array}{l}15 \text { genti. } \\
11=23^{\mathrm{h}} 19^{\mathrm{m}} 57^{\mathrm{s}}\end{array}$ & $37^{\circ}, 8 \mathrm{~N}$ & $12^{\circ}, 9 \mathrm{E}$ & 4,34 & $\mathrm{VI}+$ \\
\hline $9^{* *}$ & $\begin{array}{l}16 \text { genn. } \\
I I=14^{\mathrm{n}} 10^{\mathrm{m}}(32)^{\mathrm{s}}\end{array}$ & $37^{\circ}, 8 \mathrm{~N}$ & $12^{\circ}, 9 \mathrm{E}$ & 4,33 & VI - \\
\hline $10^{*}$ & $\begin{array}{l}16 \text { genn. } \\
\text { II }==17^{\mathrm{l}} 42^{\mathrm{m}} 45^{\mathrm{s}}\end{array}$ & $37^{\circ}, 7 \mathrm{~N}$ & $13^{\circ}, 3 \mathrm{E}$ & 5,77 & VIII $3 / 4$ \\
\hline $11^{* *}$ & $\begin{array}{l}21 \text { genn. } \\
11=03^{\text {h }} 39^{m} 05^{s}\end{array}$ & $37^{\circ}, 8 \mathrm{~N}$ & $13^{\circ}, 2 \mathrm{E}$ & 4,09 & $\begin{array}{ll}V & 1 / 2\end{array}$ \\
\hline $12^{*}$ & $\begin{array}{l}25 \text { grenm. } \\
\text { II :- } 10^{\mathrm{h}} 56^{\mathrm{m}} 47^{\mathrm{s}}\end{array}$ & $37^{\circ}, 7 \mathrm{~N}$ & $13^{\circ}, 1 \mathrm{E}$ & 5,70 & VIII $1 / 2+$ \\
\hline $13^{* *}$ & $\begin{array}{l}25 \text { genul. } \\
\text { II }=15^{\mathrm{n}} 35^{\mathrm{n}} 33^{\mathrm{s}}\end{array}$ & $\begin{array}{l}37^{\circ}, 8 \mathrm{~N} \\
h=33 \mathrm{~km}\end{array}$ & $12^{\circ}, 9 \mathrm{E}$ & 4,70 & VI $1 / 2-3 / 4$ \\
\hline $14^{* *}$ & $\begin{array}{l}26 \text { genn. } \\
I I=09^{\mathrm{h}}\left(02^{\mathrm{m}}(18)^{\mathrm{s}}\right.\end{array}$ & $\begin{array}{l}370,7^{\prime} \mathrm{N} \\
h=31 \mathrm{~km}\end{array}$ & $12^{\circ}, 8 \mathrm{E}$ & 4,21 & $V 34$ \\
\hline $15^{* *}$ & $\begin{array}{l}5 \text { febbr. } \\
\text { II }=12^{\mathrm{n}} 17^{\mathrm{m}}(39)^{\mathrm{s}}\end{array}$ & $\begin{array}{l}37^{\circ}, 9^{\prime} \mathrm{N} \\
h=33 \mathrm{~km}\end{array}$ & $12^{\circ}, 8 \mathrm{E}$ & 3,60 & IV $1 / 2$ \\
\hline $16^{*}$ & $\begin{array}{l}12 \text { febbr. } \\
\text { II } 17^{\mathrm{h}} 25^{\mathrm{m}} 59^{\mathrm{s}}\end{array}$ & $37^{\circ}, 7 \mathrm{~N}$ & $12^{\circ}, 8 \mathrm{E}$ & 4,60 & VI $\quad 1 / 2$ \\
\hline $17 *$ & $\begin{array}{l}5 \text { marzo } \\
I I=00^{\mathrm{H}} 38^{\mathrm{m}}, 0\end{array}$ & $38^{\circ} \quad \mathrm{N}$ & $13^{\circ}$ & 4,20 & $V_{1 / 2}$ \\
\hline $18^{* * *}$ & $\begin{array}{l}30 \text { marzo } \\
I I=10^{\mathrm{n}} 35^{m}(55)^{\mathrm{s}}\end{array}$ & $37^{\circ} 47^{\prime} \mathrm{N}$ & $13^{\circ} 58^{\prime} \mathrm{E}$ & 3,60 & IV $1 / 2$ \\
\hline $19 * * *$ & $\begin{array}{l}30 \text { marzo } \\
I I=14^{\mathrm{h}} 3 I^{\mathrm{m}}(15)^{\mathrm{s}}\end{array}$ & $37^{\circ} 46^{\prime} \mathrm{N}$ & $12^{\circ} 59^{\prime} \mathrm{E}$ & 3,30 & IV \\
\hline $20 * * *$ & $\begin{array}{l}30 \text { marzo } \\
\text { II }=14^{n} 38^{\mathrm{m}}(08)^{\mathrm{s}}\end{array}$ & $37^{0} 46^{\prime} \mathrm{N}$ & $12^{\circ} 50^{\prime} \mathrm{E}$ & 4,61 & $\mathrm{VI} \quad 1 / 2$ \\
\hline $21 * * *$ & $\begin{array}{l}30 \text { marzo } \\
I I=17^{\mathrm{n}} 17^{\mathrm{m}}(10)^{\mathrm{s}}\end{array}$ & $37^{\circ} 46^{\prime} \mathrm{N}$ & $13^{\circ} 00^{\prime} \mathrm{E}$ & 3,60 & IV $\quad 1 / 2$ \\
\hline $22 * * *$ & $\begin{array}{l}1 \text { aprile } \\
I I=0 I^{n} 52^{m}(43)^{s}\end{array}$ & $37^{\circ} 45^{\prime} N$ & $13^{\circ} 01^{\prime} \mathrm{E}$ & $(3,80)$ & $V$ \\
\hline $23^{* * *}$ & $\begin{array}{l}\text { I aprile } \\
\text { II }=17^{\mathrm{h}} 14^{\mathrm{m}}(27)^{\mathrm{s}}\end{array}$ & $37^{\circ} 45^{\prime} \mathrm{N}$ & $13^{\circ} 05^{\prime} \mathrm{E}$ & 4,30 & $V I$ \\
\hline \multicolumn{6}{|c|}{ 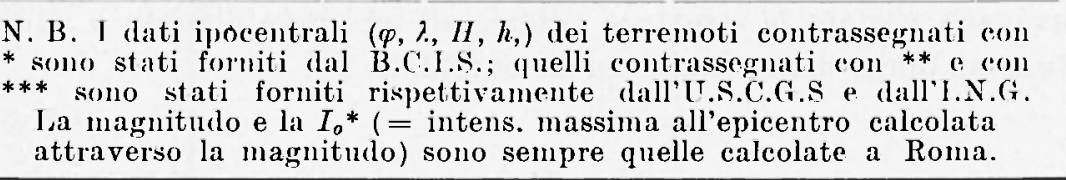 } \\
\hline
\end{tabular}


Durante il parossismo le località ripetutamente colpite sono quelle contenute entro il quadrilatero compreso tra i paralleli $37^{\circ} 40^{\prime} \mathrm{N}$. $38^{\circ} 05^{\prime} \mathrm{N}$ e i meridiani $12^{\circ} 45^{\prime} \mathrm{E}, 13^{\circ} 20^{\prime} \mathrm{E}$ (da Greenwich).

Non è escluso che a studio completato si possa riscontrare qualche epicentro anche al di fuori di detta zona.

Comunque va notato, ed è di profondo interesse scientifico, che l'area cosi delimitata - comprendente la Valle del Fiume Belice i tra le più fagliate dell'intera Sicilia, e molti dei centri abitati più duramente colpiti sono ubicati proprio in prossimità di molte di queste faglie.

La carta della Fig. 5 mette chiaramente in luce il legame che intercorre tra la situazione geologica della zona (cosi come istata rilevata dagli studi fatti dal geologo Ing. E. Beneo) e l'attuale fenomeno sismico.

Anche se per poter stabilire con esatteza la natura fisica delle scosse agli ipocentri si dovrà procedere a studi ed esami piuttosto profondi, a questa prima indagine appare tuttavia evidente che, almeno in superficie, l'energia sismica si è sprigionata nei punti di minore resistenza.

\section{5. - Aspettr MaCRosismict Det Fenomeno.}

Quando un cataclisma tellurico della portata di quello che stiamo analizzando si abbatte su una regione seminando lutti e rovine con una inesorabile continuità e violenza non è facile discriminare grli efietti delle singole scosse.

Tenteremo tuttavia, per quanto sarà possibile, di ricostruire la storia della distruzione di tanti paesi della Valle del Belice, già sapendo a priori però che il quadro sarà il risultato finale di quanto è avvenuto in quella vallata, istante per istante, a partire dalla tragica domenica del 14 Gennaio 1968.

Ci sarà di appoggio e di guida, in questo tentativo di esposizione cronologica, la Tabella 2, documento sicuro di rilievi strumentali. E ovvio, come abbiamo accenmato in precedenza, che le scosse di grado inferiore al VI inseritesi numerosissime a formare un lungo e tragico elenco - pur non essendo state gravi di per sé - formano tuttavia gli anelli minori di una catena di damni e sono divenute damose esse stesse per il fatto di essersi sovrapposte ad azioni dinamiche che già avevano portato le strutture edilizie ad un grave dissesto o addirittura ai limiti delle condizioni di equilibrio. 


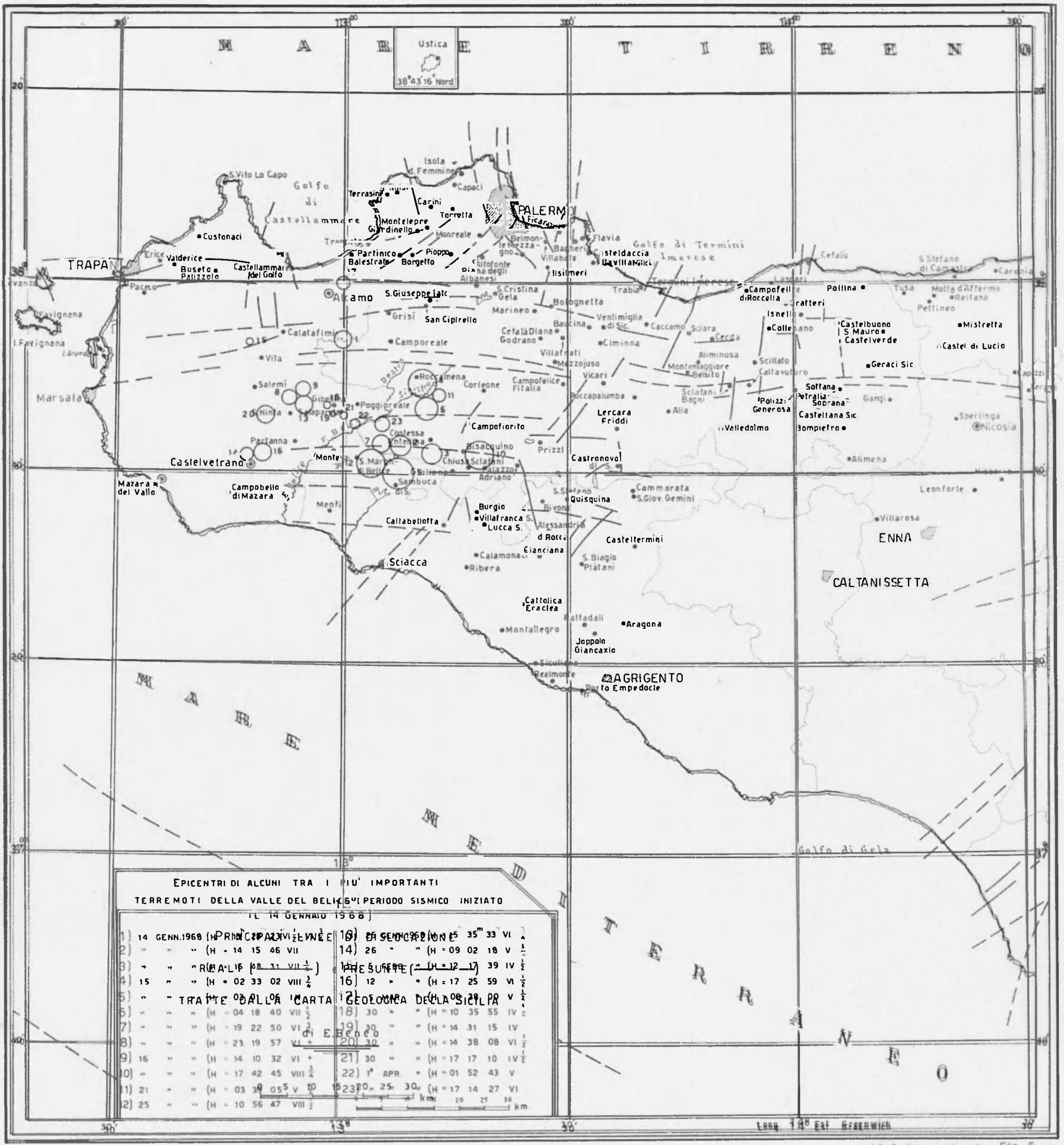

耳玨. 5 
a) La cronaca.

Non è fra gli scopi di questa memoria narrare le conseguenze umane - tragiche per l'elevato numero di vittime e per le sofferenze d'ogni genere arrecate a migliaia di superstiti - degli sconvolgimenti tellurici nella Vallata del Belice. Altri l'ha già fatto ed altri ancora probabilmente lo farà, con maggiore ampiezza di dati: ma forse non e ancora possibile un bilancio scrupoloso e completamente conforme alla realtà.

Qui ora ci limiteremo a passare cronologicamente in rassegna i sismi più importanti succedutisi nella Sicilia occidentale dal 14 Gennaio al 10 Giugno 1968, mettendo in evidenza, per ciascuno di essi, gli elementi che abbiamo potuto rilevare nei riguardi della magnitudo, dell'intensità epicentrale e della propagazione macrosismica.

\section{Domenica $1+$ Gennaio 1968.}

La scossa delle $13^{\mathrm{n}} 28^{\mathrm{m}}$, prima della serie, vemne registrata nell'Osservatorio dell'I.N.G. in Roma alle $13^{\mathrm{n}} 29^{\mathrm{m}} 29^{\mathrm{s}}, 5$; dai sismogrammi si potè ricavare la sua magnitudo $(4,70)$ e da questa - mediante formule - si dedusse l'intensità all'epicentro $\left(I_{0}^{*}=\right.$ VI $1 / 2-$ VI $3 / 4$ della Scala Mercalli).

Gli efletti della scossa, qui schematicamente riassunti, nella zona dell'epicentro ed in quelle viciniori confermano la valutazione strumentale. Si ebbero danni sensibili a Montevago, Gibellina, Salaparuta e Poggioreale; lesioni in diversi edifici di Santa Margherita di Belice, Menfi, Roccamena e Camporeale.

Il movimento sismico fu avvertito fortemente (grado V) a Castellammare del Golfo e Castelvetrano; mediocremente (grado IV) ad Agrigento, Palermo, Sciacca ed Alcamo; leggermente (grado III) a Salemi.

La seconda scossa, avvenuta meno di un'ora dopo la prima, fu registrata a Roma alle $14^{n} 16^{\mathrm{m}} 47^{\mathrm{s}}, 5$. Magnitudo: 4,$77 ; I^{*} \cong$ VII grado Mercalli.

Risultò fortissima (VII) a Gibellina, Montevago, Salaparuta, Poggioreale e S. Margherita di Belice; molto forte (VI) a Menfi; forte (V) ad Alcamo. Venne avvertita distintamente a Palermo ed a Trapani, leggermente a Sciacca.

Gli scuotimenti tellurici, durante il pomeriggio del 14 Gennaio, continuano con crescente intensità. La terza scossa è registrata dai 
sismografi dell'Osservatorio di Roma alle $16^{\mathrm{h}} 49^{\mathrm{m}} 32^{\mathrm{s}}, 8$. La sua magnitudo è 4,94 e l'intensità all'epicentro è del VII $1 / 4$ Mercalli.

Cominciano gli effetti distruttivi: damni notevoli ad Alcamo, Gibellina, Menfi, Montevago, Partamma, Poggioreale, Salaparuta, Salemi, S. Margherita di Belice, S. Ninfa; lesioni di varia entità in molti edifici di Calatafimi, di Camporeale, Corleone e Roccamena. A Palermo, lesioni in case di vechia costruzione. La scossa viene sentita fortemente, ma senza danni, a Misilmeri, a Castellammare del Golfo e a Castelvetrano.

\subsection{Gennaio.}

La prima scossa della giornata, violentissima, è registrata a Roma alle $02^{\mathrm{n}} 34^{\mathrm{m}} 03^{\mathrm{s}}, 2$. La magnitudo è di 5,76 , corrispondente ad una intensità epicentrale di grado VIII $3 / 4$.

Crollano edifici e Poggioreale, Gibellina, Salaparuta, Montevago e S. Margherita di Belice. La scossa, avvertita in tutta la Sicilia occidentale e centrale, risulta fortissima o molto forte in numerose località, fra le quali Corleone, Contessa Entellina, Termini Imerese, Trapani e Palermo. Viene sentita anche nell'isola di Pantelleria.

La seconda scossa, disastrosa, proceduta da boati, si abbatte sulla vallata del Belice circa mezz'ora dopo la precedente. I sismografi di Roma la registrano alle $03^{\mathrm{n}} 02^{\mathrm{m}} 09^{\mathrm{s}}, 2$. Magnitudo: 6,0. Intensità epicentrale: grado IX della Scala Mercalli.

I paesi di Montevago, Salaparuta e Gibellina, già rovinosamente colpiti dalle scosse precedenti, rimangono quasi del tutto distrutti. Numerosissimi edifici crollano totalmente o parzialmente a $\mathrm{S}$. Margherita di Belice, Partanna, S. Ninfa, Menfi, Poggioreale, Salemi e Vita.

Il moto sismico si propaga ampiamente attorno alla zona epicentrale arrecando danni di varia entità nelle città di Agrigento, Trapani e Palermo ed in molti comuni delle rispettive provincie. Nella provincia di Agrigento: Burgio, Calamonaci, Lucca Sicula, Ribera, Sambuca di Sicilia, Sciacca, Villafranca Sicula; nella provincia di Trapani: Aleamo, Calatafimi, Campobello di Mazara, Castellammare del Golfo, Castelvetrano, Marsala, Mazara del Vallo; in provincia di Palermo: Balestrate, Bisacquino, Borgetto, Caltavuturo, Campofiorito, Camporeale, Chiusa Sclafani, Ciminna, Contessa Entellina, Corleone, Giuliana, Godrano, Lercara Friddi, Monreale (frazioni di Grisi e Pioppo), Palazzo Adriano, Partinico, Petralia Soprana, Piana 


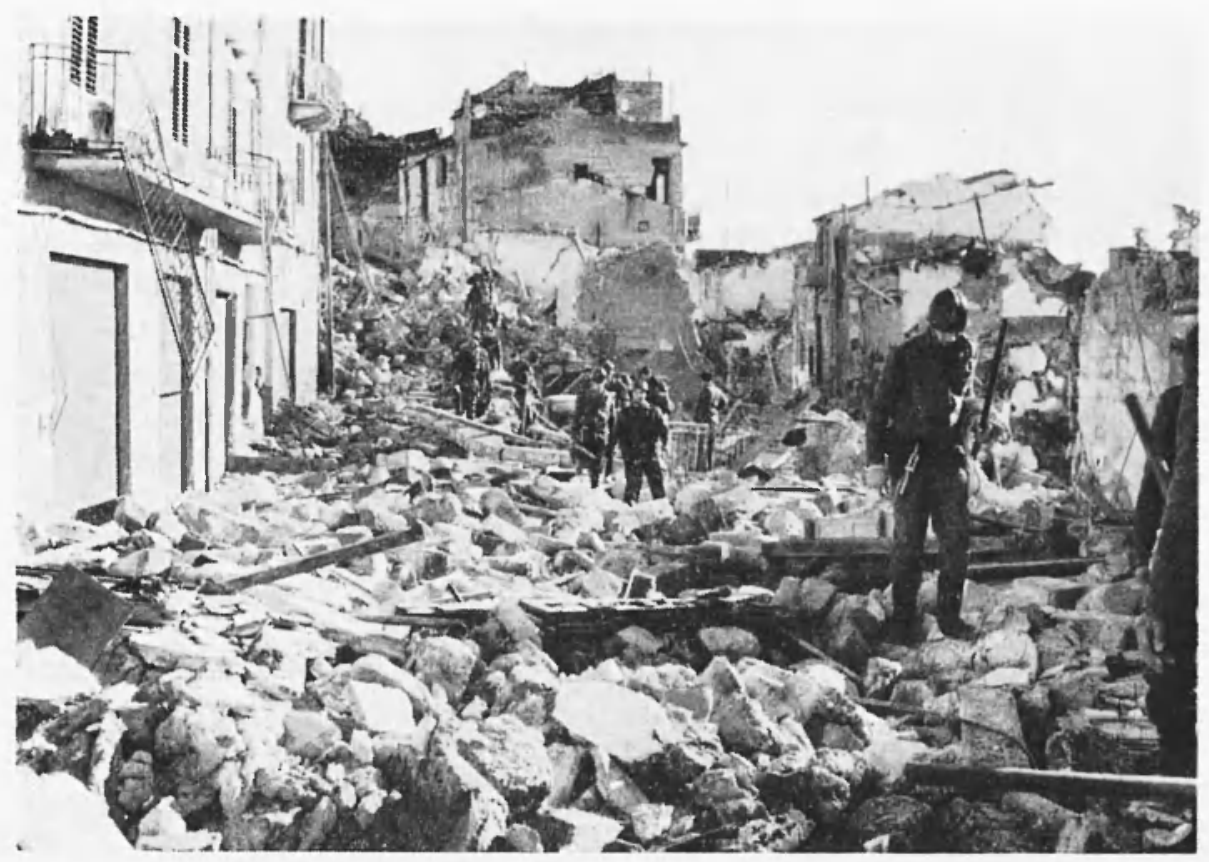

Foto 6. - Gibellina - Le macerie delle case distrutte dai sismi hanno invaso completamente e reso impraticabili le strade del paese.

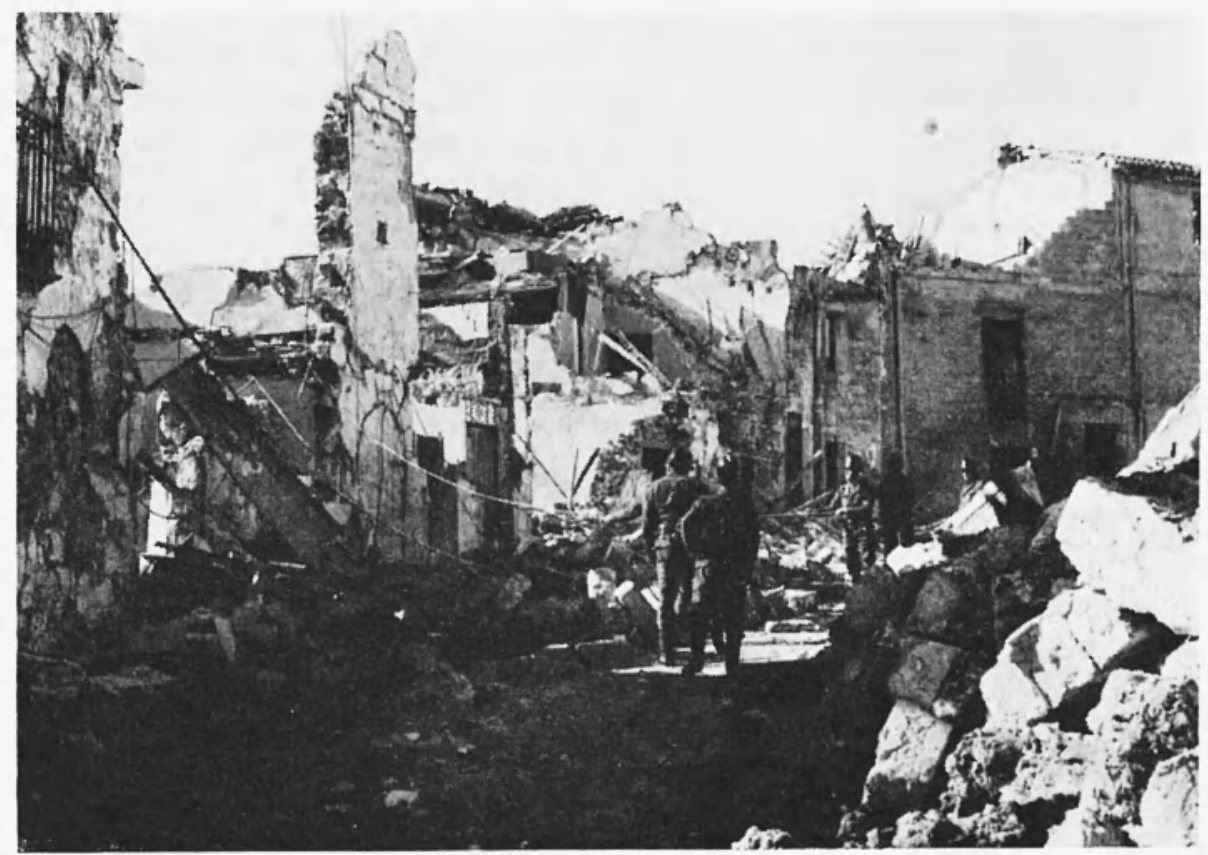

Foto 7. - Gibellina - Vigili del fuoco intenti a demolire murature pericolanti. 
degli Albanesi, Roccamena, Roccapalumba, S. Cipirello, S. Giuseppe Jato, Scillato, Torretta, Trappeto, Ventimiglia Sicula.

Anche gli effetti sul suolo, nella zona prossima allepicentro, sono cospicui: movimenti franosi vengono segnalati da alcune località; la strada statale 119 , che da Alcamo conduce a Castelvetrano, viene sconvolta, fra il ventunesimo chilometro e Gibellina, da profondi avvallamenti per circa 6 chilometri. Si afferma che in molti luoghi, dopo la scossa, si sia diffuso nell'aria un acre odore di zolfo.

Numerose altre scosse di minore intensità, le più notevoli delle quali sono riportate nella Tabella 2, si succedono durante la giornata.

\section{Gennaio.}

La convulsione sismica riprende con paurosa intensità. Alle $17^{\mathrm{h}} 43^{\mathrm{m}} \mathbf{4} 7^{\mathrm{s}}, 4$ i sismografi di Roma registrano un altro violentissimo terremoto. Magnitudo: 5,77; intensità all'epicentro: VIII $3 / 4$.

A Gibellina, Montevago, Salaparuta cadono in rovina $\mathbf{i}$ pochi edifici ancora rimasti in piedi. Altri crolli e lesioni gravissime a Poggioreale, S. Margherita di Belice, Partamma, Menfi, S. Ninfa e Roccamena. La scossa è fortissima a Sciacca, Sambuca di Sicilia, Camporeale, Alcamo, S. Giuseppe Jato, S. Cipirello, Castelvetrano, Palermo. Sentita fortemente in tutta la Sicilia centro-occidentale, essa si propaga anche nella parte orientale dell'Isola e viene avvertita lievemente anche a Catania.

\section{Gennaio.}

Alla fase parossistica segue, dal 17 al 24 Gennaio, un periodo di calma relativa; le scosse continuano, ma meno frequenti e con intensità moderata. Sembra che il periodo sismico volga verso la sua conclusione, quando, alla mattina del 25 Gennaio, un'altra violentissima scossa, inattesa e perciò tanto più terrificante, riporta lo sconvolgimento e lo sconforto nelle popolazioni cosi tragicamente colpite che lentamente andavano riprendendo un po' di calma e di coraggio.

Altre vittime si aggiungono a quelle già così numerose mietute dai sismi precedenti e, questa volta, fra i soccorritori che nei paesi devastati e già abbandonati dagli abitanti si prodigavano nella rimozione delle macerie e nella ricerca dei morti che sotto di esse erano rimasti ancora sepolti. 
La scossa è registrata a Roma alle $10^{\mathrm{h}} 57^{\mathrm{m}} 58^{\mathrm{s}}$. La magnitudo è 5,70 e l'intensitì epicentrale, VIII $1 / 2$.

A Gibellina, Montevago, Salaparuta precipitano le informi murature residue delle case crollate e le macerie si sovrappongono alle marerie. A Poggioreale vamo in rovina quasi tutte le case sfuggite ai terremoti precedenti. Altri crolli e devastazioni a Partanna, Menti, S. Margherita di Belice e S. Ninfa. Nuove e gravissime lesioni in moltissimi edifici di Aleamo, Sambuca di Sicilia, Salemi, Vita e Sciacea. Altri damni notevoli a Calatami, Camporeale, Chinsa Sclafani, Corleone, Giuliana, Palazo Adriano, Rocamena.

Il sisma viene sentito con intensità fortissima, cansa altri danni e sparge il terrore fra le popolazioni di Campobello di Mazara, Campofiorito, Castelvetrano, Contessa Entellina, Marsala, Mazara del Vallo, Palermo, Partinico, Ribera, S. Cipirello, San Ginseppe Jato, Trapani. La propagazione del movimento tellurico è molto vasta e la scossa viene avvertita fortemente anche in varie localita delle provincie di Caltanisetta, Enna e Messina.

Dopo questa, altre venti scosse si susseguono durante la giornata del 25 Gennaio; sono tutte d'intensità moderata eccetto una, avvenuta alle $15^{\mathrm{h}} 35^{\mathrm{m}}$, che ì di grado VI $3 / 4$ circa.

\section{Febbraio.}

Dal 25 Gennaio all'11 Febbraio la Valle del Belice è ogni griorno turbata da movimenti sismici. La frequenza grornaliera è talora rilevante (il 2 Febbraio, ad esempio, furono registrate 9 scosse), ma l'intensita si mantiene sempre entro limiti modesti.

Il 12 Febbraio, però, l'attività sismica torna a farsi pinttosto violenta e nuovamente il panico si diffonde nelle popolazioni di molti centri della sicilia occidentale e nelle tendopoli sorte in prossimità dei paesi completamente od in parte distrutti.

Dieci scosse si succedono durante la griornata. Isa più forte è re-

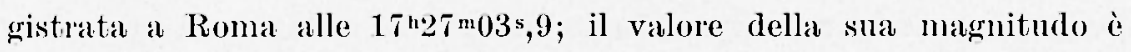
4,60 e l'intensità epicentrale è di grado VI $1 / 2$. Viene sentita con tale intensità nelle zone di Gibellina, Salaparuta, Poggioreale e Santa Ninfa; di grado $\mathrm{V}$ a Castelvetrano, Contessa Entellina, Marsala, Mazara del Vallo, MIenfi, Salemi e Sciacra; di IV nell'Agrigentino, nel Palermitano e nel Trapanese. 


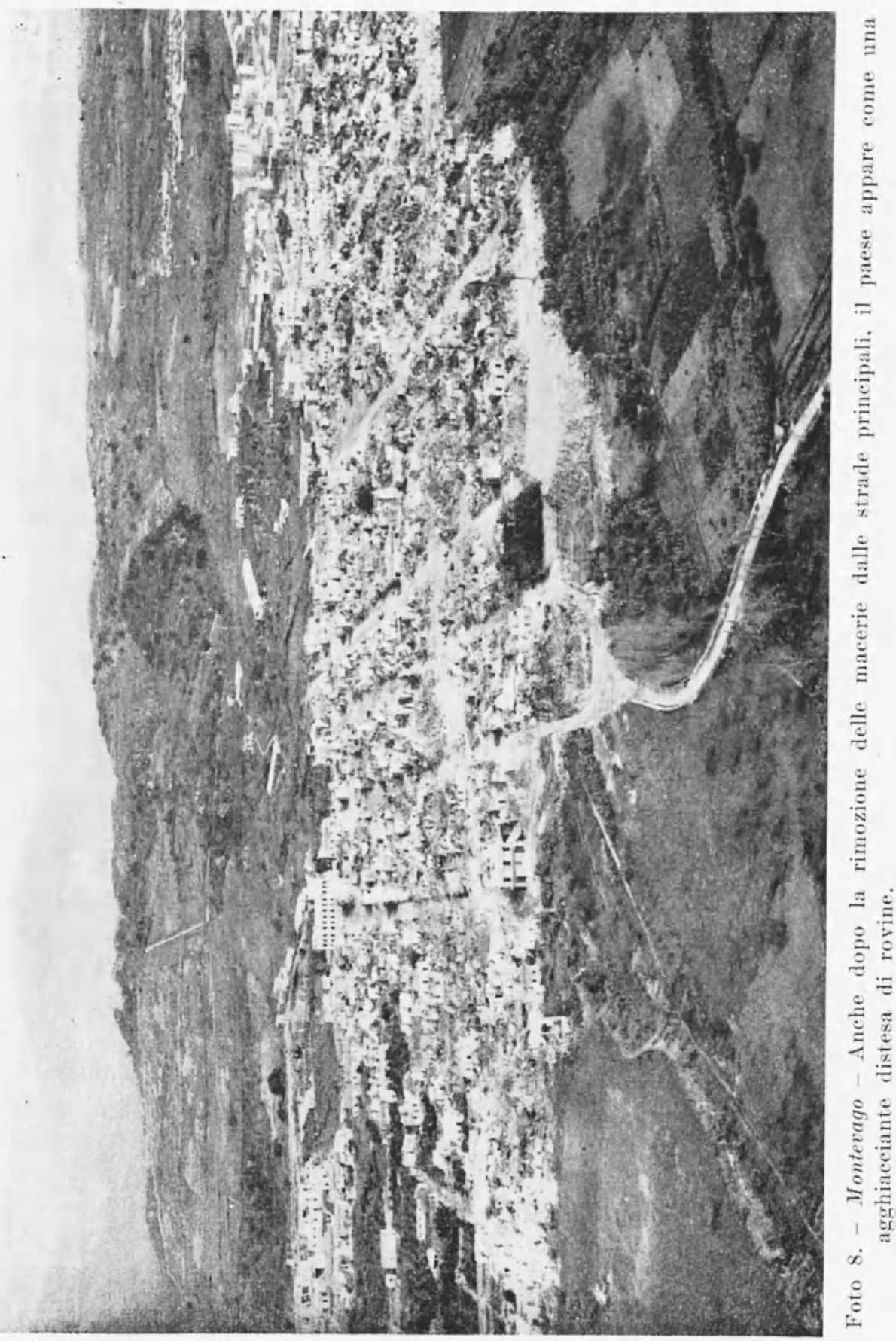


30 Marzo - 1o Aprile.

L'attività sismica si attenua notevolmente nel periodo che va dal 13 Febbraio al 29 Marzo: si hanno, ad intervalli, giorni di calma assoluta (v. Tabella 1) e le intensità delle scosse sono prevalentemente molto basse, spesso solo strumentali. I fenomeni tornano a farsi preoccupanti dal 30 Marzo al $10^{\circ}$ Aprile.

Il 30 Marzo si verificano 9 scosse ed nna di esse - quella delle $14^{\mathrm{n}} 38^{\mathrm{m}}$ - assai energica: la sua magnitudo è 4,61 e VI $1 / 2$ l'intensitì all'epicentro. Viene sentita molto fortemente a Roccamena, ove produce altri danni, fortemente ad Alcamo e Castellammare, mediocremente a Trapani, Castelvetrano, Contessa Entellina e Menfi, leggermente anche a Palermo.

Il 31 Marzo si ha ma scossa molto lieve, rilevata solo dai sismografi. Il $1^{\circ}$ Aprile, ancora tre scosse: la più forte è registrata a Roma alle $17^{\mathrm{h}} 16^{\mathrm{m} 20^{\mathrm{s}}}$; ha una magnitudo di 4,30 ed una intensita epicentrale di grado VI. Viene sentita distintamente ad Alcamo, a Trapani ed in numerosi centri del Trapanese.

\section{Maggio.}

La scossa delle $17^{\mathrm{n} 16^{\mathrm{m}}}$ del $1^{\mathrm{o}}$ Aprile $\mathrm{fu}$ segnita, nei giorni 2,3 e 6 Aprile, da altri movimenti sismici minori, i quali vennero sentiti, ove più ove meno intensamente, in varie località delle provincie di Agrigento, Palermo e Trapani: fra esse, Sciacca, Contessa Entellina, Roccamena, S. Cipirello, San Giuseppe Jato, Alcamo, Salemi.

Dal 7 Aprile in poi, i fenomeni sismici sembra che si vadano estinguendo. Si avvertono qua e là alcune scosse, ma assai lievi, prevalentemente strumentali, ed intervallate da giorni di quiete. Il periodo che va dal 7 al 22 Maggio trascorre in una calma assoluta, ma il 29 Maggio i movimenti tellurici tornano a manifestarsi e culminano alle $00^{\mathrm{n}} 21^{\mathrm{m}} 41^{\mathrm{s}}$ del 3.1 Maggio con una scossa di VI grado circa (di magnitudo 4,20 ) che si propaga nella Valle del Belice e suscita vivissimo panico in tutte le zone interessate dal fenomeno.

I a scossa risulta molto forte a Contessa Entellina, Menfi, Sambuca di Sicilia; forte a Campobello di Mazara, Castelvetrano, Corleone, Salemi e Sciacca.

Isa intensa ripresa dei movimenti sismici ha fortunatamente una breve durata: dal $1^{\circ}$ al 10 Giugno vengono registrate solo tre scosse 
e tutte lievi. E col 10 Giugno poniamo termine a questa sintetica cronaca degli eventi funesti iniziati nella Sicilia occidentale il 14 Gennaio 1968.

b) I danni. Le "isoblabe ".

Da quanto abbiamo fin qui esposto, appare evidente l'estrema difficolta incontrata nel tentativo di discriminare gli effetti delle singole scosse.

Gli A. hamo avuto modo di recarsi personalmente nelle zone epicentrali. Gli effetti complessivi delle scosse sismiche sono stati terrificanti ed in alcuni casi hamno assunto un aspetto addirittura apocalittico.

I paesi di Gibellina, Salaparuta, Pogrgioreale e Montevago hammo subito una distruzione totale e di essi non rimane che un informe ammasso di macerie, di travi contorte e di muri sbriciolati. Sarà impossibile la ricostruzione sul luogo: il solo sgombero delle macerie comporterebbe un inutile, improbo lavoro. In queste località la vita è spenta in tutte le sue manifestazioni. Il silenzio di una distruzione assoluta incombe allucinante come una cosa staccata dal mondo e dal tempo.

Nei paesi su menzionati la scossa principale del periodo sismico (quella delle ore 3 e 2 minuti del 15 (Gemnaio) si è manifestata con una intensità del grado IX della Scala Mercalli: e questa intensità - val la pena di ripeterlo - è stata valutata attraverso la magnitudo del sisma e non dagli efletti distruttivi, i quali, di per sé, in una zona come quella colpita, nella quale gli edifici erano ancora prevalentemente quelli costruiti tanti e tanti decenni fa, avrebbero portato ad una valutazione anche superiore a quella calcolata strumentalmente. Tuttavia, l'azione ripetuta delle scosse successive ha portato ad un eftetto globale pari a quello che si sarebbe potuto avere da un'unica scossa di grado $\mathrm{X}$ almeno.

di paesi predetti fanno subito seguito, in ordine di damnegriamento decrescente ma sempre gravissimo, quelli di Santa Ninfa, Partamna, Salemi, S. Margherita di Belice, Menfi e Contessa Entellina.

I danni verificatisi in tali paesi secondo i dati definitivi commicati dall'" Ispettorato Generale per le zone colpite dai terremoti del Gennaio 1968 " con sede in Palermo, possono essere assimilati a quelli prodotti da un'unica scossa di intensità compresa tra il IX ed il $\mathrm{X}$ grado della Scala Mercalli. 


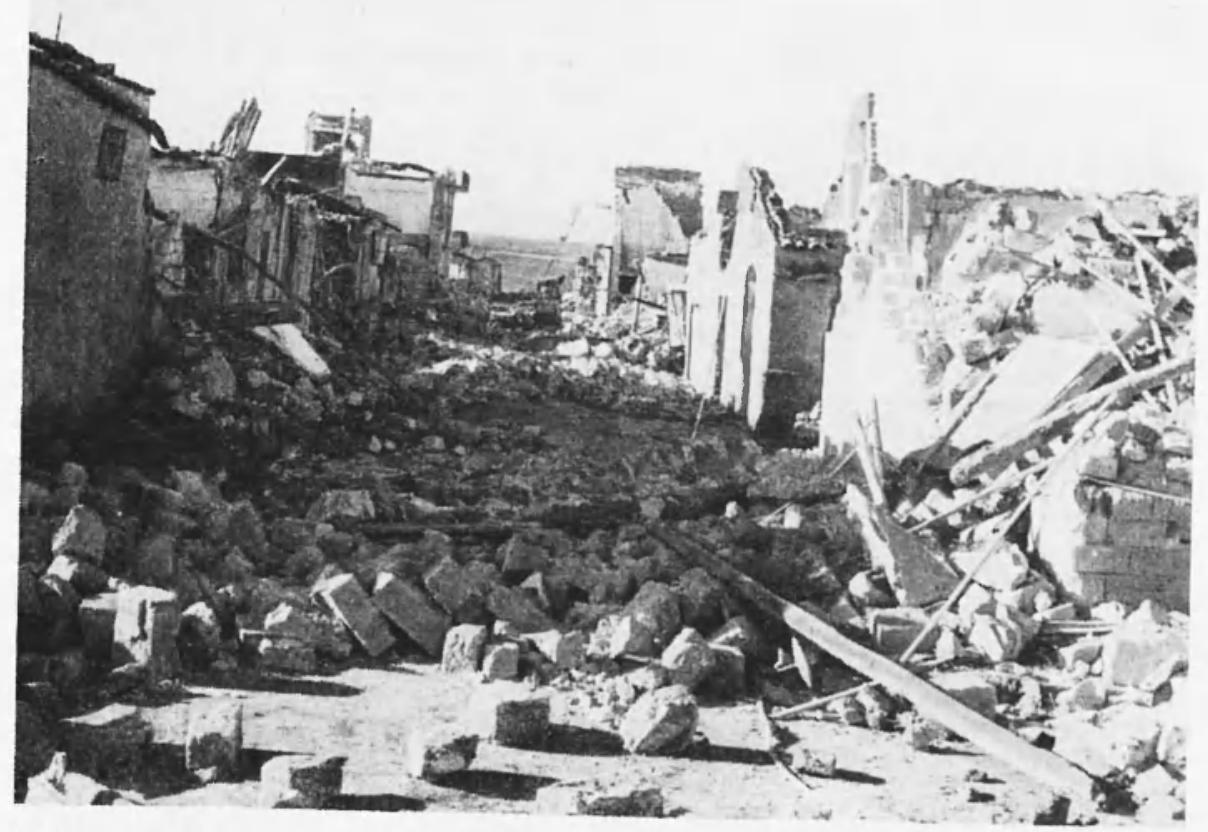

Foto 9. - Montevago - Una strada del paese fiancheggiata da case distrutte.

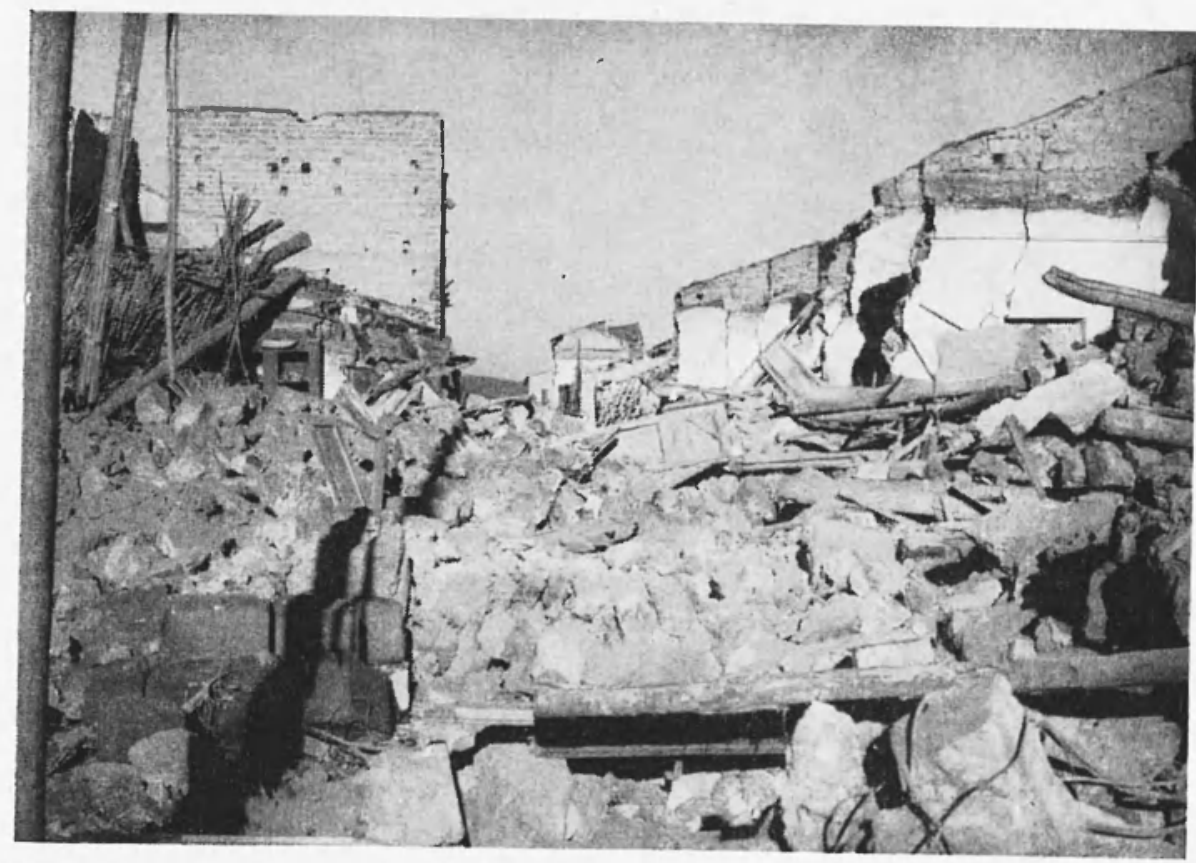

Foto 10. - Un'altra strada di Montevago ancora completamente ostruita dalle macerie delle case crollate. 
Tabella 4-A - Proviscia di Agrigexto

\begin{tabular}{|c|c|c|c|c|c|c|}
\hline \multirow[b]{2}{*}{ N. } & \multirow[b]{2}{*}{ Comune } & \multirow[b]{2}{*}{$\begin{array}{l}\text { Unità } \\
\text { immobi- } \\
\text { liari pre- } \\
\text { esistenti } \\
\text { ai sismi }\end{array}$} & \multicolumn{3}{|c|}{ Enità immobiliari } & \multirow[b]{2}{*}{$\begin{array}{l}\text { Indici } \\
\text { di } \\
\text { danneto }\end{array}$} \\
\hline & & & $\begin{array}{c}\text { Distrutte } \\
\% \\
\end{array}$ & $\begin{array}{c}\text { Grave- } \\
\text { mente } \\
\text { danneg- } \\
\text { riate } \\
\% \\
\%\end{array}$ & $\begin{array}{c}\text { Lesio- } \\
\text { nate } \\
\% \\
\%\end{array}$ & \\
\hline 1 & Agrigento & 16. 743 & - & - & 0,3 & 0,00090 \\
\hline 2 & $\begin{array}{l}\text { Alessandria della } \\
\text { Rocca }\end{array}$ & & - & - & & 0.03000 \\
\hline 3 & Aragona & 5.730 & - & - & 0,50 & 0,00150 \\
\hline 4 & Bivona & 2.447 & .... & 0,50 & 10 & 0,03350 \\
\hline 5 & Burgio & 2.975 & - & & 30 & 0,10400 \\
\hline $\begin{array}{l}6 \\
7\end{array}$ & Calamonaci & 1.012 & - & 1 & 20 & 0,06700 \\
\hline & $\begin{array}{l}\text { Caltabellotta e } \\
\text { frazione } \mathrm{S} \text {. Anna }\end{array}$ & 3.611 & - & 2 & 20 & 0,07400 \\
\hline 8 & Cammarata & +.370 & - & - & 0,50 & 0,00150 \\
\hline 9 & Casteltermini & 5.937 & - & - & 1 & 0,00300 \\
\hline 10 & Cattolica Eraclea & 5.169 & - & 2 & 10 & 0,04400 \\
\hline 11 & Cianciana & 3.467 & - & 1 & 18 & 0,06100 \\
\hline 12 & Joppolo Giancaxio & 748 & - & - & $\cdots$ & \\
\hline 13 & Incea Sicula & 1.569 & -.- & & 20 & 0,09500 \\
\hline 14 & ILenfi & 5.078 & $\cdots$ & $40 \div 50$ & $40 \div 50$ & 0,45000 \\
\hline 15 & Montallegro & 1.876 & ... & 2 & 15 & 0,05900 \\
\hline 16 & Monterago & 1.393 & 99 & $\bar{l}$ & - & 0,09700 \\
\hline 17 & Porto Empedocle & 6.380 & - & - & - & \\
\hline 18 & Raffadali & 5.260 & - & - & 5 & 0,01500 \\
\hline 19 & Realmonte & 2.078 & ... & - & - & \\
\hline 20 & Ribera & 7.765 & - & 0,50 & 10 & 0,03350 \\
\hline 21 & Sambuca di Sicilia & 3.657 & - & 8 & 25 & 0,13100 \\
\hline 22 & San Biagio Platani & 2.310 & .. & - & 2 & 0,00600 \\
\hline 23 & San Giovanni & & & & & \\
\hline 24 & $\begin{array}{l}\text { Gemini } \\
\text { Santa Jargherita }\end{array}$ & 2.845 & - & - & $\cdots$ & - \\
\hline & di Belice & 3.646 & 70 & -80 & 20 & 0,58500 \\
\hline 20 & $\begin{array}{l}\text { S. Stefano } \\
\text { Quisquina }\end{array}$ & 3.160 & - & - & 6 & 0,01800 \\
\hline 26 & Sciacca & 9.958 & - & 0,50 & 5 & 0,01850 \\
\hline 27 & Siculiana & 3.710 & - & - & 10 & 0,03000 \\
\hline 28 & Villafranca Sicula & 1.349 & - & 2 & 20 & 0.07400 \\
\hline
\end{tabular}

Nella evidente impossibilità di procedere ad un particolaregriato tracciamento delle isosiste per ciascuna delle scosse dell'intero periodo, abbiamo cercato di affrontare il problema della propagazione della energia sismica ricorrendo ad un espediente che abbiamo ritenuto altamente significativo.

Sopra una carta della regione investita dai terremoti abbiamo tracciato le "isoblabe " (ved. Fig. 6), cioè le linee di eguale dannergiamento globale. 
Tabella 4-B - Provixcia di Palermo

\begin{tabular}{|c|c|c|c|c|c|c|}
\hline \multirow[b]{2}{*}{ N. } & \multirow[b]{2}{*}{ Comune } & \multirow[b]{2}{*}{$\begin{array}{l}\text { Unità } \\
\text { immobi- } \\
\text { liari pree } \\
\text { sistenti } \\
\text { ai sismi }\end{array}$} & \multicolumn{3}{|c|}{ Unità immobiliari } & \multirow[b]{2}{*}{$\begin{array}{l}\text { Indici } \\
\text { di } \\
\text { dann.to }\end{array}$} \\
\hline & & & Distrutte & $\begin{array}{c}\text { Grave- } \\
\text { mente } \\
\text { danneg- } \\
\text { giate } \\
\% \\
\end{array}$ & $\begin{array}{c}\text { Lesio- } \\
\text { nate } \\
\% \\
\%\end{array}$ & \\
\hline 1 & Alia & 2.112 & - & 0,09 & 0,90 & 0,00333 \\
\hline 2 & Alimena & 1.605 & - & 0,06 & 0,19 & 0,00099 \\
\hline 3 & Aliminusa & 494 & - & - & 0,81 & 0,00243 \\
\hline 4 & Altavilla Milicia & 1.146 & - & - & 0,17 & 0,00051 \\
\hline 5 & Altofonte & 1.693 & - & 0,06 & 1,77 & 0,00573 \\
\hline 6 & Bagheria & 8.463 & - & 0,11 & 0,59 & 0,00254 \\
\hline 7 & Balestrate & 1.501 & - & 0,13 & 13,32 & 0,04087 \\
\hline 8 & Baucina & 863 & - & 0,93 & 10,89 & 0,03918 \\
\hline 9 & Belmonte Mezzagno & 1. 769 & - & - & 3,62 & 0,01086 \\
\hline 10 & Bisacquino & 2.122 & 0,05 & 0,94 & 6,13 & 0,02547 \\
\hline 11 & Bolognetta & 795 & - & $\ldots$ & 1,26 & 0,00378 \\
\hline 12 & Borgetto & 1.850 & - & 0,32 & 9,73 & 0,03143 \\
\hline 13 & Bompietro & 1.212 & - & $\ldots$ & 0,74 & 0,00222 \\
\hline 14 & Caccano & 3.424 & - & 0,15 & 0,79 & 0,00342 \\
\hline 15 & Caltavuturo & 1. 932 & - & & 1,55 & 0,00465 \\
\hline 16 & Campofelice Fitalia & 379 & - & 3,69 & 59,37 & 0,20394 \\
\hline 17 & Campofelice Roc- & & 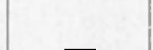 & & & \\
\hline 18 & $\begin{array}{l}\text { cella } \\
\text { Campofiorito }\end{array}$ & $\begin{array}{r}1.077 \\
608\end{array}$ & - & 6,58 & $\begin{array}{r}0,40 \\
21,38\end{array}$ & $\begin{array}{l}0,00158 \\
0,11020\end{array}$ \\
\hline 19 & Camporeale & 1.562 & 1,09 & 23,69 & 33,35 & 0,27678 \\
\hline 20 & Capaci & 1.076 & - & 1,39 & 13,94 & 0,05155 \\
\hline 21 & Carini & 4.836 & - & 0,14 & 4,98 & 0,01592 \\
\hline 22 & Castelbuono & 2.680 & - & - & 0,37 & 0,00111 \\
\hline 23 & Castellana & 1.488 & - & - & 0,13 & 0,00039 \\
\hline 24 & Casteldaccia & 1.643 & — & - & 0,30 & 0,00090 \\
\hline 25 & Castronovo Siculo & 1.400 & - & 0,43 & 0,71 & 0,00514 \\
\hline 26 & Cefalà Diana & 338 & - & - & 5,92 & 0,01776 \\
\hline 27 & Cefalù & 3.189 & — & - & 0,31 & 0,00093 \\
\hline 28 & Cerda & 1.570 & - & - & 0,32 & 0,00096 \\
\hline 29 & Chiusa Sclafani & 1.683 & - & 7,13 & 11,88 & 0,08555 \\
\hline 30 & Ciminna & 1.518 & 0,07 & 10,01 & 19,76 & 0,13005 \\
\hline 33 & Cinisi & 2.173 & - & 0,28 & 4,97 & 0,01687 \\
\hline 34 & Collesano & 1.702 & - & - & 0,35 & 0,00105 \\
\hline 35 & Contessa Entellina & 1.200 & 1,67 & 34,92 & 43,42 & 0,39140 \\
\hline 13 & Corleone & 4.179 & 0,1 & 2,42 & 28,71 & 0,10427 \\
\hline$\varepsilon^{2}$ & Ficarazzi & 1.234 & - & 0,65 & 2,51 & 0,01208 \\
\hline 36 & Gangi & 3.028 & - & - & 0,43 & 0,00129 \\
\hline 37 & Geraci Siculo & 1.013 & - & - & 0,69 & 0,00207 \\
\hline 38 & Giardinello & 354 & - & 7.06 & 45,20 & 0,18502 \\
\hline 39 & Giuliana & 938 & - & 1,07 & 10,66 & 0,03947 \\
\hline 40 & Godrano & 315 & - & 9,84 & 47,62 & 0,21174 \\
\hline 41 & Gratteri & 378 & - & - & 0,79 & 0,00237 \\
\hline 42 & Isnello & 1.026 & - & - & 0,39 & 0,00117 \\
\hline 43 & Isola delle Femmine & 635 & -. & 0,31 & 1,57 & 0,00688 \\
\hline 44 & Lascari & 890 & - & & 0,34 & 0,00102 \\
\hline 45 & Lercara Friddi & 3.099 & - & 0,81 & 3,23 & 0,01536 \\
\hline 46 & Marineo & 1.957 & 0,25 & 2,20 & 17,42 & 0,07016 \\
\hline
\end{tabular}


(segue Tabella 4-B)

\begin{tabular}{|c|c|c|c|c|c|c|}
\hline \multirow[b]{2}{*}{ N. } & \multirow[b]{2}{*}{ Comune } & \multirow[b]{2}{*}{$\begin{array}{l}\text { Unita } \\
\text { immobi- } \\
\text { liari pree- } \\
\text { sistenti } \\
\text { ai sismi }\end{array}$} & \multicolumn{3}{|c|}{ Unita immobiliari } & \multirow[b]{2}{*}{$\begin{array}{l}\text { Indice } \\
\text { di } \\
\text { danm.to }\end{array}$} \\
\hline & & & $\begin{array}{c}\text { Distrutte } \\
\% \\
\end{array}$ & $\begin{array}{c}\text { Grave- } \\
\text { mente } \\
\text { danneg- } \\
\text { griate } \\
\% \\
\end{array}$ & $\begin{array}{c}\text { Lesio- } \\
\text { nate } \\
\% \\
\%\end{array}$ & \\
\hline 47 & Mezzojuso & 1.250 & — & 1,44 & 7,20 & 0,03168 \\
\hline 48 & Misilmeri & 3.908 & - & 0,31 & 2,30 & 0,00907 \\
\hline 49 & $\begin{array}{l}\text { Monreale } \\
\text { (Grisi-Pionno) }\end{array}$ & 7.344 & - & 30 & 36 & $0 \quad 01318$ \\
\hline 50 & Montelepre & 1.536 & - & $\begin{array}{l}1,30 \\
4,30\end{array}$ & $\begin{array}{r}1,30 \\
10,42\end{array}$ & 0,06136 \\
\hline 51 & Montemaggiore Bel- & & & & & \\
\hline 52 & $\begin{array}{l}\text { sito } \\
\text { Palazzo Adriano }\end{array}$ & $\begin{array}{l}1.575 \\
1.216\end{array}$ & 二 & $\begin{array}{l}1,33 \\
0,49\end{array}$ & $\begin{array}{l}6,67 \\
6,17\end{array}$ & $\begin{array}{l}0,02932 \\
0,02194\end{array}$ \\
\hline 53 & Palermo & 139.997 & - & 0,53 & 5,36 & 0,01979 \\
\hline 54 & Partinico & 6.651 & 0,01 & 0,75 & 2,25 & 0,01210 \\
\hline 55 & Petralia Soprana & 2.659 & - & 0,07 & 1,88 & 0,00613 \\
\hline 56 & Petralia Sottana & 1.986 & - & - & 1,01 & 0,00303 \\
\hline 57 & Piana regli Albanesi & 1.937 & - & 0,31 & 9,81 & 0,03160 \\
\hline 58 & Polizzi Generosa & 2.035 & - & - & 0,39 & 0,00117 \\
\hline 59 & Pollina & 851 & - & - & 0,59 & 0,00177 \\
\hline 60 & Prizzi & 2.746 & - & 0,15 & 0,91 & 0,00378 \\
\hline 61 & Roccamena & 793 & 0,25 & 17,02 & 31,53 & 0,21623 \\
\hline 62 & Roccapalumba & 1.235 & 0,08 & 0,16 & 7,45 & 0,02427 \\
\hline 63 & S. Cipirello & 1.320 & - & 2,27 & 18,94 & 0,07271 \\
\hline 64 & San Giuseppe Jato & 2.365 & 0,04 & 6,34 & 19,03 & 0,10187 \\
\hline 65 & San Mauro Castel- & & & & & \\
\hline & verde & 1.437 & - & - & 1,11 & 0,00333 \\
\hline 66 & S. Cristiana Gela & 313 & - & 1,60 & 6,07 & 0,02941 \\
\hline 67 & Santa Flavia & 1.967 & - & - & 4,58 & 0,01374 \\
\hline 68 & Sciara & 858 & - & - & 6,53 & 0,01959 \\
\hline 69 & Scillato & 376 & - & 2,66 & 7,98 & 0,04256 \\
\hline 70 & Sclafani Bagni & 257 & - & - & 1,17 & $0,0035 \mathrm{l}$ \\
\hline 71 & Termini Imerese & 5.839 & - & 0,48 & 1,42 & 0,00762 \\
\hline 72 & 'Terrasini & 2.128 & - & 0,56 & 3,76 & 0,01520 \\
\hline $7 \overline{3}$ & Torretta & 990 & - & 5,05 & 10,10 & 0,06565 \\
\hline 74 & Trabia & 1.767 & - & 0,06 & 0,40 & 0,00162 \\
\hline 75 & 'Trappeto & 641 & - & 0,62 & 7,80 & 0,02774 \\
\hline 76 & Ustica & 390 & - & - & 0,51 & 0,00153 \\
\hline 77 & Valledolmo & 2.044 & - & 0,10 & 0,49 & 0,00217 \\
\hline 78 & Ventimiglia di Sicilia & 1.163 & - & 0,43 & 6,88 & 0,02365 \\
\hline 79 & Vicari & 1. 180 & - & 0,17 & 5,00 & 0,01619 \\
\hline 80 & Villabate & 2.280 & - & - & 0,71 & 0,00213 \\
\hline 81 & Villafrati & 889 & - & 0,45 & 6,86 & 0,02373 \\
\hline
\end{tabular}

Esse danno una idea abbastanza chiara degli effetti dinamici sulle costruzioni da parte del complesso dei sismi succedutisi nella zona, e potrebbero essere interpretate come le isosiste di un unico ipotetico terremoto avente per epicentro un punto interno alla zona di maggior devastazione. 
Tabella 4-C - Provincia di 'Trapaxi

\begin{tabular}{|c|c|c|c|c|c|c|}
\hline \multirow[b]{2}{*}{ N. } & \multirow[b]{2}{*}{ Comme } & \multirow{2}{*}{$\begin{array}{l}\text { Cnità } \\
\text { immobi- } \\
\text { liari (ur- } \\
\text { bane) } \\
\text { preesi- } \\
\text { stenti } \\
\text { ai sismi }\end{array}$} & \multicolumn{3}{|c|}{ Cnità immobiliari } & \multirow[b]{2}{*}{$\begin{array}{l}\text { Indice } \\
\text { di } \\
\text { dannto }\end{array}$} \\
\hline & & & Distrutte & $\begin{array}{c}\text { Grave- } \\
\text { mente } \\
\text { dannegr- } \\
\text { griate } \\
\% \\
\%\end{array}$ & $\begin{array}{c}\text { Jesio- } \\
\text { nate } \\
\% \\
\end{array}$ & \\
\hline 1 & Aleamo & 13.383 & - & 22,07 & 42,33 & 0,28148 \\
\hline $\begin{array}{l}2 \\
3\end{array}$ & Calatafimi & 3.288 & & 6,39 & 61,28 & 0,22857 \\
\hline 1 & $\begin{array}{l}\text { Mazara } \\
\text { Casella }\end{array}$ & 3.972 & - & 9,99 & 32,02 & 0,16599 \\
\hline $\boldsymbol{\Psi}$ & $\begin{array}{l}\text { Golfo } \\
\text { Gellame de }\end{array}$ & 5.942 & 0,20 & 0,50 & 5,05 & 0,02065 \\
\hline 5 & Castelvetrano & 8.479 & 2,01 & 8,90 & 11,97 & 0,11831 \\
\hline 6 & Gibellina & 1.980 & 100 & - & $\cdots$ & 1,00000 \\
\hline 7 & IIarsala & 18.070 & - & 3,50 & 4,00 & 0,03650 \\
\hline 8 & Mazara del Villo & 8.213 & - & 4, & 20,00 & 0,09493 \\
\hline 9 & Partanna & 4.345 & 29,90 & 41,80 & 18,76 & 0,64788 \\
\hline 10 & Poggioreale & 993 & 100 & - & & 1,00000 \\
\hline il & Salaparuta & 1.001 & 100 & 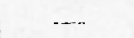 & & 1,00000 \\
\hline 12 & Saleni & 4402 & 24,4 & & 28,49 & 0,64285 \\
\hline 13 & Santa Ninfa & 1.928 & 43,30 & 47 & 9,23 & 0,79291 \\
\hline 14 & Trapani & 21.311 & $\ldots$ & 0 & 2,00 & 0,00656 \\
\hline 15 & Vita & 1.446 & 9,96 & 14,8 & 15,56 & 0,25037 \\
\hline 16 & Buseto Palizzolo & 677 & - & 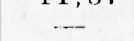 & 11,00 & 0,03300 \\
\hline 17 & Custonaci & 1.325 & - & 0 & 7,60 & 0,02539 \\
\hline 18 & Erice & 6.678 & $\ldots$ & 0,09 & 1.40 & 0,00483 \\
\hline 19 & Favignana & 2470 & - & - & 10,10 & 0,03030 \\
\hline 20 & Paceco & 3877 & $\ldots$ & 0,18 & 2,60 & 0,00906 \\
\hline 21 & S. Vito Jo Capo & 172.5 & -. & $\ldots$ & $0, \mathbf{1 6}$ & 0,00048 \\
\hline 22 & Valderice & 3897 & $\ldots$ & - & 0,08 & 0,00024 \\
\hline
\end{tabular}

A tale scopo abbiamo anzitutto calcolato, per ognuna delle località comunque interessate dai movimenti tellurici e sulla base delle percentuali dei danni di diversa entità accertate ufficialmente dai Geni Givili di Agrigento, Palermo e Trapani (vedansi Tabelle 4 -A, $4-B$ e 4-C), degli "indici di danneggiamento $i$ " (uno per ciascuna località), ciò̀ dei numeri atti a rappresentare l'entità complessiva dei danni in relazione alla consistenza edilizia abitativa di ogni paese.

Mediante tali coefficienti è stato possibile ordinare le località segnalate per i damni subiti, secondo un ordine decrescente, a partire da quelle ove la distruzione è stata totale $(i=1)$ fino a quelle che sono state danneggiate lievemente (v. Tab. 5). Calcolati detti indici, secondo un procedimento già adottato dal Provveditorato alle OO.PP. 
Tabella 5 - ELExco DELLE LOCALITA TERREMOTATE SECONDO I VALORI DECRESCEXTI DELL'IXDICE DI DAXXEGGIAEXTO.

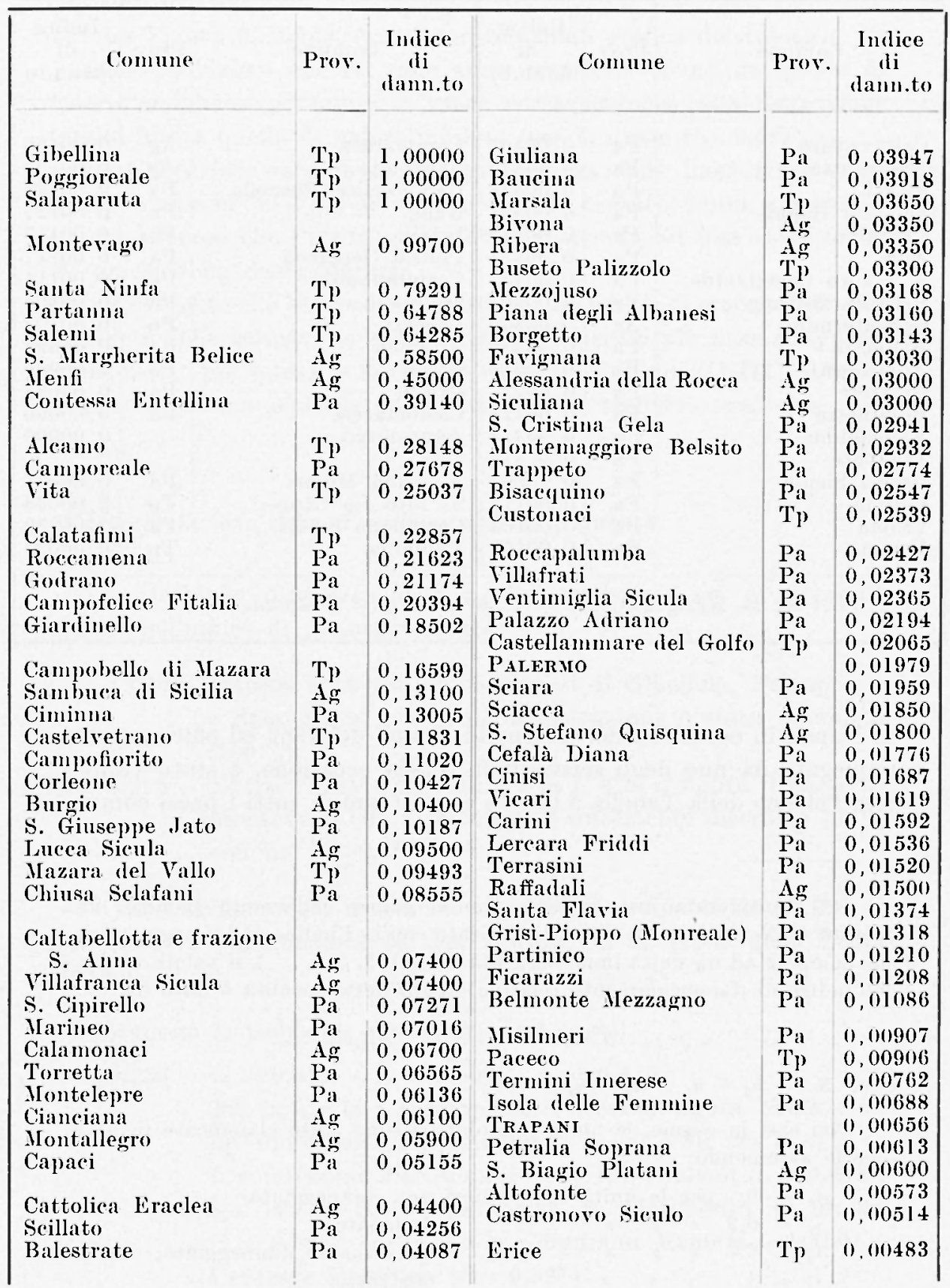


segue Tabella 5)

\begin{tabular}{|c|c|c|c|c|c|}
\hline Comune & Prov. & $\begin{array}{c}\text { Indice } \\
\text { di } \\
\text { dann.to }\end{array}$ & Comune & Prov. & $\begin{array}{c}\text { Indice } \\
\text { di } \\
\text { dann.to }\end{array}$ \\
\hline Caltavuturo & $\mathrm{Pa}$ & 0,00465 & Cammarata & $\mathrm{Ag}$ & 0,00150 \\
\hline Bolognetta & $\mathrm{Pa}$ & 0,00378 & Aragona & $\mathrm{Ag}$ & 0,00150 \\
\hline Prizzi & $\mathrm{Pa}$ & 0,00378 & Campofelice Roccella & $\mathrm{Pa}$ & 0,00138 \\
\hline Sclafani Bagni & $\mathrm{Pa}$ & 0,00351 & Gangi & $\mathrm{Pa}$ & 0,00129 \\
\hline Caccamo & $\mathrm{Pa}$ & 0,00342 & Isnello & $\mathrm{Pa}$ & 0,00117 \\
\hline Alia & $\mathrm{Pa}$ & 0,00333 & Polizzi Generosa & $\mathrm{Pa}$ & 0,00117 \\
\hline S. Mauro Castelverde & $\mathrm{Pa}$ & 0,00333 & Castelbuono & $\mathrm{Pa}$ & 0,00111 \\
\hline Petralia Sottana & $\mathrm{Pa}$ & 0,00303 & Collesano & $\mathrm{Pa}$ & 0,00105 \\
\hline Casteltermini & $\mathrm{Ag}$ & 0,00300 & Lascari & $\mathrm{Pa}$ & 0,00102 \\
\hline Bagheria & $\mathrm{Pa}$ & 0,00254 & Alimena & $\mathrm{Pa}$ & 0,00099 \\
\hline Aliminusa & $\mathrm{Pa}$ & 0,00243 & Cerda & $\mathrm{Pa}$ & 0,00096 \\
\hline Gratteri & $\mathrm{Pa}$ & 0,00237 & Cefalù & $\mathrm{Pa}$ & 0,00093 \\
\hline Bompietro & $\mathrm{Pa}$ & 0,00222 & Casteldaccia & $\mathrm{Pa}$ & 0,00090 \\
\hline Valledolmo & $\mathrm{Pa}$ & 0,00217 & AGRIGENTO & & 0,00090 \\
\hline Villabate & $\mathrm{Pa}$ & 0,00213 & & & \\
\hline Geraci Siculo & $\mathrm{Pa}$ & 0,00207 & Altavilla Milicia & $\mathrm{Pa}$ & 0,00051 \\
\hline Pollina & $\mathrm{Pa}$ & 0,00177 & S. Vito Lo Capo & $\mathrm{Tp}$ & 0,00048 \\
\hline Trabia & $\mathrm{Pa}$ & 0,00162 & Castellana Sicula & $\mathrm{Pa}$ & 0,00039 \\
\hline Ustica & $\mathrm{Pa}$ & 0,00153 & Valderice & $\mathrm{Tp}$ & 0,00024 \\
\hline
\end{tabular}

di Napoli in occasione del terremoto Irpino del 1962 ed efficacemente impiegato da uno degli scriventi in quella occasione, è stato compilato l'elenco della Tabella 5 (*). In esso i nomi di tutti i paesi comun-

(*) Considerata una località avente, prima dell'evento sismico, una totalità di $N$ unità immobiliari ed indicato con $i_{K}$ l'indice di danneggiamento che compete ad $\mathrm{n}_{K}$ unità immobiliari $(k=0,1,2,3 \ldots)$, il valore medio $i$ dell'indice di danneggiamento relativo all'anzidetta località è dato da

$$
i=\frac{i_{0} n_{0}+i_{1} n_{1}+i_{2} n_{2}+i_{3} n_{3}+\ldots}{N}
$$

dove $N=n_{0}+n_{1}+n_{2}+n_{3}+\ldots$

Nei casi in esame, le unità immobiliari sono state classificate in 4 categorie assumendo:

$$
\begin{array}{llll}
i_{0}=0 & \text { per le unità immobiliari non danneggiate; } \\
i_{1}=0,3 & \text { " " " } & \text { " } & \text { lesionate; } \\
i_{2}=0,7 \text { " " " } & \text { " } & \text { gravemente danneggiate; } \\
i_{3}=1 & \text { distrutte. }
\end{array}
$$


que danneggiati sono stati trascritti nell'ordine dato dai valori decrescenti di « $i$ ».

La Figura 6, infine, è la interpretazione grafica dei calcoli.

Le "isoblabe" che ivi sono state tracciate vanno da quella di valore massimo (per cui $i=1,000$ corrispondente alla distruzione totale) fino a quella di valore minimo (per la quale $i=0,001$ ).

La superficie racchiusa dalla più esterna delle linee tracciate è quindi quella in cui il movimento sismico ha causato danni, e pertanto si può ritenere che l'ultima isoblaba corrisponda ad una isosista del VI grado della Scala Mercalli.

E evidente che se avessimo avuto la possibilità di tracciare le reti complete delle isosiste, la zona investita dai sismi più intensi apparirebbe molto più estesa, e le isosiste di grado minimo (II-III) abbraccerebbero praticamente la quasi totalità del territorio siciliano.

c) Interpretazione della Tabella 5 e della Figura 6 .

Le isoblabe disegnate sono quelle corrispondenti ai seguenti valori dell'indice di danneggiamento:

$i_{1}=1,000$ - Questa linea racchiude i paesi di Gibellina, Poggioreale e Salaparuta, nei quali la distruzione è stata completa $(100 \%)$;

$i_{2}=0,995$ - Entro l'area compresa tra la $i_{1}$ e la $i_{2}$ figura il paese di Montevago che è stato quasi totalmente distrutto $(99 \%$ con un $i=0,997$ )

Come abbiamo già accennato dunque, la isoblaba $i_{2}=0,995 \mathrm{si}$ può ritenere paragonabile ad una isosista del $\mathrm{X}$ grado della Scala Mercalli.

Seguono le isoblabe:

$i_{3}=0,750-i_{4}=0,625-i_{5}=0,500-i_{6}=0,375$.

Tra la $i_{2}$ e la $i_{3}$ è compreso il paese di Santa Ninfa (con un indice di danneggiamento $i=0,793)$; tra la $i_{3}$ e la $i_{4}$ compaiono: Partanna $(i=0,648)$ e Salemi $(i=0,643)$; tra la $i_{4}$ e la $i_{5}$ è compresa $\mathrm{S}$. Margherita di Belice ( $i=0,585)$; tra la $i_{5}$ e la $i_{6}$ figurano Menfi $(i=0,450)$ e Contessa Entellina $(i=0,391)$. 
Si può ritenere che le prime 5 località quivi menzionate siano state investite da un sisma del IX-X grado della Scala Mercalli e Contessa Entellina da un sisma di IX grado.

Infatti Menfi, che risulta la penultima di questa graduatoria, su 5978 unità immobiliari ne ha avute 2690 tra distrutte e gravemente dannegriate e altrettante lesionate; Contessa Entellina, su 1200, ne ha avute 410 tra distrutte e gravemente dameggiate e 520 lesionate.

I)alla isoblaba $i_{0}(0,375)$ attraverso la $i$ - $(0,250)$ arriviamo alla $i_{8}(0,175)$ : i danni provocati dall'energia sismica decrescono in modo paragonabile al passaggio da un IX ad un VIII grado della Scala Mercalli.

Ja $i_{10}=0,075$ (che segue la $i_{\vartheta}=0,125$ ) si può ritenere il limite inferiore della isosista di grado VII-VIII.

Attraverso le curve $i_{11}=0,050, i_{12}=0,025, i_{13}=0,010$ vengono discriminati danni via via decrescenti, ma sempre notevoli se si tien conto che nella città di Palermo, il cui indice di damnegriamento non è tra i più elevati $(i=0,020 \mathrm{ca})$, sono state accertate 750 unità immobiliari danneggiate gravemente e ben 7500 lievemente.

İ̀ più che giustificato quindi interpretare la isoblaba $i_{13}=0,010$ come l'equivalente della isosista del VII grado; la $i_{14}=0,005$ invece come l'equivalente della isosista del VI-VII grado.

Si può ritenere che tutti i paesi che compaiono nell'elenco della Tabella 5 con un indice di danneggiamento inferiore allo 0,005 siano stati raggiunti da una energia sismica quale quella dovuta ad un VI grado della Scala Mercalli perché, pur coprendo gli ultimi posti della graduatoria, sono stati in essi accertati danni; e anche se questi sono di lieve entità, il loro accertamento costituisce elemento valido per la valutazione assegnata. Tutt'al più, agli ultimi quattro (per i quali $i$ è alquanto inferiore a 0,001 ) si può attribuire un V-VI.

Difatti, nei gradi inferiori al VI non si riscontrano generalmente danni di sorta, anche se le scosse vengono avvertite distintamente. ì per questo motivo che, come abbiamo già precedentemente accennato, qualora si volessero prendere in considerazione anche $i$ gradi più bassi della Scala Mercalli, si avrebbe una rete di isosiste che co. prirebbe quasi l'intero territorio dell'Isola.

d) Anomalie.

Osservando la rete delle isoblabe della Fig. 6, si notano alcuni elementi di apparente contrasto con quello che è l'andamento pre- 


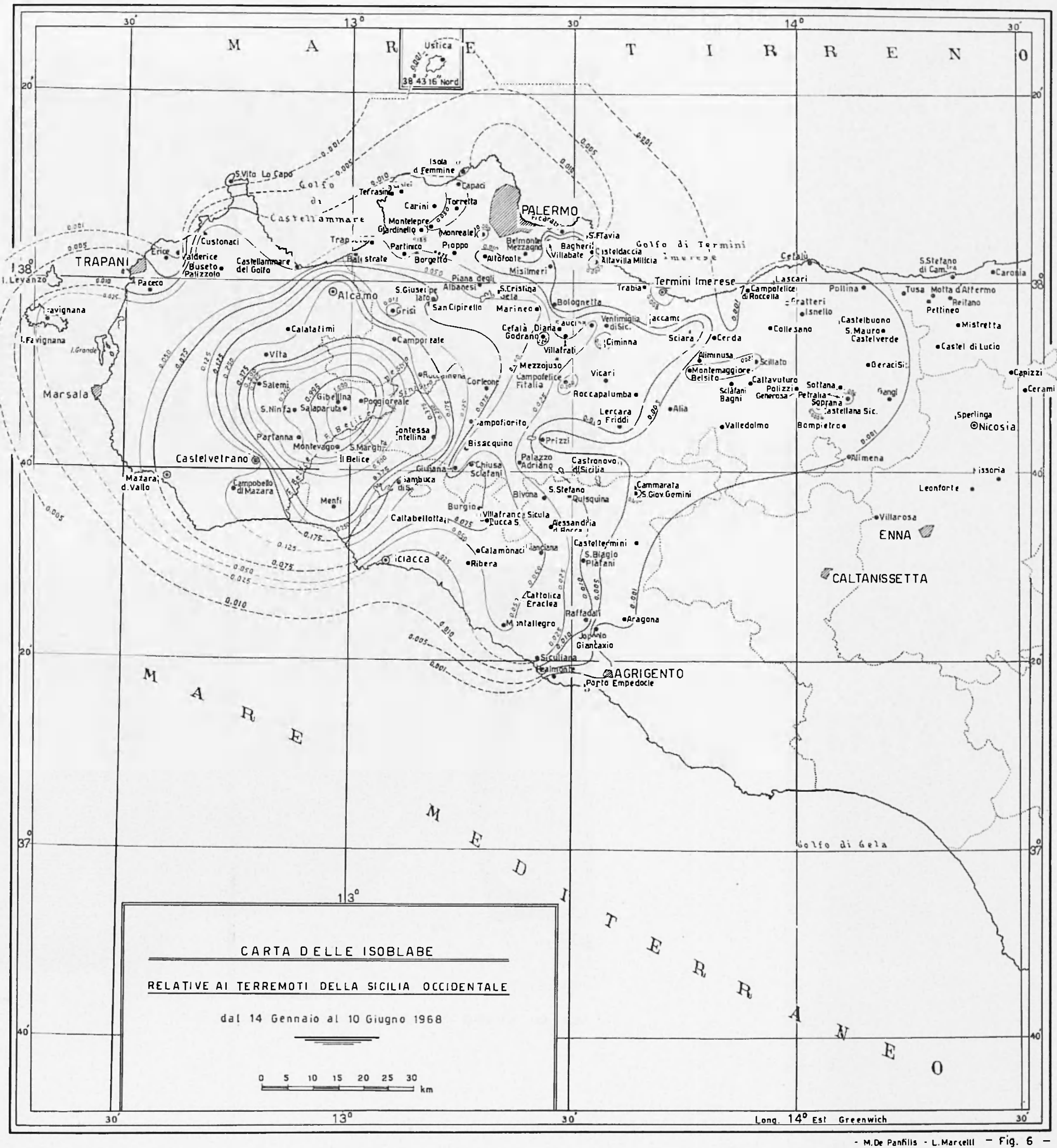

Fig. 6 


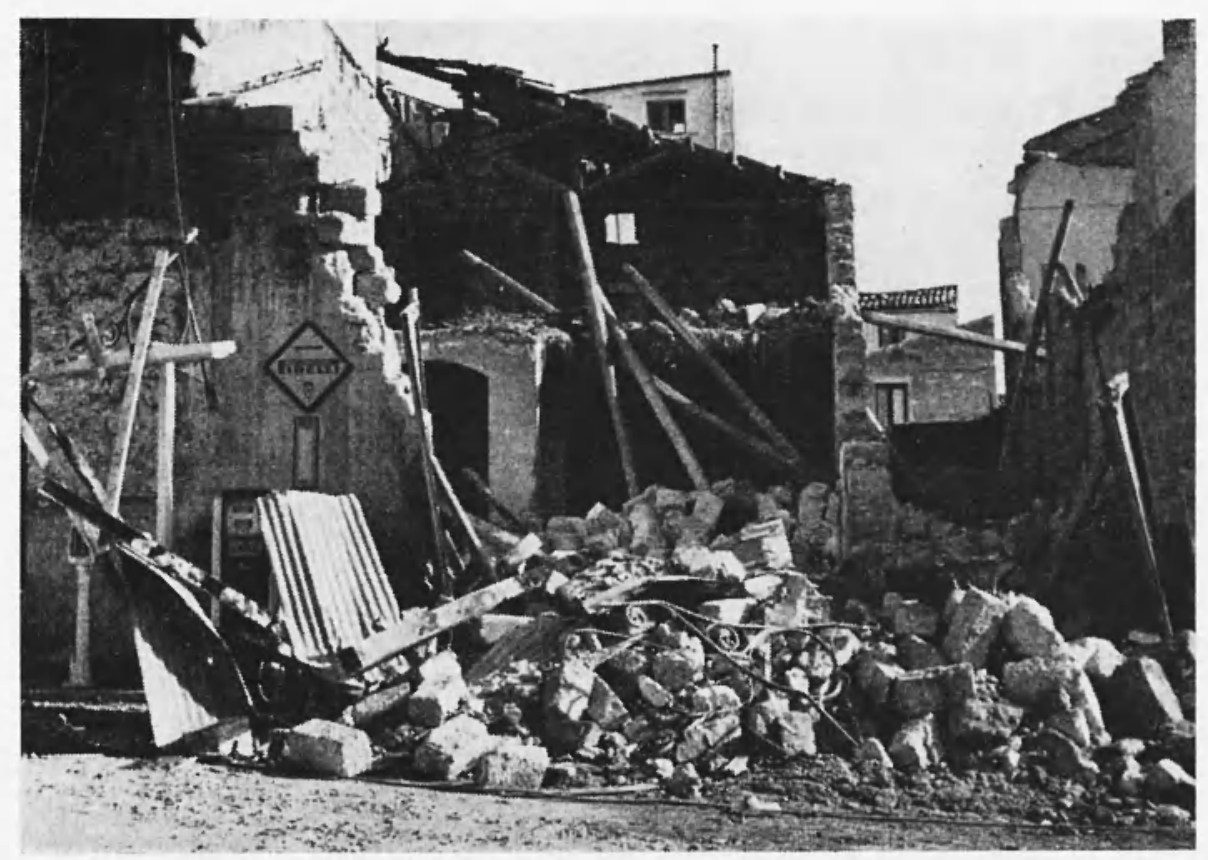

Foto 11. - Montevago - Una abitazione in muratura di blocchetti di tufo completamente crollata.

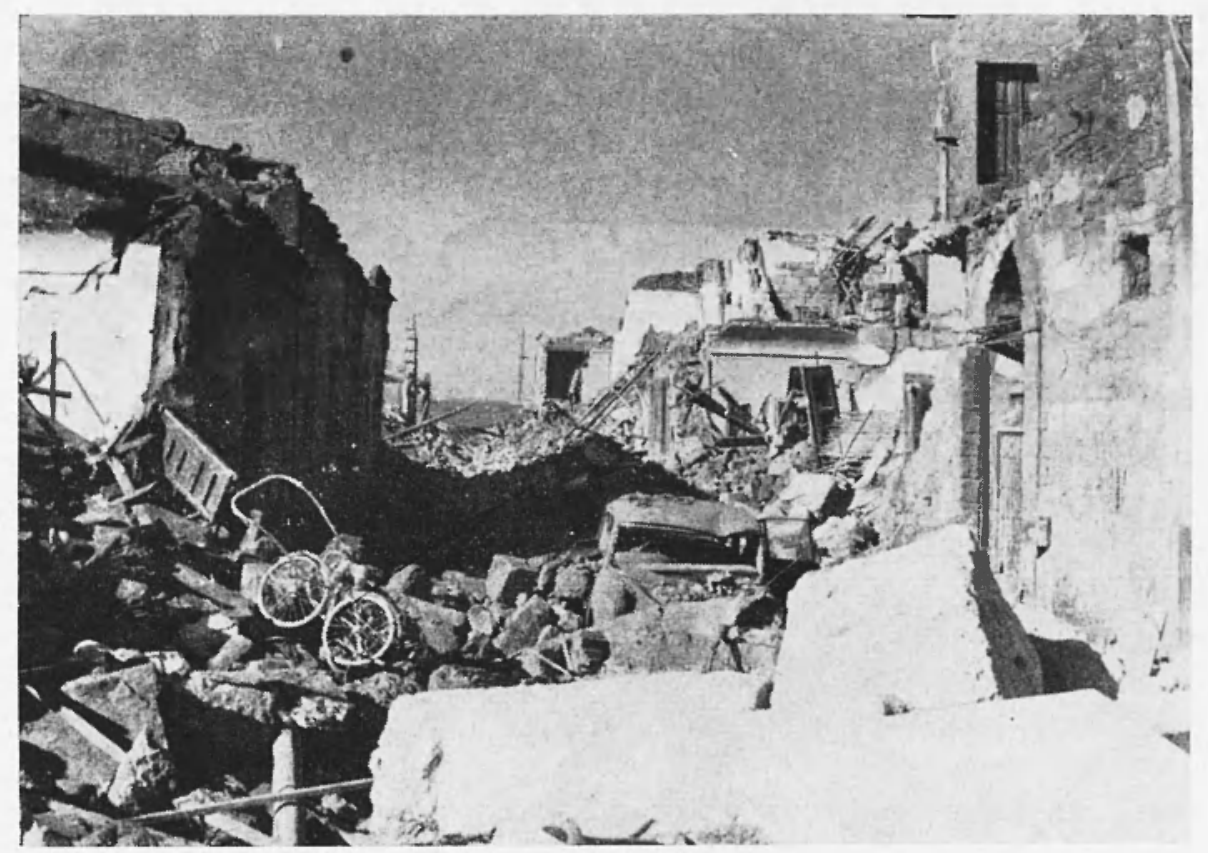

Foto 12. - Montevago - Impressionante accatastamento di macerie in una strada del paese. 
dominante delle linee tracciate. Ove ci si allontani dalla parte più gravemente colpita, per la quale è stato possibile tracciare le curve con sufficiente regolarità, si notano delle anomalie per talune località: l'indice di danneggiamento calcolato per esse non trova il giusto posto in quello che è l'andamento delle linee tracciate.

Cosi, tanto per citarne qualcuno, il paese di Godrano, cui per i danni subiti $(i=0,212)$ compete l'equivalente di almeno un VIII grado della Scala Mercalli, si trova nell'area racchiusa tra l'isoblaba. 0,050 e la 0,025 , entrambe incluse, come detto, nella isosista di grado VII. Giardinello $(i=0,185)$ e Montelepre $(i=0,061)$, vicinissimi geograficamente, sono separati l'uno dall'altro da una differenza di 0,124 nell'indice di danneggiamento; Campofelice di Fitalia $(i=0,204) \mathrm{e}$ Ciminna $(i=0,130)$ si trovano in mezzo a località meno gravemente danneggiate.

Lungo la direzione Epicentro-Palermo alcune località (come ad esempio Monreale, Belmonte Mezzagno ed Altofonte) hanno avuto, percentualmente, danni inferiori a quelli subiti da Palermo.

A cosa attribuire tali anomalie? Le spiegazioni potrebbero essere molteplici, ma tutte ipotetiche: da quelle di natura geologica, per cui le varietà dei terreni su cui poggiano questi paesi o la prossimità dei paesi stessi a linee di dislocazione potrebbero costituire elemento di differenziazione alle sollecitazioni elastiche; a quelle di natura edilizia (costruzioni eseguite con tecnica e materiali diversi); a quelle infine di natura sismica per cui alcune località potrebbero essersi trovate, in qualche momento del periodo sismico, più vicine ad epicentri secondari, periferici rispetto alla zona di massimo scuotimento.

\section{e) I capoluoghi di provincia e $i$ centri piu importanti.}

Non vogliamo chiudere questo capitolo senza dedicare alcune osservazioni particolari ai centri più importanti della Sicilia così duramente provata.

Se ci liberiamo dal concetto delle percentuali, che costituiscono come abbiamo veduto un elemento indispensabile di calcolo per un criterio uniforme ed obbiettivo di valutazione, e torniamo ai numeri pieni, il dramma vissuto dai paesi siciliani sembra riacquistare tutta la sua tragica eloquenza.

I capoluoghi di provincia non sono stati risparmiati dal sisma. Lo testimoniano i gravi danni riportati da circa 750 abitazioni di 
Palermo e quelli più lievi riportati da circa altre 7500 unità, sempre nella capitale della Sicilia, e le 17 abitazioni gravemente danneggiate nella più piccola Trapani, accompagnate da altre 426 danneggiate in misura minore. I danni riportati da circa 50 unità immobiliari di Agrigento portano percentualmente questa città agli ultimi posti della graduatoria. ì ovvio che gli edifici cosi colpiti sono stati prevalentemente quelli meno solidi, resi tali dal tempo o da cattiva costruzione; è ovvio altresi, che sulla più lontana Agrigento abbia giocato un ruolo abbastanza importante la situazione franosa del terreno, situazione che si ripete frequentemente in varie parti del territorio siculo; tuttavia è da sottolineare il fatto che nei tre capoluoghi, appunto perchó tali, l'edilizia risponde già di per sè a requisiti di una certa sicurezza; che se, ad esempio, le costruzioni di Palermo o di Trapani fossero state come quelle di Gibellina, o di Salaparuta, o di Montevago..., le cifre esposte sarebbero state destinate a salire notevolmente.

Gravissima la situazione di Castelvetrano che ha veduto 170 delle sue 8480 abitazioni crollate e 755 gravemente compromesse, mentre più di 1000 hanno subito danni più lievi; e così Alcamo, nella quale 2954 unità hanno subito gravi danni e più di 5600 danni meno gravi; nella più lontana Marsala 632 sono state le abitazioni gravemente danneggiate e 723 più lievemente; Mazara del Vallo lamenta gravi danni a 410 unità e damni più lievi a oltre 1600; anche a Sciacca, altra città costiera, circa 50 sono state le case gravemente colpite e circa 500 quelle lesionate.

Questo per accennare solo ad alcuni dei centri più densamente popolati, escludendo quelli racchiusi entro la zona di massimo scuotimento.

Chi ha vissuto questo dramma in tutta la sua tragedia perdendo persone care e beni non lo dimenticherà per tutta la vita. Purtroppo i terremoti, come tutti gli eventi naturali, non sono controllabili e l'uomo non potrà mai impedire che essi avvengano. Può però trovare la maniera di difendersi impiegando le sue capacità a servizio di una tecnica che oggi ha raggiunto in tutto il mondo e in tutti i campi vette veramente luminose. 


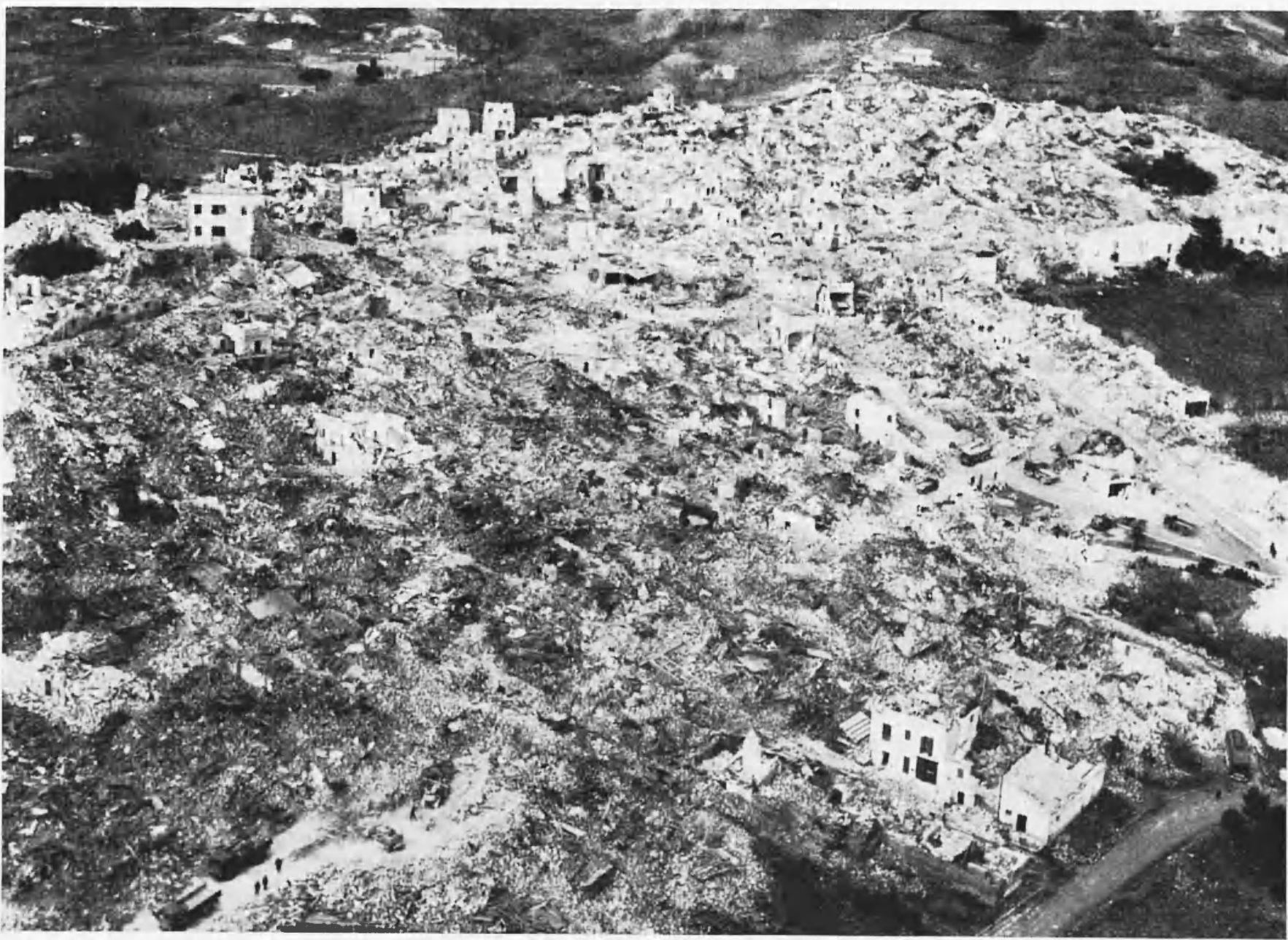

Foto 13. - Salaparuia - Veduta dall'aereo dopo le violentissime scosse sismiche: un'allucinante distesa di rovine e di case sbriciolate. 


\section{6. - Precedenti sismici Nelle localita colpite da terrearoti DEL 1968 (vedi Fig. 8).}

Remotissimi e violenti fenomeni tellurici nella sicilia evidentemente adombra la fantasiosa creazione del mito di Encelado di cui vi è traccia nelle opere di molti poeti dell'antichita, greci e latini. Era costui uno dei Giganti, esseri di struttura colossale, figli della Terra, che mossero gruerra a Giove e tentarono la scalata all'Olimpo. Ma vennero debellati ed Ence. lado, atterrato dal fulmine di Giove, restò sepolto sot to la Sicilia con il capo schiacciato sotto la mole dell'Etna. Quando, nel tentativo disperato di alleviare l'enorme peso, il Gigante, shuffando, tentava di svincolarsi e di mutar posizione, l'Etna emetteva fiamme e vapori ed intense vibrazioni scuotevano il suolo della Sicilia. Cosi Virgilio, nel III libro dell Eneide (vv. 578-582):
Fama est Énceladi semustum fulmine corpus urgeri mole hac ingentemque insuper Aetnam impositam ruptis flammam expirare caminis, et jessum quotiens mutet latus, intremere omnem murmure Trinacriam et caelum subtexere fumo.

Premesse. - Poiché ogni fenomeno sismico difficilmente rappresenta. un episodio isolato nel tempo, ma si collega quasi sempre a fenomeni analoghi di maggiore o minore intensità verificatisi nel passato, in epoche più o meno remote, riteniamo utile far seguire allo studio fin qui svolto una sintetica esposizione di notizie macrosismiche su terremoti che hanno già colpito alcune località interessate dai recenti avvenimenti.

Chi esamini le carte geologiche della Sicilia compilate da E. Beneo si forma facilmente una chiara idea della tettonica dell'Isola e può da essa trarre elementi utili per una spiegazione dell'intensa attività sismica che fin dai secoli più lontani, ad intervalli di tempo più o meno lunghi, ha sconvolto, e più volte in modo catastrofico, il territorio siciliano: fasci, o sistemi, di faglie lo solcano secondo determinate direzioni scomponendolo in un gran numero di zolle tettoniche di diversa estensione. Un primo sistema, il più importante forse, ha una direzione prevalente est-ovest ed interessa la magrior parte della Sicilia occidentale; alcune delle linee di dislocazione che lo compongono attraversano la Valle del Fiume Belice passando non lontano dalla zona disastrosamente colpita dai terremoti del 1968. Un altro sistema ha una direzione all'incirca SO-NE, quasi parallela alla direttrice Sciacca-Palazzo Adriano-Termini Imerese. Un terzo fascio is quello formato dalle diverse faglie che, con andamento approssimati- 
vamente N-S, interessano i monti che orlano i golfi di Castellammare, Carini, Palermo, Termini Imerese e, più a sud, la parte orientale dei Honti Sicani.

Altre linee di dislocazione lambiscono le coste orientali della Sicilia e fra esse, importantissima, quella che attraversa lo stretto di Messina prolungandosi poi entro il territorio della Calabria.

Si può presumere che le arcennate condizioni strutturali del territorio siciliano e la possibilità di bruschi movimenti relativi di due o più compartimenti del grande mosaico tettonico quando, sotto l'azione di enormi pressioni subcrostali, venga superata la resistenza opposta dagli attriti o dagli stessi materiali rocciosi, possano spiegare almeno fino a un certo punto, l'origine dei grandi terremoti che più volte hanno portato la distruzione su estese zone della Sicilia e dare ragione altresi delle apparentemente anomale propagazioni macrosismiche manifestatesi qualche volta in superficie. A questo riguardo nell'anamnesi sismologica che tenteremo qui di fare per una gran parte delle località colpite dai terremoti del 1968, avremo occasione di ricordare qualche caso particolarmente importante.

a) Le manifestazioni sismiche rella Valle del Belice. - Se si consulta la carta sismica d'Italia pubblicata da M. Baratta nel 1934, nella quale l'Autore riassunse le accuratissime indagini macrosismi(he cui con passione dedicò molti anni della sua vita, si nota - a tutta prima con sorpresa, dopo i recenti avvenimenti - che la Valle del Belice, eccetto ma piccola parte di essa in prossimità di Corleone che ì valutata di sismicità mediocre, viene considerata praticamente come asismica.

L'individuazione delle aree sismiche d'Italia e la valutazione del loro grudo di sismicitì erano state fatte dal Baratta con un criterio quasi esclusivamente storico e ciò in base alla frequenza e all'intensità dei terremoti verificatisi, nelle singole zone, nei secoli passati e durante il primo trentennio di questo secolo. L'indicazione di asismicità - sulla carta sismica predetta - della zona compresa nel quadrilatero Gibellina, Poggioreale, S. Margherita di Belice, Montevago deriva dal fatto che per essa, fino al 1934, non risultavano notizie di movimenti sismici corocentrici e non risultava nemmeno che essa fosse stata colpita fortemente da terremoti esocentrici.

A. Mongitore, nella sua "Istoria cronologica dei terremoti di Sicilia ", edita nel 1743 , dà notizia di un terremoto sentito il 28 Maggio 1727 a Palermo, Partanna, S. Ninfa, S. Margherita di Belice, Villa- 


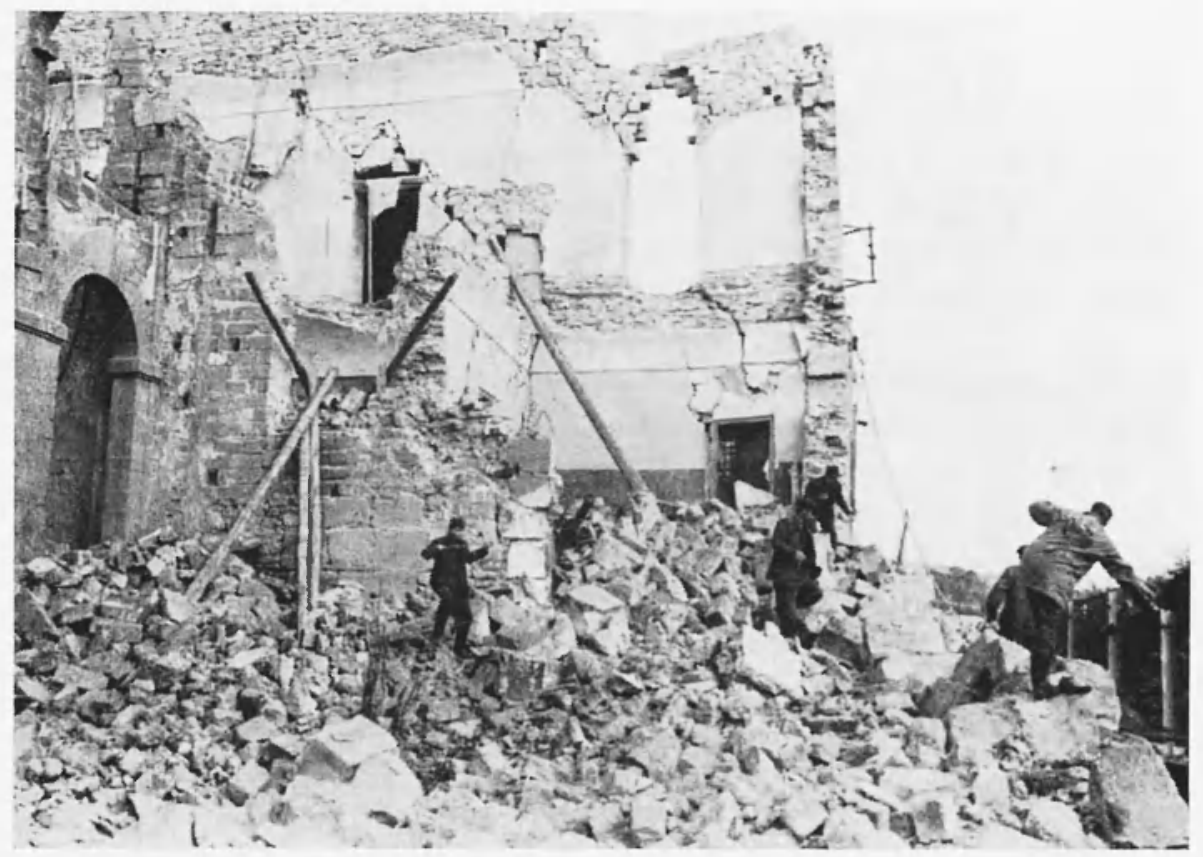

Foto 14. - Salaparuta - T'n edificio in muratura di blocchi di tufo distrutto lal terremoto.

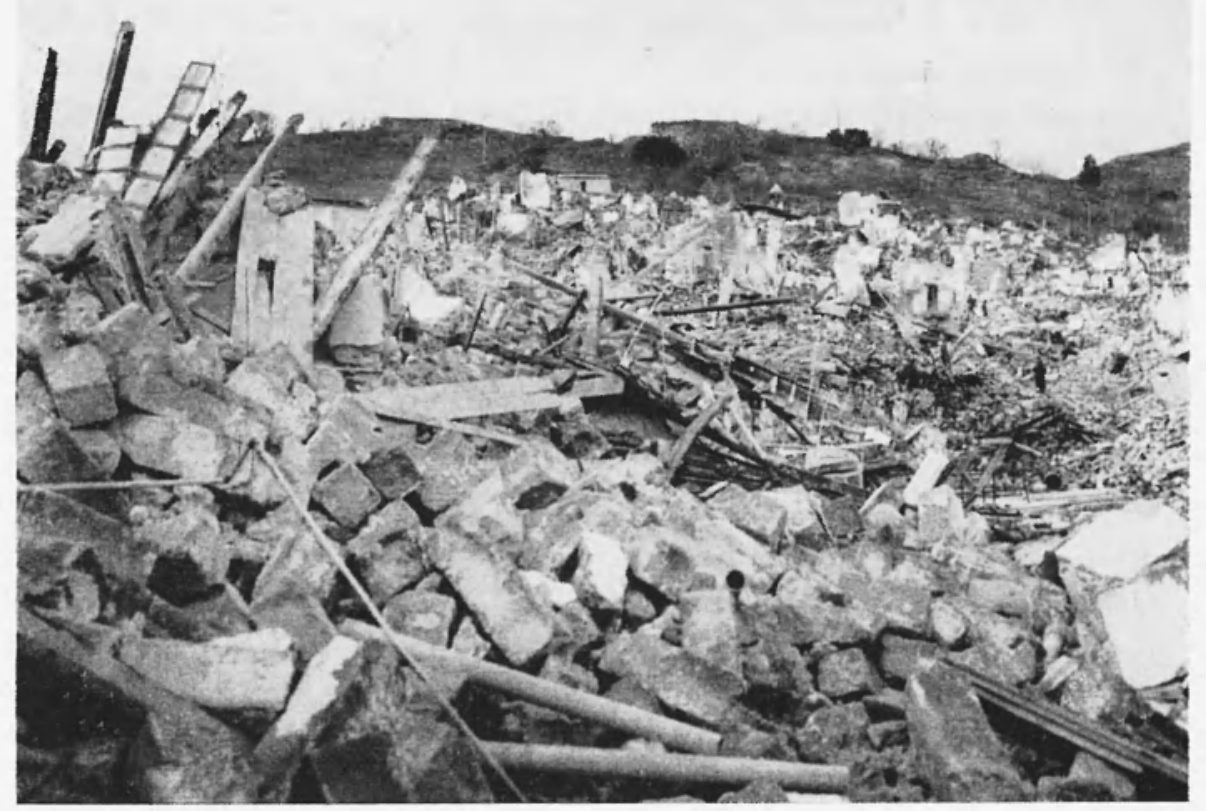

Foto 15. - Salaparuta - Un altra delle apocalittiche scene che si ripetono fre. quenti nei paesi della zona epicentrale e che danno un'idea della gravita del disastro. 
franca Sicula e Agrigento, ma non è possibile da essa dedurre quale sia stata la zona epicentrale; solo si può aggiungere che detto terremoto avvenne quando da poco s'era iniziato un lungo ed intenso periodo sismico che culminò il 9 Agosto 1727 con una scossa di VII grado almeno e ch'ebbe il suo epicentro probabilmente a mare, nei pressi di Sciacca.

M. Baratta poi, nella sua opera "I terremoti d'Italia " (1901), da cui attingiamo gran parte delle notizie che qui riferiamo, ricorda un terremoto con epicentro in prossimità di Salemi avvenuto il 19 Iaggrio 1891 e che venne avvertito, fra altre località, anche a Gibellina: ma si trattó di un fenomeno di entità assai modesta, che non recò alcun danno nei luoghi ove venne sentito.

Molto probabilmente nella Valle del Belice dovettero essere avvertite, ma senza notevoli conseguenze, alcune scosse irragcriate dalle zone di Corleone e di Sciacca, assai vicine a quella maggiormente colpita dai terremoti del 1968 e note, specialmente la seconda, come zone di sismicità alquanto elevata.

Dal centro sismico di Corleone ebbero origine: un terremoto rovinoso nell'Aprile 1593; alcune forti scosse verificatesi dal 18 al 22 Aprile 1845; un lungo, molto intenso, periodo sismico che s'iniziò verso la fine di Aprile 1876 e si protrasse fino al successivo mese di dicembre. Le scosse più intense del periodo (25 Maggio e 10 Giugno) raggiunsero il VII grado almeno a Corleone e furono sentite a Bisacquino, Campofiorito, Roccamena, Piana degli Albanesi, Marineo, Mezzoiuso, Prizzi e Palazzo Adriano.

Molto numerose, e talune di notevole intensità, le manifestazioni sismiche attribuibili a un ipocentro sottomarino situato in prossimità di Sciacca. Una gran parte di esse - ad esempio quelle, anche le più intense (VII grado), del già citato periodo sismico del 1727 che dal Naggio si prolungò fino all'Ottobre - furono di carattere strettamente locale; altre però ebbero propagazione più vasta e arrecarono qualche danno anche in localita alquanto distanti da Sciacca. Ricordiamo, fra queste ultime, la scossa rovinosa (VIII grado) avvenuta il 13 Giugno 1740, massima di un breve ma molto intenso periodo sismico, la quale fece danni a Mazara del Vallo e fu sentita anche a Palermo.

Notevole fu anche una serie di scosse avvenute fra la fine di Dirembre 1816 e il 23 Gennaio 1817 . Una delle più intense (14 Gennaio, VI grado) fu sentita anche a Menfi e apportò qualche danno a Sambuca di Sicilia. 
Infine, fra le manifestazioni del centro sismico di Sciacca avvenute durante questo secolo, dobbiamo qui segnalare un terremoto molto forte (VI grado) del 26 Febbraio 1933. Esso fu preceduto da due scosse di minore intensità e venne sentito di $\mathrm{V}$ grado a Sambuca di Sicilia, a Caltabellotta e a Ribera, di IV a Montallegro e Villafranca Sicula, di III a Calamonaci e a Menfi.

Solo recentemente, a quanto sappiamo, prima del 1968, si è avuto nella Valle del Belice uno scuotimento sismico corocentrico, d'intensità non elevata, ma che oggi alla luce degli ultimi avvenimenti, acquista una certa importanza. Si tratta del sisma avvenuto l'11 Maggio 1957, che ebbe il suo epicentro nei pressi di S. Margherita di Belice e che raggriunse la sua maggiore intensità ( $V$ grado) in detto paese e a Sambuca di Sicilia. Ia scossa fu accompagnata da un forte boato ed ebbe una propagazione assai limitata: fu sentita di IV grado a Caltabellotta, di III-IV a Sciacca, di III a Menfi, Montevago e Salaparuta e soltanto di II a Gibellina.

Pochi anni prima, il 20 Novembre 1954, era stata avvertita in alcuni paesi della Vallata del Belice, con intensità ove mediocre ove leggera, un'altra scossa di terremoto, il cui epicentro però fu individuato nei pressi di Grisi (frazione del Comune di Monreale); ma di questo notevole sisma daremo più avanti maggiori particolari.

I sismi che abbiamo fin qui ricordato, ove si eccettui quello dell'I1 Maggio 1957, interessante per la posizione del suo epicentro più che per la sua intensità, non assunsero mai, come s'è detto, un particolare rilievo nella Valle del Belice; nè d'altra parte ve l'assunsero, almeno in tempi storici, i forti terremoti generati da ipocentri lontani. Questa relativa tranquillità sismica ingenerò purtroppo nelle popolazioni la opinione che tale zona potesse considerarsi immune da forti movimenti tellurici. E i paesi sorsero e si estesero nel passato senza nessun riguardo alle norme di una buona tecnica costruttiva. I'incuria degli uomini, allo scatenarsi improvviso dell'energia che s'era andata lentamente accumulando nei secoli, doveva cosi trasformare in una catastrofe un evento che, ove si fosse abbattuto su centri abitati costruiti razionalmente, con materiali idonei e con qualche precauzione antisismica, avrebbe certamente avuto conseguenze incomparabilmente meno gravi.

b) I terremoti di Grisi del 1954-56. - Grisì è un paesino situato nel territorio del Comune di Monreale e dista, in linea d'aria, circa 


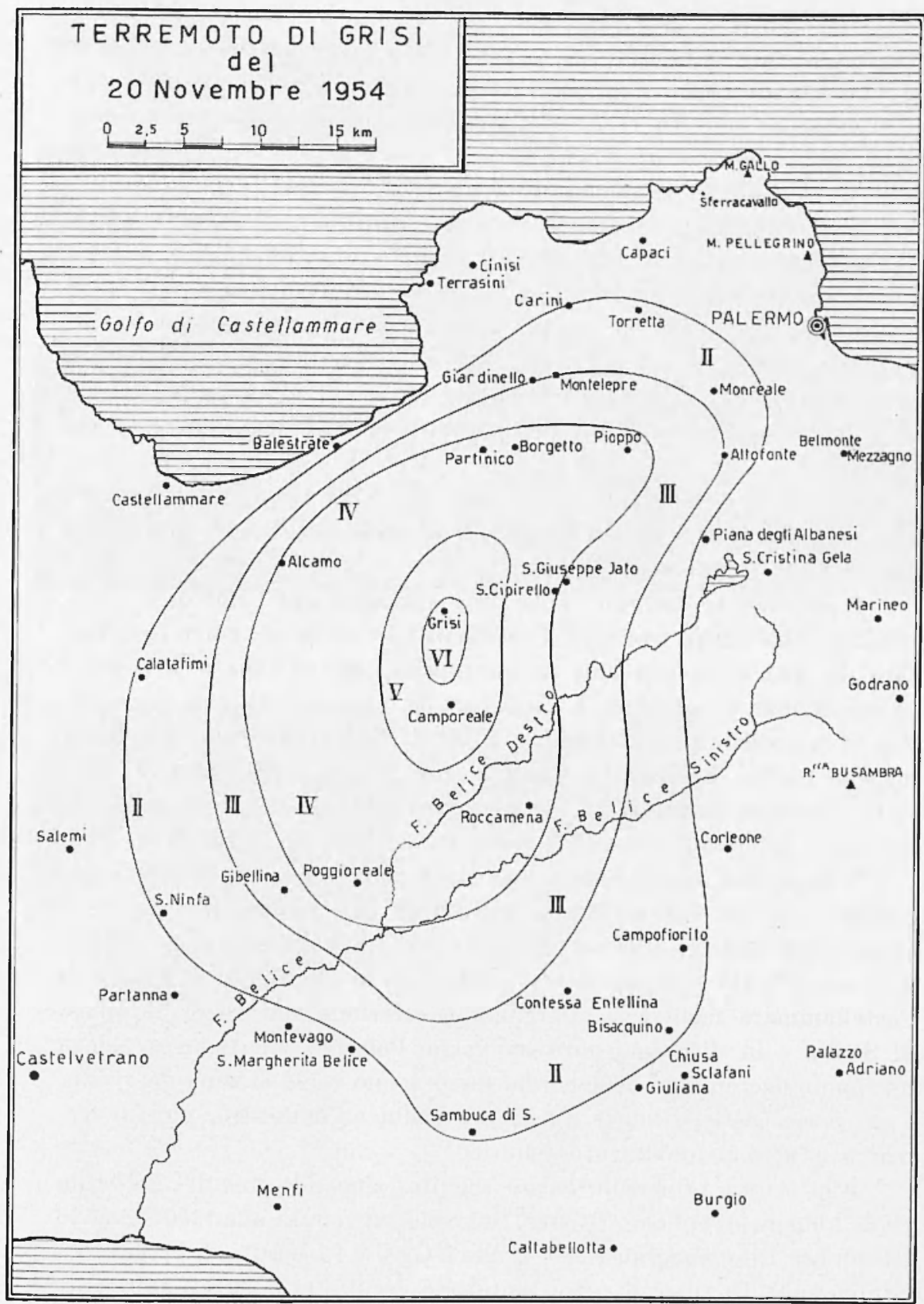


venticinque chilometri dal centro della zona magriormente devastata dai recenti terremoti, dai quali esso è stato molto fortemente colpito.

La zona di Grisi è comparsa nella storia sismica della Sicilia solo recentemente: nel Novembre 1954 infatti, per la prima volta, essa risulta essere stata sede di una serie di scosse telluriche corocentriche delle quali, data la vicinanza di detta zona all'area megasismica dei terremoti del 1968, puó essere interessante dare qui qualche particolare.

Il periodo sismico ebbe inizio il 18 Novembre 1954 con una lieve scossa premonitoria avvertita soltanto dagli abitanti di Grisi. Il 20 Novembre, alle $06^{\mathrm{n}} 35^{\mathrm{m}} 06^{\mathrm{s}}$, si verifico la scossa principale che a Grisi e negri immediati dintorni spiegò la sua maggiore intensità (VI grado), causando numerose ma leggere fenditure in case di recente costruzione, notevoli in case vecchie e poveramente costruite, gravi in case già fatiscenti.

Nel paese di Camporeale, distante da Grisì circa sei chilometri, la scossa risultò di $\mathrm{V}$ grado e provocò soltanto lievi lesioni in qualche casa antica e malamente costruita.

Il movimento tellurico ebbe una propagazione piuttosto limitata: la zona infatti ove esso si rese sensibile all'uomo, come fu accertato da uno degli scriventi in un sopralluogo effettuato nei primi grorni di marzo del 1955, è racchiusa da una isosista che passa (v. Fig. T) in prossimità di Calatatimi, S. Ninfa, S. Margherita Belice, Sambuca di Sicilia, Bisacquino, Campofiorito, Piana degli Albanesi, Torretta, Carini e Balestrate. Ia scossa pertanto, sia pure con modesta intensità, interessò una buona parte della Vallata del Belice.

L'epicentro macrosismico può essere ubicato nel punto di coordinate $37^{\circ} 56^{\prime} \mathrm{N}$ e $13^{\circ} 06^{\prime} \mathrm{E}$, ciò fra Grisì e Camporeale, ma più prossimo alla prima che alla seconda località. L'andamento delle isosiste di grado IV, III e II, le quali si addensano in prossimità del Golfo di Castellammare mentre si allargano in direzione sud verso Sambuca di Sicilia e in direzione nord-est verso Palermo, mette in evidenza un rapido decremento dell'energia sismica solo verso la zona del Golfo, i cui paesi costieri, anche quelli piu vicini all'epicentro, non avvertirono afratto il movimento tellurico.

Alla scossa principale fecero segruito, sino alla tine del Febbraio 1955 , numerose repliche. Di esse, una sola, avvenuta alle $11^{\mathrm{h}} 0 \mathrm{~T}^{\mathrm{m}}$ del 25 Novembre 1954, raggiunse il V grado a Grisi e fu sentita di IV grado a Camporeale. In tutte le altre l'intensità oscillò fra il II e il IV grado.

Dopo circa un anno dal predetto periodo sismico, il 15 Gennaio 1956 alle $20^{\mathrm{h}} 19^{\mathrm{m}}$, un altro terremoto, di $\mathrm{V}$ grado e di carattere stret- 


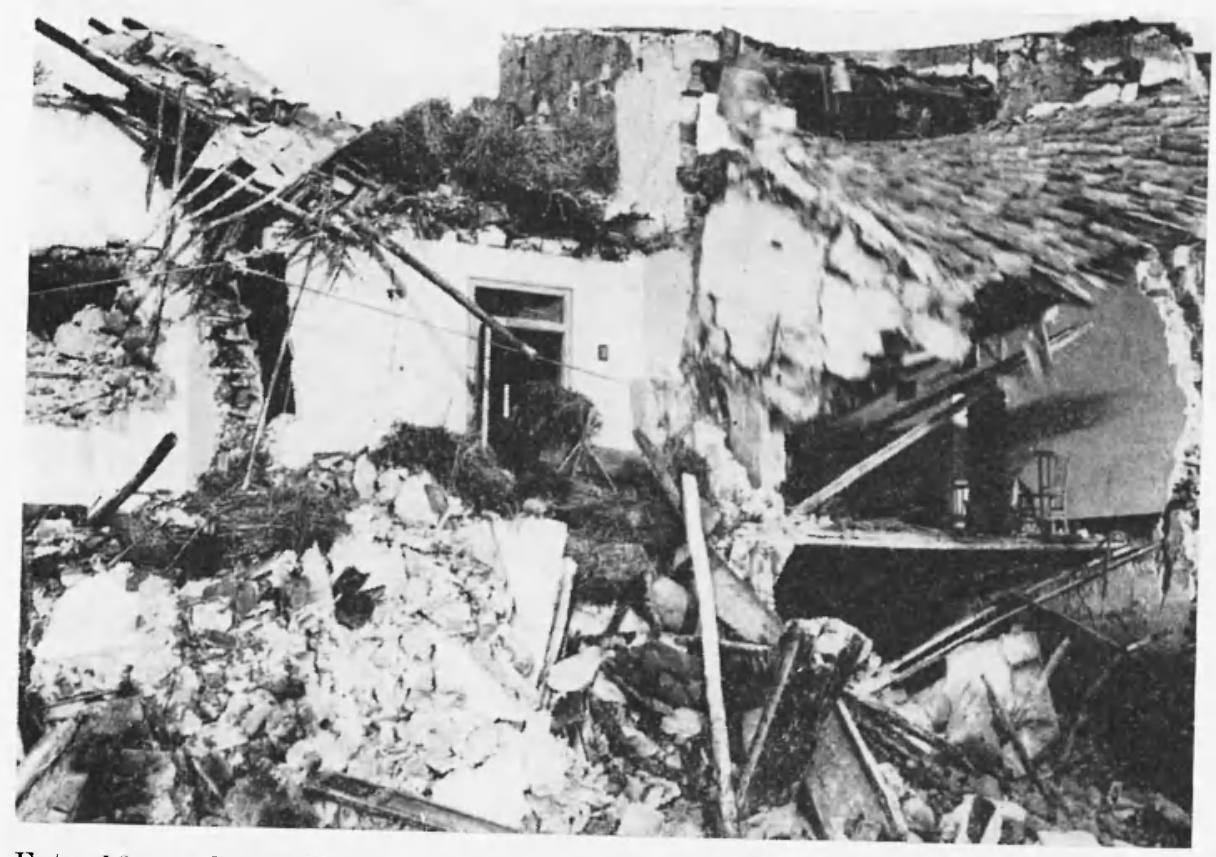

Foto 16. - Santa Ninja - La poverta dei materiali usati ha reso disastrosi in molt casi gli efietti del sisma.

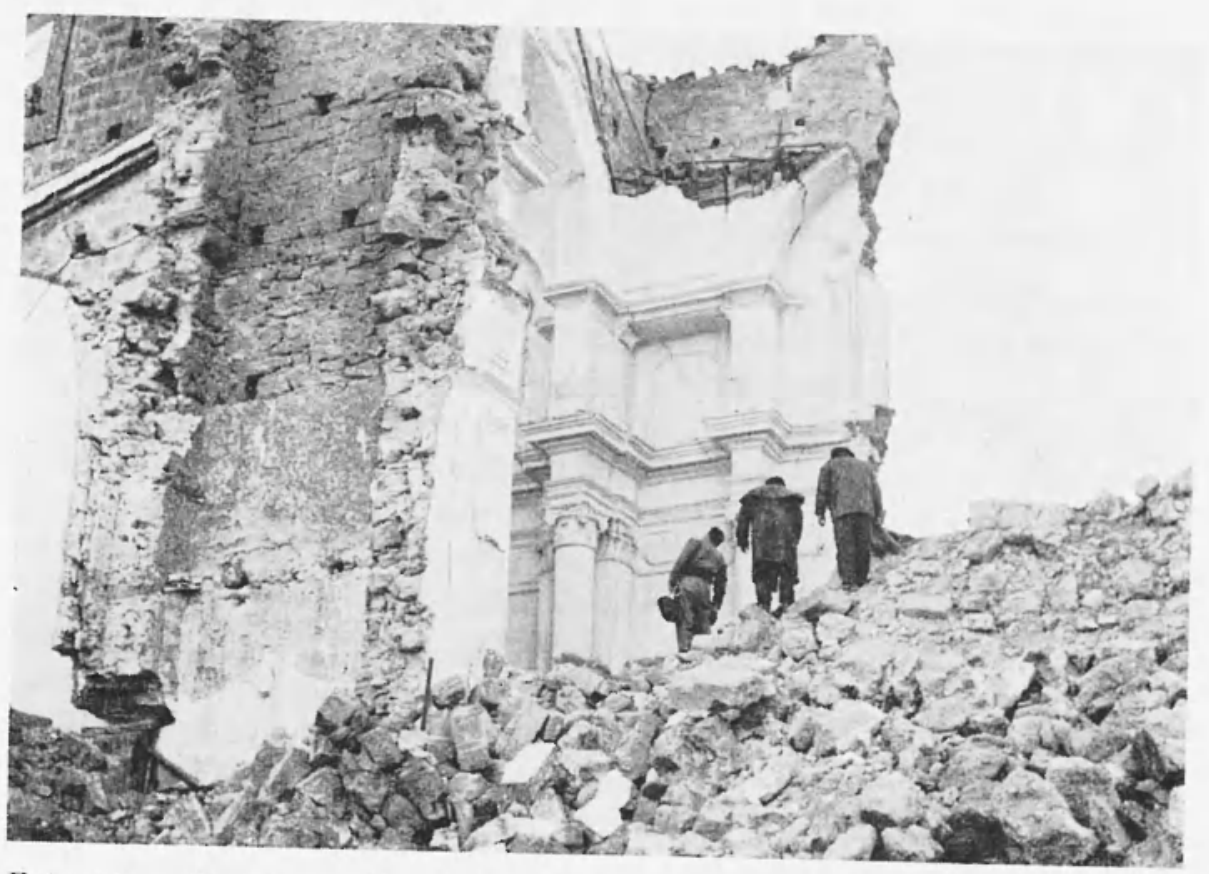

Foto 17. - Partanna - Una bella chiesa quasi completamente crollata sotto i violentissimi urti delle onde sismiche. 
tamente locale, venne avvertito nel territorio di Grisi. Seguirono per qualche giorno alcune repliche, ma tutte lievissime.

c) La sismicità del Palermitano. - Già nella carta sismica del Baratta l'areuata zona costiera in cui sorge Palermo viene indicata come grandemente instabile ed è classificata di sismicità intensissima. I a ragione di una siflatta valutazione risiede nel gran numero di terremoti, nella maggioranza di modesta intensita, ma spesso fortissimi e talora rovinosi, che hamo interessato la citta di Palermo fin dai secoli lontani e per molti dei quali si hanno sicure e particolareggiate notizie. Qui ci intratterremo un pò ampiamente su quelli di maggriore importanza e accenneremo soltanto ad altri di minore entità.

Lungo la fascia costiera settentrionale della Sicilia esistono numerose aree sismiche messe chiaramente in luce da forti terremoti, anche recenti. Esse formano un allineamento che s'inizia ad est con una zona di sismicita intensa racchiudente Milazzo, Barcellona Pozzo di Gotto e Castroreale. A questa, procedendo verso ovest, fanno seguito una zona costiera di sismicità elevatissima intorno al paese di Naso e la regione intensamente sismica del gruppo montuoso delle Madonie con i paesi di Castelbuono, Isnello, S. Mauro Castelverde, Gangi e le due Petralie; poi seguono la zona sismica comprendente Trabia, Termini Imerese e Ciminna, quella di Misilmeri e infine, a quest'ultima contigua, la zona di Palermo.

Ad ovest di Palermo, nella zona costiera che si estende lungo il Golfo di Castellammare, la sismicità diviene molto più bassa, ma torna ad essere intensa nella città di Trapani e nel territorio circostante.

Veniamo ora, in particolare, a considerare la zona di Palermo.

Già il tremendo terremoto dell'11 Gennaio 1693, immane catastrofe che distrusse totalmente o quasi un gran numero di paesi e fiorenti città della Sicilia sud-orientale, fra cui Catania, ove 16.000 persone, su una popolazione di 24.000 abitanti, perirono sotto le macerie, e Siracusa, ove il sisma mieté 4.000 vite su una popolazione di circa 15.000 abitanti, fa pensare ad un centro di scuotimento situato nei pressi della città di Palermo: in questa città infatti la scossa riusci molto violenta e lesionò più o meno gravemente la maggior parte delle case, mentre molte altre località più vicine alla zona epicentrale, come per esempio Agrigento e Caltanissetta, rimasero del tutto indenni. Si ebbe dunque nel Palermitano una recrudescenza degli effetti dinamici del movimento sismico: la qual cosa, oltre che con particolari condizioni geologiche locali e con particolari caratteristiche del 
sottosuolo della città (*), potrebbe spiegarsi con la contemporanea, o quasi, entrata in attività di un ipocentro situato nei pressi di Palermo.

Ma l'esistenza di un centro sismico, probabilmente sottomarino e non nolto lontano dalla costa palemitana, è comprovata dal terremoto del $1^{\circ}$ Settembre 1726 . Esso risulto disastroso nella sola citta di Palermo ed ebbe l'epicentro a mare, come si può desumere dall'andamento delle isosiste e dal fatto che le acque marine, al momento della scossa, si ritirarono ampiamente dal lido.

I'urto delle onde sismiche fu violentissimo e ne vennero devastati molti quartieri della citta, specialmente quelli fondati su terreni poco coerenti o di riporto. Inolte arse arollarono e moltissime rimasero gravemente danneggiate; 250 furono i morti e 151 i feriti. Lna partionlaregrata descrizione della distribuzione dei damni nei vari quartieri della città è stata data da $\Lambda$. Mongitore, dianzi citato.

Un altro terremoto rovinoso per Palermo, e assai importante perche mette in evidenza il colleganento sismico fra le varie aree instabili, precedentemente elencate, della costa settentrionale della Sicilia e la loro tendenza ad entrare in vibrazione quando vi gimgano onde sismiche da centri anche lontani, fu quello del 5 Marzo 1823, che ebbe epicentro in mare fra Capo d'Orlando e Capo Galava.

Nel paese di Naso, in provincia di Messina, la scossa fu disastrosa (X grado). Rimase distrutto un gran numero di case, chiese ed edifici di altro genere. Se solo pochissime furono le vittime, cio fu dovuto al fatto che alcune forti scosse premonitorie avevano indotto gli abitanti ad abbandonare in massa le case e a fuggire nelle campagne circostanti. Il movinento sismico investi con varia intensita tutta la costa settentrionale della Sicilia, dal Capo Rasocolmo alla Punta del Saraceno, na fu proprio Palermo rhe, dopo Naso, nonostante la notevole distanza fra le due localita (oltre $120 \mathrm{~km}$ ), ebbe a soffrire i più gravi damni, i quali, fu notato, si verificarono in maggior misura in quelle parti della città ch'erano state più colpite dal terremoto del 1726. Anche questo sisma fu a Palermo anusa di lutti: si ebbero 19 morti e 25 furono i feriti.

Danni gravi si verificarono a Patti, in provincia di Messina, e con intensità più o meno elevata, ma sempre notevole, vennero col-

(*) Vedi in proposito la recente publicazione di G. B. Floridia citata nella Bibliogratia. 
pite numerose località della provincia di Palermo: Alimena, Altavilla Milicia, Caltavuturo, Castelbuono, Cefalu, Cerda, Ciminna, Collesano, Geraci Siculo, Godrano, Gratteri, Isnello, Jascari, Montemaggiore Belsito, Pollina, Roccapalumba, S. Mauro Castelverde, Scillato, Termini Imerese e Trabia.

Nei mesi successivi, fino all'Agosto 1823, si ebbero molte scosse lungo la fascia settentrionale della Sicilia, ma esse più che repliche del grande terremoto del 5 Marzo furono movimenti tellurici dovuti al risveglio di altri centri sismici. 11 terremoto del 5 Marzo fu invece causato dall'entrata in azione del focolare di Naso e, molto probabilmente, dal risveglio quasi contemporaneo di quello di Palermo.

Il Baratta non esita ad attribuire a quest'ultimo numerosi terremoti dei secoli passati, ricordati per Palermo da storici e cronisti; per esempio: un terremoto violento del 21 Settembre 1571 , varie scosse del Gennaio e Febbraio del 1661, un terremoto molto forte del 18 Gingno 1686 , un altro del $1^{\circ} \mathrm{Ag}$ gosto 1732 ; inoltre due forti scosse dell' $\mathrm{Ago}$ sto 1751 che arrecarono damni alle case.

Dal 1823 al 1940, varie volte furono avvertite a Palermo delle scosse telluriche, ma si trattò di fenomeni di modesta importanza per la città, provenienti da centri più o meno lontani, che causarono soltanto un certo allarme nella popolazione. Alcuni di essi (per esempio quelli dell'11 Naggio 1893, 15 Maggio 1897 e 20 Dicembre 1928) ebbero origine da ipocentri tirrenici di ubicazione non ben determinata e colpirono con intensita quasi uguale (IV-V grado) la costa nord-oceidentale della Sicilia e l'isola di Ustica. Altri, come quelli del 29 Dicembre 1908 e 25 Gennaio 1910, di VI grado ad Ustica ove causarono anche danni agli edifici e nelle cui vicinanze fu probabilmente l'epicentro, vennero sentiti a Palermo, che da Ustica dista $57 \mathrm{~km}$, con un'intensità di IV-V grado. Il terremoto ealabro del 16 Novembre 1891 e quello calabro-siculo del 28 Dicembre 1908 , che ebbero i rispettivi epicentri ad una distanza di oltre $200 \mathrm{~km}$ da Palermo, furono ivi avvertiti, il primo di III e il secondo di IV-V grado.

Ia sorvoliamo su questi movimenti sismici, di scarso rilievo per la città di Palermo, per venire al recente terremoto del 15 Gennaio 1940 .

Come si è accennato precedentemente, ad est della zona sismica di Palermo e ad essa contigua si estende l'area sismicamente instabile di Misilmeri. Nei pressi di questa cittadina, che dista una dozzina di km da Palermo, esiste un centro di scuotimento già noto per due scosse di VI grado e di carattere locale avvenute l'8 Dicembre 1843, 
ma la cui attività poteva essere considerata, fino a non molto tempo fa, come alquanto dimessa e quindi d'importanza secondaria. Con il terremoto del 15 Gennaio 1940 però detto centro ha avuto un pauroso risveglio ed ha improvvisamente assunto, nella storia sismica del Palermitano, in notevole rilievo.

Alle $14^{\mathrm{h}} 19^{\mathrm{m}}$ circa del giorno predetto, senza essere preceduta da alcun sensibile fenomeno premonitorio, una forte scossa di terremoto accompagnata da un fortissimo rombo si abbatté improvvisamente su Palermo. Tutta la popolazione, atterrita, abbandonò in massa le case riversandosi all'aperto e numerosi feriti si ebbero a lamentare negli episodi di panico conseguenti alla fuga precipitosa dalle case e dai vari locali pubblici. Qualche ora dopo l'evento sismico una grande folla si radunava nella Villa Bonanno e l'Arcivescovo, dal balcone della sua sede, impartiva la benedizione alla moltitudine.

Notevoli furono i danni cagionati dal sisma nella città. In piazza S. Anna precipitò il fastigio della facciata della bella chiesa secentesca ferendo gravemente tre persone. A Porta Nuova, il crollo del cornicione di un fabbricato causò la morte di un carabiniere e gravi ferite ad una ragazza. Cadde in parte la volta del transetto della Chiesa di S. Nicolò da Tolentino; serie lesioni si verificarono nel Palazzo Arcivescovile, nella cupola della Chiesa di S. Giuseppe e in diversi altri edifici pubblici di antica costruzione. Diverse centinaia di vecchi fabbricati rimasero più o meno gravemente danneggiati e molti furono quelli che, per cautela, dovettero essere sgomberati dagli abitanti.

I danni alle persone, relativamente, non furono molti: un morto ed una cinquantina di feriti, di cui alcuni però gravemente.

Dal complesso dei danni riportati dagli edifici, tenendo conto della loro età, ubicazione e modalità costruttive si può arguire che I sisma abbia raggiunto a Palermo un'intensità di grado VII almeno della Scala Mercalli.

Oltre all'intenso boato, che venne avvertito da tutti anche lontano dalla zona più fortemente colpita, un altro notevole fenomeno concomitante fu una forte agitazione del mare notata sulla costa palermitana e su quelle contigue.

Ise repliche, a Palermo, per lo più lievi ma sempre sentite con vivo spavento dalla popolazione, si susseguirono abbastanza frequenti fino alla line di Gennaio. Secondo F. Dalmasso, autore di uno studio sul sisma di cui stiamo trattando, quelle sensibili all'uomo furono quattordici: una di IV-V grado $\left(21^{\mathrm{h}} 13^{\mathrm{m}}\right.$ del 16 Gennaio), una di IV 


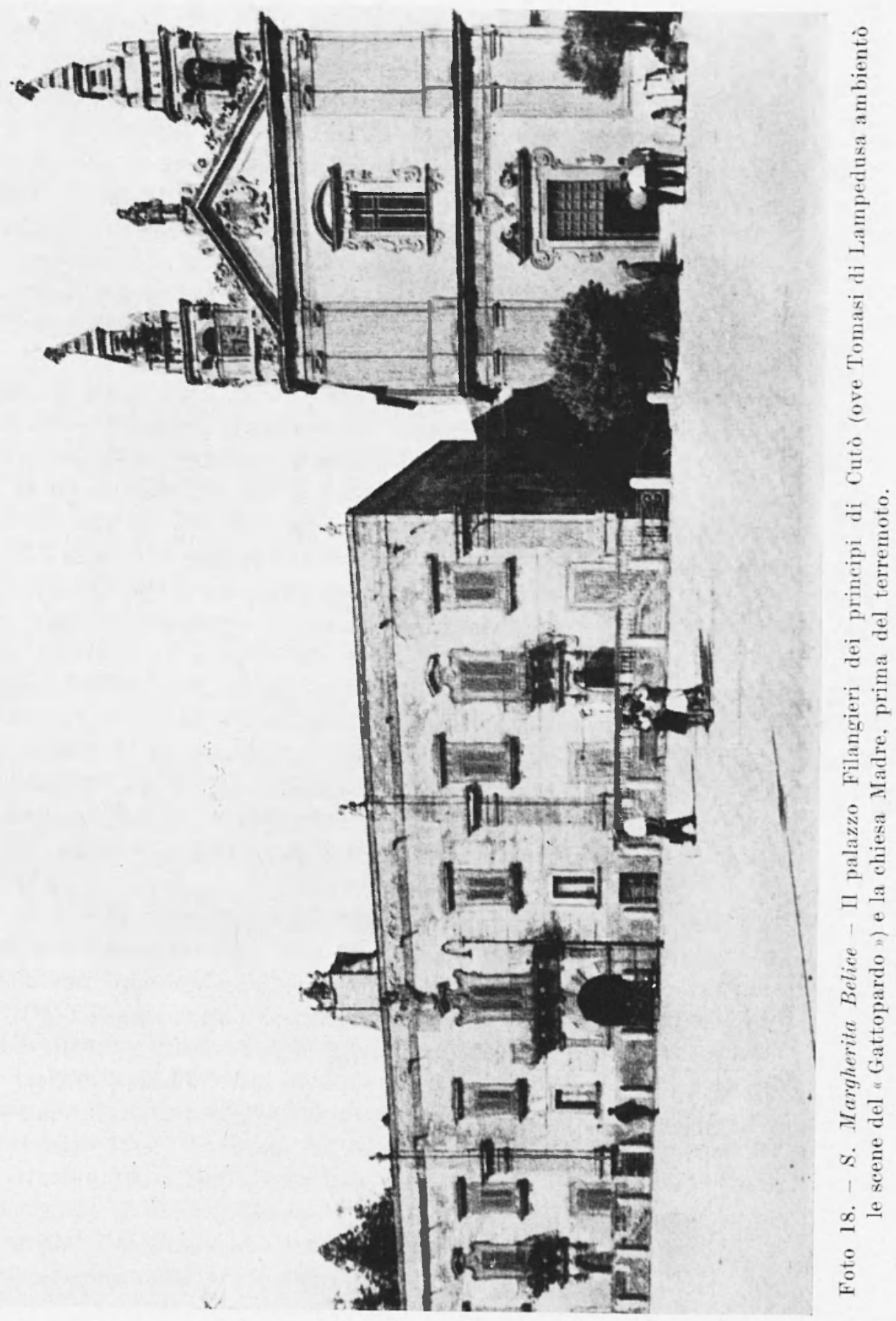


$\left(23^{\mathrm{n}} 15^{\mathrm{m}}\right.$ dello stesso giomo) e una di III-IV (21 ${ }^{\mathrm{n}} 2 \mathrm{0}^{\mathrm{m}}$ del 24 Gennaio); tutte le altre, d'intensità legrgera (III) o leggerissima (II).

L'epicentro macrosismico delle scosse può essere ubicato con buona approssimazione attorno ad un punto di coordinate $38^{\circ}\left(4^{\prime} \mathrm{N}\right.$ e 13028' E, cioè nella zona di Misilmeri e Villabate dove il sisma ebbe effetti rovinosi e raggiunse un'intensità di VIII grado. Tale zona, come appare dalla carta geologica di E. Beneo, ì interessata da due linee di frattura, l'una diretta da SE a NW e l'altra approssimativamente da nord a sud; il che, nei riguardi della genesi del movimento tellurico, sembra convalidare l'ipotesi fatta dal I)almasso, nello studio sopra citato, di dislocazioni e successivi fenomeni di assestamento lungo ma faglia esistente nella zona e diretta press'a poco da nord a sud, "con probabile commozione - secondo il Dalmasso - anche del sottofondo marino in prossimità della costa".

La propagazione del terremoto, in relazione alla elevata intensità epicentrale, non fu molto vasta; ciò lascia presumere che i supposti fenomeni di brusca dislocazione si siano prodotti ad una profondità ipocentrale piuttosto modesta (13 km secondo C. Raimondi). Ja scossa - ricordiamo le localita da cui si ebbero notizie - in valutata di VII-VIII grado a Ficarazzi, di VII a Bolognetta e a Piana degli Albanesi, di VI a Marineo, di V-VI a Termini Imerese, Trabia, Mezzoiuso, Corleone e Partinico; di $\mathrm{V}$ a Ciminna e a Castellammare del Golfo; di IV a Cefalì, Castelbnono, Lercara Friddi, Gibellina, Calatafimi, Aleamo e Trapani; di II-III a s. Stefano di Camastra, Collesano, Prizzi, Castelvetrano e Mazara del Vallo. Non venne affatto avvertita a Bivona, Caltabellotta, Casteltermini e Villalba.

Dai nomi sopra citati appare dunque che il terremoto del 1940 interessò anche, sia pure con intensità non elevata, diverse zone fra quelle cosi duramente colpite dai sismi recenti.

Dal Gemnaio 1940 al Gemnaio 1968 non si sono avute scosse sismiche di rilevante intensità (cioè di grado uguale o superiore al VI grado) nel territorio di Palermo. Sarà però ancora vivo nella memoria dei Palermitani, anche se affievolito dalle giornate di terrore del Gennaio e Febbraio 1968, il ricordo del movimento tellurico delle $22^{\mathrm{h}} 0 \mathrm{~g}^{\mathrm{m}}$ del 31 Ottobre 1967, che a Palermo, distante ben $100 \mathrm{~km}$ dalla zona epicentrale (Mistretta-Cerami-Sperlinga) non apportò alcun danno materiale, ma giunse pur sempre con intensita tale da arrecare un certo allarme nella popolazione. 
Tesideriamo infine qui ricordare, e con essi chindiamo questa rapida rievocazione dei sismi avvertiti in Palermo anteriormente al 1968, tre terremoti del basso Tirreno. Il primo, con epicentro a nord delle Isole Egadi, avvenne il 16 Mar\%o del 1941. Registrato in tutti gli Osservatori d'Europa e assai importante per il contributo da esso portato alle conoscenze sui terremoti tirrenici profondi, questo sisma venne fatto oggetto di studio nell'Istituto Nazionale di Geofisica da parte di I. Ini Filippo, il quale determinò per le coordinate epicentrali i valori $38^{\circ} 26^{\prime} 19^{\prime \prime} \mathrm{N}, 12007^{\prime} 23^{\prime \prime} \mathrm{E}$ e per l'ipocentro una profondità di $85 \mathrm{~km}$ ca. L'epicentro cadde dumque in un punto situato a circa $60 \mathrm{~km}$ da Trapani e $110 \mathrm{~km}$ da Palermo. Nonostante la notevole profondità ipocentrale, la scossa si manifestò molto fortemente a Trapani causando danni gravi alle abitazioni e grande spavento nella popolazione. $A$ Palermo il movimento sismico fu sentito con una intensità di IV-V grado e fu accompagnato, cosi come a Trapani, da un boato e da un vasto ondeggiamento del mare.

Gli altri due, originati da uno stesso focolare, avvennero rispettivamente il 20 ed il 21 Maggio 1957 ed ebbero l'epicentro, secondo l'u International Seismological Summary" nel punto di coordinate $38^{\circ} 39^{\prime} \mathrm{N}$ e $14^{\circ} 07^{\prime} \mathrm{E}$, cioè poco più di ma ventina di chilometri a N $\mathrm{NW}$ dell'isola di Nlicudi. I due sismi, la cui profondita ipocentrale venne dal B.C.I.S. valutata di circa $60 \mathrm{~km}$, furono distintamente avvertiti, e con qualche apprensione, nella citta di Palermo, mentre in altre località vicine, come Bagheria ed Altavilla Milicia, passarono del tutto inosservati.

Giungiamo cosi agli avvenimenti sismici del 1968 che anche a Palermo si sono manifestati con una intensita tuttaltro che trascurabile. E non intendiamo con ciò riferirci soltanto al turbamento grave della popolazione, che, iniziatosi con una viva apprensione, si è trasformato ben presto, sotto l'incalzare martellante delle scosse dei primi due grorni, dapprima in allarme, poi in terrore e infine in un panico generale difficilmente descrivibile.

All'arrivo della scossa delle ore 3 e 2 minuti del 15 (tennaio, disastrosa all'epicentro e fortissima a Palermo, tutti fuggono dalle abitazioni: migliaia e migliaia di persone, dopo essersi portate fuori della citta sull autostrada per Punta Raisi e sulle strade di circonvallazione, passano la notte dentro le automobili; altri, sotto tende messe a disposizione dalle Autorità militari; altri ancora, sostando nei parchi e giardini della città. È un ritorno, certo più pauroso e drammatico per il continuo ripetersi dei movimenti tellurici, delle scene di 28 amni fa, quando 


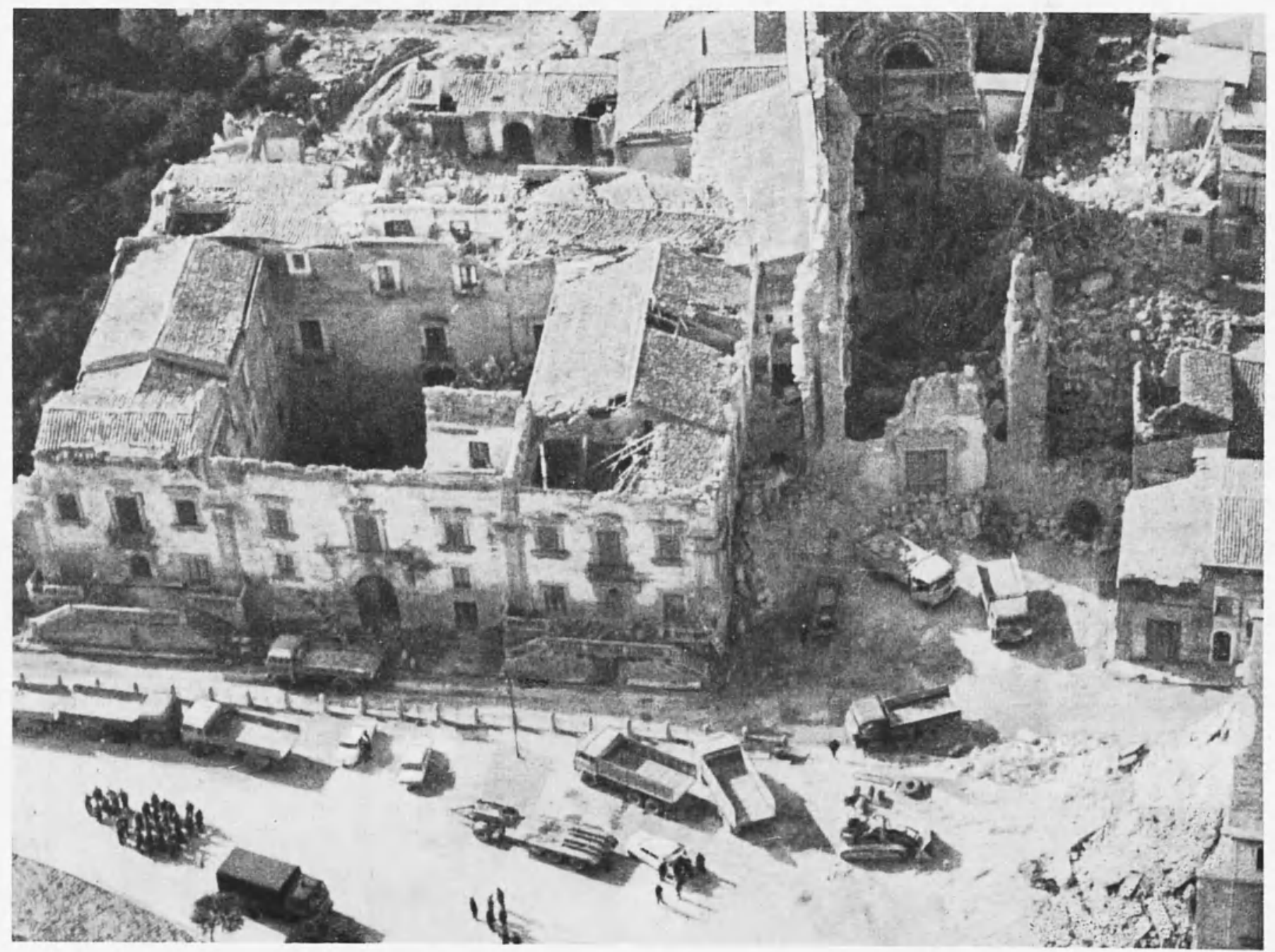

Foto 19. - S. Margherita Belice - Il palazzo Filangieri e la Chiesa Madre dopo i terremoti del 15 gennaio 1968. 
Palermo fu colpita dal terremoto del Gennaio 1940. Dopo la scossa delle ore 17 e 43 minuti del griorno 16 , che cosparge altre rovine e semina altri lutti nelle zone epicentrali già sconvolte dai sismi precedenti e che si propaga violentemente anche a Palermo, l'esodo diviene. generale e la città si fa quasi deserta. I detenuti nelle carceri dell' $r$ cciardone, per timore di crolli, vengono fatti uscire dalle celle e radunati all'aperto nei cortili riservati alla passegriata.

Poi la tensione degli animi a mano a mano si attenua e la vita nella città tende a tranquillizzarsi. Ma ecco improvvisamente, con la violenta scossa delle ore 10 e 58 del 25 Gennaio, la situazione farsi ancora una volta angosciosa e drammatica: la gente, terrorizzata, fugge nuovamente dalla città con tutti i mezzi disponibili e si ripetono, aggravate, le scene caotiche di una settimana prima.

Passata la nuova grande paura, gli abitanti ritoruano alle loro occupazioni, le scuole si riaprono e Palermo, a poco a poco, torna alla normalità. Le scosse però non cessano del tutto ed ancora ogrgi - mentre stiamo scrivendo questa nota - di quando in quando, ad intervalli più o meno lunghi, se ne avverte qualcuna di lieve intensità specialmente nei piani alti delle case.

Ma, come dicevamo, non è soltanto il profondo turbamento e lo stato d'animo di terrore suscitati in tutta la popolazione che stanno ad indicarci la notevole intensità con cui si sono manifestati a Palermo i sismi maggiori della Valle del Belice. Questi, come abbiamo visto, pur avendo avuto i loro epicentri ad una distanza media da Palermo di circa $50 \mathrm{~km}$, hamno arrecato, con il loro ripetersi a brevi intervalli di tempo, danni rilevanti, anche se limitati principalmente alle costruzioni dei quartieri più antichi della città. Ed è importante ricordare, quale ulteriore elemento di griudizio per una valutazione della sismicità del territorio palermitano, come Palermo abbia sofferto danni percentualmente superiori a quelli subiti da altri centri - come Monreale, Altofonte e Belmonte Mozzagno - situati fra detta città e la zona epicentrale e quindi a questa più vicini.

d) I centri sismici delle Madonie. - La regione delle Madonie, cioè quella parte dell'Appennino siculo che è limitata ad ovest dall'Tmera Settentrionale e ad est dalla fiumara del Pollina, è caratterizzata da una notevole sismicità, come attestano i numerosi terremoti manifestatisi in essa anche in tempi recenti.

Il gruppo montuoso, che nella sua parte centrale si erge con cime imponenti, quali il Pizzo Carbonara e il Monte S. Salvatore, fin quasi 
a sfiorare i 2.000 metri, ̀̀ solcato da complessi sistemi di faglie. Probabilmente da movimenti tettonici lungo tali faglie trassero origine i sismi sopra accennati, dei quali ora diremo in particolare ricordando le località che da essi furono più o meno fortemente colpite e che sono state interessate anche ora dai terremoti della Valle del Belice.

Una tipica manifestazione sismica nelle Madonie è rappresentata dai violenti terremoti del 1818 e 1819 illustrati da D. Scinà in una sua relazione del 1819. Il periodo sismico, che mise in luce due centri di scuotimento, l'uno prossimo a Petralia Sottana e l'altro a Castelbuono, ebbe inizio 1'8 Settembre con una scossa di VIII grado che riusci rovinosa nelle due Petralie (Soprana e Sottana) e a Polizzi Generosa. Fra queste località fu probabilmente l'epicentro. Danni gravi si ebbero a Caltavuturo e Scillato; notevoli a Gangi e Geraci Siculo; minori a Collesano, Isnello, Castelbuono e S. Mauro Castelverde. Numerose repliche si succedettero fino al mese di Novembre.

Dopo un periodo di calma di quasi tre mesi, il 25 Febbraio 1819 un'altra scossa rovinosa si abbatté sui paesi delle Madonie. I'epicentro però si spostò questa volta verso nord, in prossimità di Castelbuono, e la propagazione macrosismica fu più ampia di quella della scossa dell'8 Settembre 1818. I paesi maggiormente colpiti, oltre a Castelbuono, furono Isnello, Collesano, Geraci Siculo, S. Mauro Castelverde e Iascari. Danni minori subirono Pollina, Gratteri, Cefalì, le due Petralie, Gangi, Caltavuturo. Questo secondo massimo sismico fu seguito da forti scosse a Castelbuono, Collesano, Isnello e S. Mauro Castelverde nei mesi di Marzo e Aprile. Le repliche ebbero una propagazione molto limitata mentre le due scosse principali furono sensibilmente avvertite anche a Palermo.

Il centro sismico di Castelbuono tornò a dar segni di attività anche nell'anno 1823. Dopo il violentissimo terremoto del 5 Marzo di quell'anno, numerose scosse, come precedentemente si ̀̀ detto (pag. 401), turbarono la Sicilia settentrionale: una di esse, avvenuta il 28 Maggio 1823 , fu sentita con forte intensità a Castelbuono e nei vicini paesi di Isnello e Gratteri.

Un altro terremoto attribuibile allo stesso focolare sismico fu quello verificatosi alle $0^{\mathrm{h}} 15^{\mathrm{m}}$ del 23 Aprile 1906 , che fu di VI grado a Castelbuono, di V a Pollina, s. Mauro Castelverde e Tusa, di IV a Gangi, Polizzi Generosa, Collesano e Pettineo. Una scossa leggera premonitoria era stata sentita a Castelbuono il giorno precedente ed 


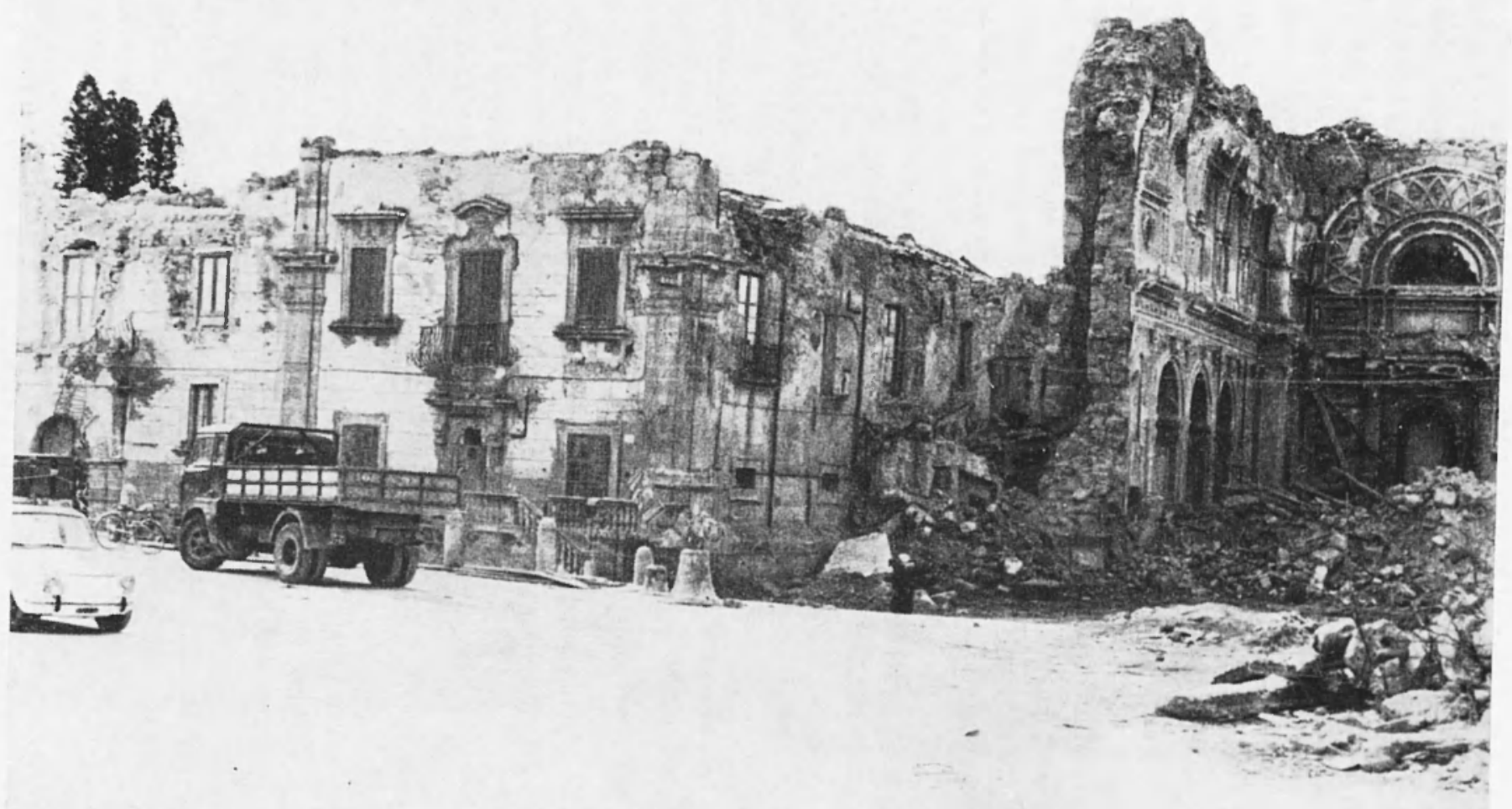

Foto 20. - S. Margherita Belice - Il palazzo Filangieri e la Chiesa Madre dopo la forte replica del 25 gennaio 1968. 
una replica lieve, pure a Castelbuono, fu avvertita poco più di un'ora dopo la scossa principale.

Dall'altro dei centri sismici sopra accennati, cioè da quello prossimo a Petralia Sottana, ebbe origine un fortissimo terremoto l'11 Settembre 1934. In detta località la scossa fu di VI-VII grado; ad Mlimena e Nicosia di VI, a Gangi di V. La propagazione macrosismica fu assai vasta poiché il movimento tellurico, oltre che alla provincia di Palermo, si estese a quelle di Catania, Siracusa, Enna, Caltanisetta e Ragusa; però la distribuzione delle intensità risultò apparentemente molto irregolare: dopo un rapido decremento verso sud, si notò una notevole recrudescenza nelle zone di Niscemi (Caltanissetta) e di Mineo (Catania) ove la scossa fu di V-VI grado, come se il sisma, oltre che dal focolare di Petralia, fosse stato generato dalla quasi contemporanea entrata in azione di un altro centro sismico situato fra le anzidette due localitì.

Due altri centri di scuotimento probabilmente esistono nelle Madonie orientali, in prossimità di Gangi e di Geraci Siculo rispettivamente.

Del primo si conoscono delle manifestazioni rappresentate da alcune forti scosse del 26 Settembre 1888 .

Dal secondo ebbe origine l'8 Giugno 1910 una scossa molto forte, ma di carattere locale, che a Geraci raggiunse il VI grado. Una replica di minore intensità ebbe luogo nel giomo successivo.

Debbono poi essere segnalati due ipocentri poco profondi situati a sud delle Madonie, l'uno in prossimità di Alimena e l'altro di Valledolmo, messi in evidenza da terremoti di estensione macrosismica limitata, ma piuttosto intensi.

Il territorio di Alimena venne colpito, il 30 Gennaio 1912, da una scossa di VI grado sentita, con minore intensità, anche a Petralia Sottana.

A Valledolmo, il 22 Settembre 1927 si ebbe un sisma di VI grado di carattere strettamente locale cui tennero seguito diverse repliche fino alla fine del mese, alcune anche di forte intensità ma sentite soltanto a Valledolmo.

Pochi anni or sono, il 13 Giugno 1957, un altro terremoto di VI grado fu sentito in detta località. Si tratto anche in questo caso di un fenomeno molto localizzato che non arreco danni alle persone, ma per il quale varie case rimasero lesionate.

Terminiamo questo paragrafo ricordando il violento terremoto che, due mesi e mezzo prima che s'iniziasse la disastrosa serie dei mo- 
vimenti sismici nella Valle del Belice, s'era verificato in Sicilia con effetti rovinosi in alcuni paesi della regione occidentale dei Monti Nebrodi. Ne abbiamo già fatto cenno, ma crediamo opportuno parlarne qui un po' più diffusamente poiché tale sisma, con la sua ampia propagazione, si estese anche nelle Madonie interessando fortemente numerosi Comuni della provincia di Palermo poi ancora colpiti dai moti tellurici irradiati dalla Valle del Belice.

Esso avvenne alle $22^{\mathrm{h}} 08^{\mathrm{m}}$ del 31 Ottobre 1967 e il suo epicentro fu individuato nel punto di coordinate $37^{\circ} 48^{\prime} \mathrm{N}$ e $14^{\circ} 22^{\prime} \mathrm{E}$, cioè nei Nebrodi occidentali nei pressi del Monte Sambughetti. Nell'area epicentrale rimasero compresi i capoluoghi dei Comuni di Mistretta (Messina), Cerami e Sperlinga (Enna), nei quali, a cura dei competenti Uffici del Genio Civile, vennero accertati danni assai gravi ascrivibili ad una intensitì di poco superiore al grado VIII della Scala Mercalli. La carta delle isosiste (Fig. 8) mostra la vasta estensione del movimento tellurico e da essa si rileva che la scossa, in provincia di Palermo, fu fortissima (grado VII) a Pollina, S. Mauro Castelverde (*), Gangi, Geraci Siculo, e molto forte (VI) nelle due Petralie.

Quasi tutti gli Osservatorî europei in cui il sisma fu registrato concordarono nell'attribuire al fuoco una profonditì di circa $70 \mathrm{~km}$ e fu in grazia di questa notevole profondità ipocentrale se l'energia sismica, assorbita dagli strati sovrastanti della crosta terrestre, non si manifestò in superficie con effetti di gran lunga maggiori.

e) La sismicità del territorio di Trabia e Termini Imerese con particolare riferimento al periodo sismico 1906-1908. - Un ipocentro probabilmente sottomarino prossimo alla costa di Trabia e Termini Imerese è stato chiaramente messo in luce da terremoti avvenuti in questo secolo.

Un sisma di $\mathrm{V}$ grado, preceduto da un fortissimo rombo, fu sentito in dette località, con vivo spavento della popolazione, il 14 Febbraio 1905. Esso ebbe però un carattere strettamente locale poiché la scossa, avvertita appena a Sciara, passò del tutto inosservata nei vicini paesi di Caccamo e di Cerda. Seguirono alcune sensibili repliche nella giornata, in quella successiva e il giorno 24 dello stesso mese.

(*) Il paese di S. Mauro Calstelverde fu danneggiato anche dal terremoto del 15 agosto 1908 che ragriunse la sua maggiore intensita (VII) a Castel di Iucio (Messina) nei cui pressi sembra essere stato l'epicentro. 


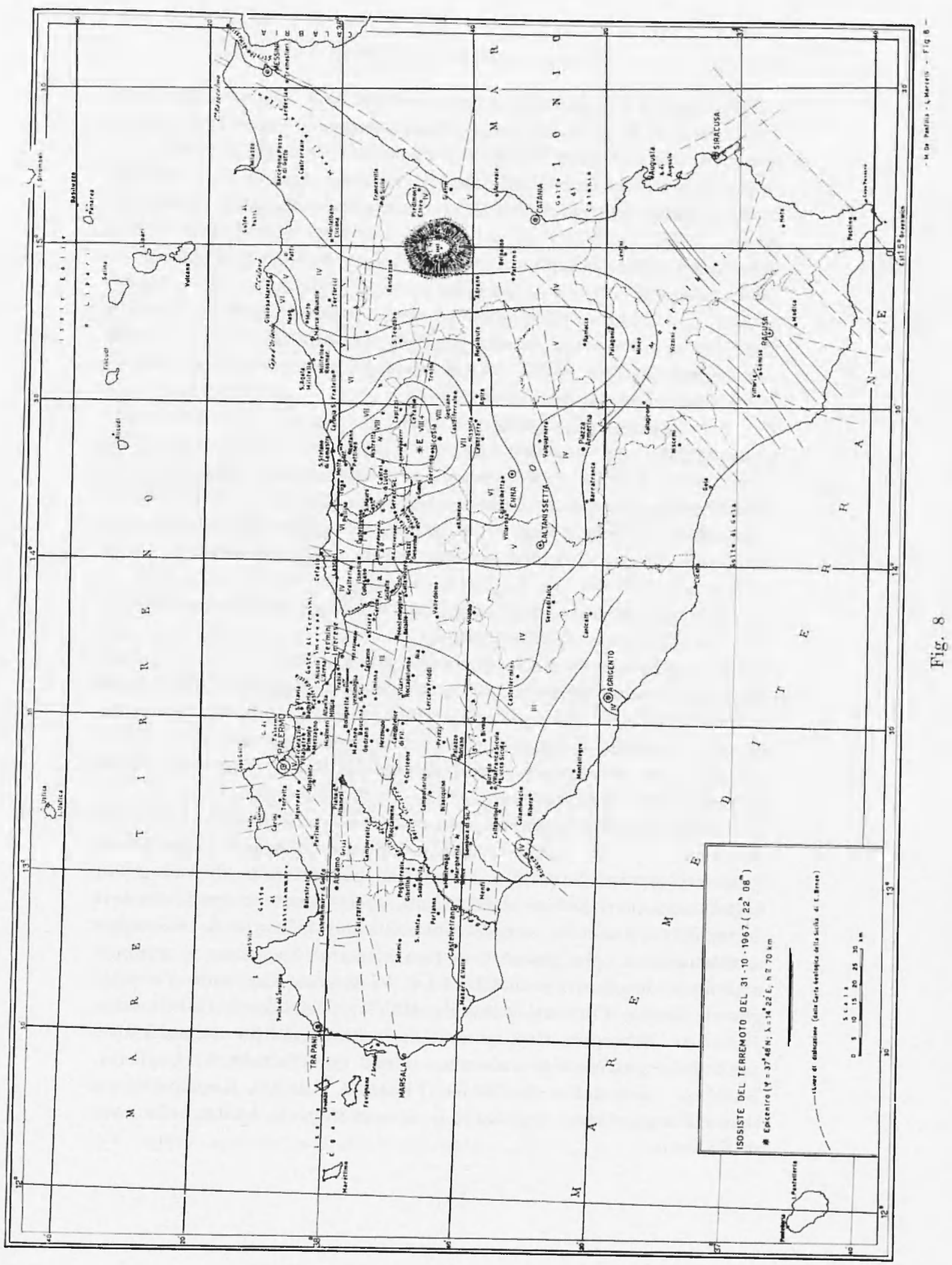


Ia ben più importante è la manifestazione data da detto ipocentro con il lungo ed intenso periodo sismico svoltosi negli ultimi mesi del 1906, durante il 1907 e nella prima metà del 1908. Esso si iniziò l's Settembre 1906 con una lieve scossa e si protrasse arrecando notevoli danni nei Comuni di Termini Imerese e di Trabia fino al 29 Giugno 1908. Oltre 200 scosse, fra leggere, forti e fortissime, si susseguirono durante tale intervallo di tempo. Secondo M. Ciofalo, antore di una memoria su questo periodo sismico, quelle più intense furono avvertite entro una zona non molto estesa limitata a nord dalla costa fra Palermo e Cefalù, a sud dal parallelo passante per Lercara Friddi e Valledolmo, ad est e ad ovest dai meridiani passanti rispettivamente per Castelbuono ed Altofonte.

I maggiori effetti dinamici si ebbero in una zona molto ristretta: approssimativamente quella racchiusa da una linea che, partendo dalla costa ad est di Termini Imerese e attraversando il Monte S. Calogero, passa poi immediatamente a nord di Caccamo e torna a mare fra Trabia e S. Nicolo l'Arena. î interessante notare come per questa zona passi la grande linea di frattura che, attraversando la Sicilia in direzione SW-NE va da Pantelleria alle Isole Eolie.

Del periodo sismico ricorderemo qui le manifestazioni principali e i paesi che ne furono colpiti.

La prima scossa molto forte avvenne alle $2^{\mathrm{n}} 50^{\mathrm{m}}$ circa del 9 Settembre 1906 e fu accompagnata da forte rombo. Raggiunse il VI grado a Trabia, Termini Imerese e Caccamo, ove le popolazioni, prese da grande spavento, fuggirono dalle abitazioni e passarono la notte all'aperto. Fu notato un notevole aumento di temperatura nelle acque termali di Termini Imerese.

Dopo alcume repliche di minore intensità, il giorno 11 alle ore 20 circa si verificò il primo massimo del periodo sismico. Una scossa fortissima investi Termini e Trabia con una intensità di VII grado cagionando gravi lesioni ai fabbricati, specialmente in quelli fondati su terreno alluvionale poco coerente. Gli abitanti in preda al panico si attendarono nelle piazze e in riva al mare. La scossa si propagò attorno ai due centri predetti e fu di VI grado a Caccamo, Ventimiglia di Sicilia, Ciminna, Altavilla Milicia, Casteldaccia, Misilmeri e Belmonte Mezzagno. Con intensità minore fu sentita in molti altri paesi della provincia di Palermo - fra i quali Altofonte, Bagheria, Baucina, Campofelice di Fitalia, Ficarazzi, Isascari, Roccapalumba, Santa Flavia, Vicari, Villabate - e sensibilmente anche nella città di Palermo. 
Altre scosse di mediocre intensità seguirono durante la notte; poi, alle $12^{\mathrm{h}} 35^{\mathrm{m}}$ del giorno 12 , un altro sisma di VI grado tornò a colpire Trabia e Termini Imerese aggravando notevolmente i danni prodotti dalle scosse precedenti. Esso ebbe una propagazione presso a poco uguale a quella della scossa fortissima del giorno prima e venne avvertito anche a Palermo.

Scosse di III, IV e V grado si verificarono con rilevante frequenza a Termini e Trabia sino alla fine del mese di Novembre. Alcume di quelle di minore intensità vennero sentite soltanto a Trabia ed altre soltanto a Termini Imerese, come se esse provenissero da epicentri diversi ma poco discosti l'uno dall'altro. Una di $V$ grado, avvenuta il 21 Settembre alle $15^{\mathrm{h}} 25^{\mathrm{m}}$, arrecò danni anche ad alcuni edifici di Casteldaccia che, per precauzione, vennero fatti sgomberare.

Nel Dicembre 1906 l'attività sismica diminui notevolmente: solo poche scosse e quasi tutte leggere, eccetto una, di $\mathrm{V}$ grado, avvenuta il giorno 23. Ugualmente moderata si mantenne durante la prima metà del Genmaio 1907 e il periodo sismico sembrò vicino al suo esaurimento; ma si ravvivò improvvisamente nella seconda metà del mese e il giomo 21 si ebbe un altro massimo.

Alle $4^{\mathrm{h}} 40^{\mathrm{m}}$ circa di detto giorno, una scossa noterole (VI-VII grado) tornò a colpire Trabia e, con un'intensità un po' minore (VI grado), Termini Imerese. Altri damni si aggiunsero a quelli che erano stati prodotti dalle scosse del mese di Settembre e gli abitanti, atterriti, tornarono a rifugiarsi nelle baracche precedentemente costruite.

La scossa si estese in provincia di Palemo quasi come quella dell'11 Settembre. Fu forte a Carcamo, Ventimiglia di Sicilia, Altavilla Milicia, Casteldaccia, Bagheria, Misilmeri e Belmonte Mezzagno; mediocre a Ciminna, Santa Flavia, Marineo e Piana degli Albanesi; leggera ad Alia, Corleone e Roccapalumba.

I movimenti sismici continuarono nei mesi successivi del 1907 però con frequenza minore che nella prima fase del periodo. Alcuni raggiunsero il $\mathrm{V}$ grado (25 Febbraio, 26 Marzo, 29 Aprile, 16 Maggio, 29 Giugno); poi una interruzione nei mesi di Luglio ed Agosto ed una breve e poco intensa ripresa nel mese di Settembre. Segui una lunga pausa fino all'Aprile del 1908. Altre scosse leggere e mediocri avvertite in maggio ed in giugno segnarono la fine del periodo sismico.

Dal 1908 fino ad oggi non si sono avuti terremoti corocentrici importanti nel territorio trabiese e termitano. Possiamo ricordare solo un sisma di $\mathrm{V}$ grado avvenuto il 31 Maggio 1922 seguito da una sola replica leggera nella stessa giomata. 
Yel ricercare le cause dei movimenti sismici svoltisi dal 1906 al 1908, M. Ciofalo, basandosi su osservazioni tettoniche e stratigrafiche, faceva rilevare la probabile esistenza, nell'ambito dell'area megasismica, di una originaria anticlinale la quale, squarciandosi e crollando, avrebbe lasciato ad oriente il Monte S. Calogero, ad occidente le alture di Trabia e, fra l'mo e le altre, la massa montuosa di Rosamarina. Sul Monte S. Calogero, imponente rilievo che a poca distanza dal mare si erge a SE di Termini, vi è un completo e recente studio di A. Moretti. In esso questo antore, ravvisata nel gruppo del S. Calogero la conformazione di un semi-ellissoide originato dal crollo di una grande cupola anticlinale, descrive, fra l'altro, le numerose fagrlie da cui esso è solcato. All'equilibrio ancora instabile della zona ed a conseguenti movimenti lungo qualcuma delle faglie ivi esistenti il Ciofalo attribuiva la causa di quei terremoti di Trabia e di Termini Imerese.

\section{7. - CONSIDERAZIONI FINALI.}

Da quanto è stato esposto nella presente nota appare manifesta la complessità di uno studio che voglia esser condotto su tutti gli aspetti del fenomeno geofisico in esame. Qui e stata trattata una parte dell'argomento e le considerazioni che si possono dedurre dallo studio effettuato si riferiscono ovviamente alla parte trattata.

Risulta evidente che con il 14 Gennaio 1968 si è aperto un nuovo ciclo nella vita sismica della Vallata del Belice, ciclo non ancora esanrito a sei mesi di distanza.

Il fatto che a memoria d'nomo questa zona della Sicilia occidentale abbia poco fatto parlare di sé ha suscitato, al momento dell'insorgere della crisi, un doloroso stupore, come se l'uomo si fosse sentito tradito dalla Natura. Ma in fatti di portata cosmica, com'è la vita di un pianeta inserita in quella dell'universo, la memoria dell'uomo copre un intervallo di tempo infinitesimo, assolutamente insufficiente a grustificare previsioni e pronostici.

Ci piace citare ancora una volta L. Ammeo Seneca $\left(^{*}\right)$ il quale, in veste di scienziato e di filosofo, ci ammonisce: "Quis enim promit-

(*) L. Annaens Seneca, "De Terrae motu ". Nat. quaest. VI (Traduz. di A. Traglia, Ed. dell'Ateneo, Roma, 1965). 
tit melioribus fundamentis hoc aut illud solum stare?.. Erramus enim, si ullam terrarum partem exceptam immunemque ab hoc periculo credimus ", e cioè: "Chi infatti può garantire che questo o quel suolo poggi su fondamenta più sicure?... Noi infatti c'inganniamo, se crediamo che vi sia qualche parte della terra esente e immune da questo pericolo" (il terremoto).

Ed infatti, pazienti ricerche condotte nella storia sismica della regione hamo messo in luce episodi tellurici documentati e dimenticati.

Più oltre lo stesso Seneca continua saggiamente: "Quare autem. quicquam nobis insolitum est? Quia naturam oculis, non ratione comprehendimus nec cogitamus, quid illa facere possit, sed tantum quid fecerit ", cioè: "Ma perché poi una cosa ci è insolita? Perché noi osserviamo la natura con gli occhi, non con la ragione, e non pensiamo a quello che essa può fare, ma soltanto a quello che ha fatto ".

E ben vero che millenovecento anni sono passati dalle parole dell'Autore latino, ed è ben vero che la scienza ha camminato con l'uomo aprendo allo spirito ed alla conoscenza nuove e più ampie prospettive, però è anche vero che ancor oggi, forse più di prima, l'nomo vuol guardare la natura con gli occhi, sia pure con l'ausilio di preziose e complicate apparechiature tecniche.

In particolare, nel campo della sismologia si deve umilmente riconoscere che il patrimonio culturale finora acquisito non consente la possibilità di fare previsioni attendibili e umanamente soddisfacenti sul come e sul quando si verificheranno scosse sismiche in determinate zone.

Tuttavia anche se l'uomo osserva " con gli occhi " ciò che la natura " ha già fatto ", sta alla ragione ed all'intelligenza dello studioso far buon uso dell'esperienza acquisita per pensare anche a ciò che la natura " può fare ".

I 20 secoli di Cristianesimo che ci separano da Seneca ci consentono di dissentire da lui quando, nell'opera citata, egli dice che essendo la morte cosa inevitabile, è indifferente il modo come essa avvenga ed in un certo senso vorrebbe indurre il suo amico Lucilio, cui è dedicata l'opera, ad un fatalismo stoico. Ia vita dell'nomo è prezioso dono divino e, per quanto umanamente possibile, va protetta e salvaguardata. La società in cui ciascuno di noi vive ha il dovere di proteggere ogni suo membro e, anche se i fenomeni naturali sono imprevedibili e inevitabili, ogni individuo, specie se socialmente responsabile, deve sentirsi moralmente impegnato ad apportare il pro- 
prio contributo tecnico, scientifico, sociale, morale per la salvezza e l'incolumiti dei popoli.

Ora cominceranno in Sicilia le opere di ricostruzione dei paesi distrutti e quelle di riparazione dei centri più o meno gravemente colpiti ed è da sperare che presto torni a fiorire la vita là dove essa i stata repentinamente e tragicamente interrotta. Noi vivamente auspichiamo che nell'esecuzione di tali opere le Autorità locali, convinte di tutelare cosi $\mathrm{i}$ veri ed essenziali interessi delle popolazioni da loro amministrate, si adoperino volenterosamente per una rigorosa adozione delle norme tecniche di edilizia antisismica. Ed anche gli abitanti dei centri che non sono stati ora gravemente colpiti, ma dove nel passato si ebbero manifestazioni telluriche, dovrebbero accogliere di buon grado l'osservanza delle norme costruttive contro i terremoti senza lasciarsi fuorviare da contingenti considerazioni di natura economica. Occorre premunirsi in tempo e non attendere che un sisma rovinoso abbia portato la distruzione e la morte per indursi ad applicare all'attivita edilizia le norme tecniche intese a limitare grandemente gli efletti dei forti terremoti ed il conseguente grave depauperamento economico e morale per le zone colpite, con ripercussioni più o meno profonde nell'intera Nazione.

Gli Autori ringraziano vivamente la Direzione Generale della Protezione Givile del Ministero dell'Interno alla aui cortesia devono le fotografic inserite nel testo, ad cocezione delle 11 e 12 gentilmente fornite dal geologo dr. A. Fiorella del Provveditorato alle OO.PP. di Palermo. 


\section{BIBLIOGRAFIA}

Baratta M., I terremoti d'Italia. Fr. Bocea, 'Torino, 1901.

Beneo E., Carta geologica della Sicilia. Scala 1:500.000 (1962. Assessorato Industria e Commercio della Regione Siciliana).

Bosi C., Cavaluo R., Manfredini M., Il terremoto della Valle del Belice del Gennaio 1968. "Rass. dei Lavori Pubblici ", (1968).

Calor P., Attività sismica in Italia nel decennio 1930-1939. Le Monnier, Firenze, 1942.

Cavasino A., I terremoti d'Italia nel trentacinquennio 1899-1933. Istituto Poligr. dello Stato, 1935.

Crofalo IL., Orografia, geologia e tettonica della zona scossa dai terremoti di T'ermini Imerese del Settembre 1906. "Boll. Soc. Sismol. Ital. "XIII, (1908.09).

Dalmasso F., Sul terremoto palermitano del 15 Gennaio 1940. "Geof. pura e applicata " II, (1940).

De Panfilis M., Un'indagine macrosismica effettuata nella zona di Grisi. Relaz. pubbl. sul "Giornale di Sicilia " dell'I1-3-1955.

De Panfilis M., Attività sismica in Italia dal 1953 al 195\%. "Ann. di Geofisica ", XII, (1959).

Di Ficrppo D., Studio microsismico del terremoto del basso Tirreno del 16 Marzo 1941. Pubbl. dell'I.N.G., 1942.

Di Filippo D., Marcelli L., Magnitudo ed energia dei terremoti in Llalia. "Ann. di Geofisica ", III, 3, (1950).

Flonidia G. B., Notizie sul sottosuolo della città di Palermo. "Riv. Miner. Sicil ", 39, (Maggio-Giugno 1956).

Malaroda R., Ramiondi C., Linee di dislocazione e sismiciti in Italia. "Boll. di Geodesia e Scienze Affini ", (Firenze, 1957).

Marcerli L., Breve relazione sull'altività dell'Istitulo Naz. di Geofisica di Roma in occasione degli eventi sismici della Sicilia occidentale (Gennaio. Febbraio-Marzo 1968). "Atti dell'Ass. Geof. It." (Marzo 1968).

Marceldi L., Monteccir P., Contributi per uno studio sulla sismicità dell'Italia. "Ann. di Geofisica " XV, 2.3, (1962).

Martinelli G., La sismicità all'Isola di Ustica e il periodo Marzo-Aprile 1906. "Ann. dell'Uff. Centr. Meteor. e Geod. XXX, (1908).

Mongitore A., Istoria cronologica dei terremoti in Sicilia, in "Della Sicilia ricercata nelle cose più notevoli n, tomo II, Palermo 1743.

Moretti A., Osservazioni geologiche sul Monte S. Calogero presso Termini Imerese. "Boll. Serv. Geolog. d'It. ". LXXV, 1953.

Scin À D., Rapporto del viaggio alle Madonie impreso per ordine del Governo in occasione dei terremoti del 1818 e 1819. Palermo, 1819. 
Riassunto .................... 343

Introduzione .................. . . 347

1. Generalità e considerazioni varie . . . . . . . . . . . 348

2. - Installazioni strumentali locali . . . . . . . . . . . 351

3. - Rilevamenti e considerazioni sulla sequenza dell'intero periodo sismico: frequenza, magnitudo, intensità . . . . . . . . 352

4. - Gli epicentri . . . . . . . . . . . . . . . 355

5. - Aspetti macrosismici del fenomeno . . . . . . . . . . . 362

a) L a cronaca . . . . . . . . . . . . . . . . . . . . . . 363

b) I dami - Ie "isoblabe" . . . . . . . . . . . . . . . . 372

c) Interpretazioni della Tah. 5 e della Fig. 6 . . . . . . . 381

d) Anomalie . . . . . . . . . . . . . . . . . 382

e) I capoluoghi di Provincia e i centri più importanti . . . . 385

6. - Precedenti sismici nelle località colpite dai terremoti del $1968 \quad 389$

a) Le manifestazioni sismiche nella Valle del Belice . . . . . 390

b) I terremoti di Grisi del 1954-56 ............ . 394

c) La sismicità del Palermitano . . . . . . . . . . . . . . . . 399

d) I centri sismici delle Madonie . . . . . . . . . . . . . 409

e) La sismicità del territorio di Trabia e Termini Imerese con particolare riferimento al periodo sismico 1906-1908 . . . . 414

7. - Considerazioni finali . . . . . . . . . . . . . . . . 418

Bibliografia ................. . 421 